LBL-35542

UC-000

\title{
Structure and Efficiency of Energy Use In a Reforming Economy: The Case of Estonia
}

\author{
Lee Schipper and Eric Martinot ${ }^{\mathrm{a}}$ \\ with \\ Marta Khrushch, Jurgen Salay ${ }^{\mathrm{a}}$, Claudia Sheinbaum, and Diana Vorsatz \\ Energy Analysis Program \\ Energy and Environment Division \\ Lawrence Berkeley Laboratory \\ Berkeley, CA 94720
}

\section{B}

May 1994

Sponsored by the Stockholm Environment Institute

Stockholm, Sweden

\section{SEI}




\section{DISCLAIMER}

This report was prepared as an account of work sponsored by an agency of the United States Government. Neither the United States Government nor any agency thereof, nor any of their employees, make any warranty, express or implied, or assumes any legal liability or responsibility for the accuracy, completeness, or usefulness of any information, apparatus, product, or process disclosed, or represents that its use would not infringe privately owned rights. Reference herein to any specific commercial product, process, or service by trade name, trademark, manufacturer, or otherwise does not necessarily constitute or imply its endorsement, recommendation, or favoring by the United States Government or any agency thereof. The views and opinions of authors expressed herein do not necessarily state or reflect those of the United States Government or any agency thereof. 


\section{DISCLAIMER}

Portions of this document may be illegible in electronic image products. Images are produced from the best available original document. 


\section{TABLE OF CONTENTS}

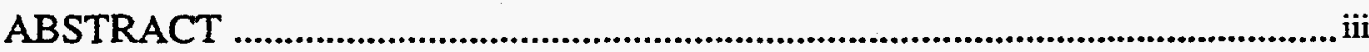

ACKNOWLEDGEMENTS ............................................................................... iv

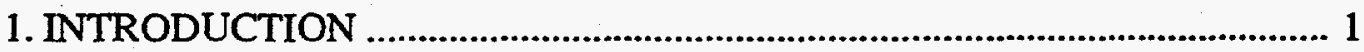

1.1 Project Formation ............................................................................................. 2

1.2 Goal of this Report ......................................................................................... 2

2. ECONOMY, ENERGY, AND ENVIRONMENT IN ESTONIA ........................ 5

2.1 The Economy in the Soviet Period ....................................................................... 5

2.2 The Onset of Economic Transition ............................................................. 5

2.3 Energy Prices .................................................................................................... 7

2.4 Energy Supply ...................................................................................................... 10

2.5 Environmental Effects of Energy Use ..................................................................11

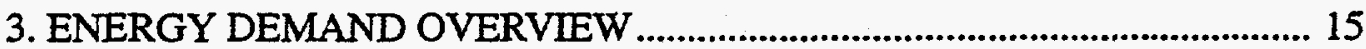

3.1 The Economy: Aggregate Structural Data .......................................................... 15

3.2 Sectoral Trends in the Structure of Energy Use ............................................... 15

3.2.1 Industry: Manufacturing ......................................................................... 19

3.2.2 Other Industry: Agriculture, Construction and Mining ............................ 21

3.2.3 Residential Sector ................................................................................ 22

3.2.4 Services ("Other Consumers") ................................................................ 29

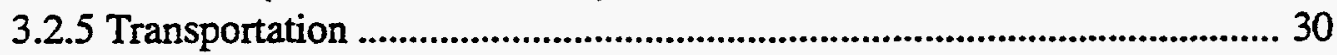

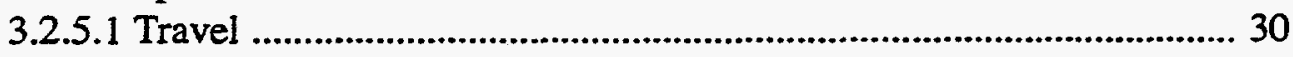

3.2.5.2 Freight and Others Energy Use .......................................................... 33

3.2.5.3 Other Uses in Transportation ............................................................. 35

3.3 Conclusions from the Demand Overview ....................................................... 35

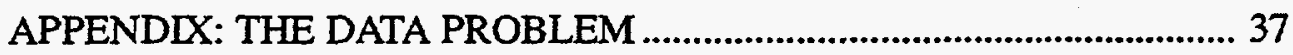

Energy Data Problems .................................................................................. 37

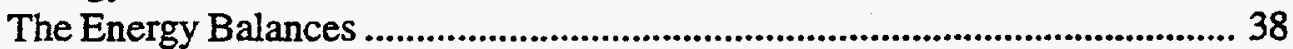

Transformations of the Energy Supply Data ................................................ 39

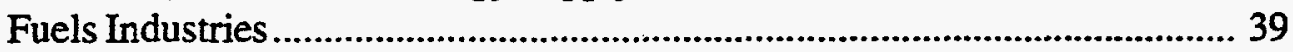

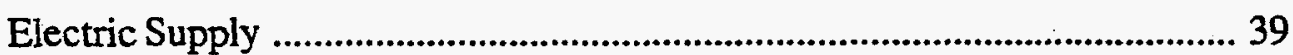

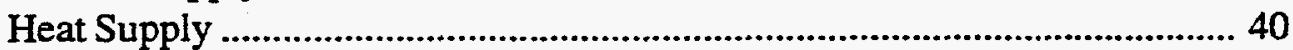

Adjustments to End-Use Categories ............................................................. 43

4. ENERGY USE IN ESTONIA: AN INTERNATIONAL COMPARISON ....... 47

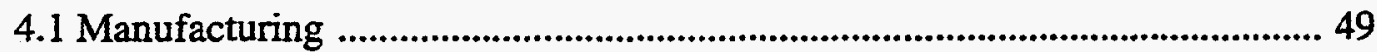

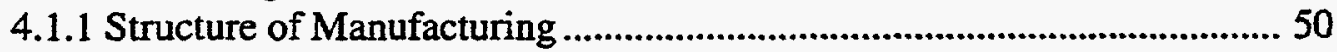

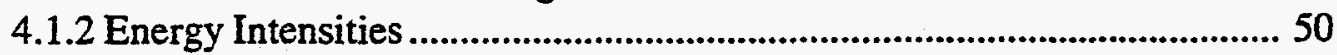

4.2 Passenger Transportation (Travel) .............................................................5 50

4.2.1 Activity and Structure ............................................................................... 51

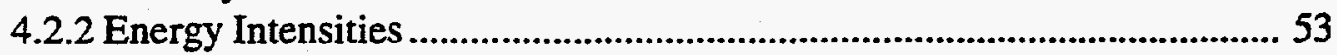

4.3 Freight Transportation .................................................................................. 53

4.3.1 Activity and Structure ......................................................................... 53 


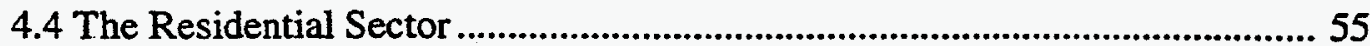

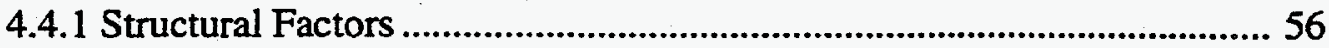

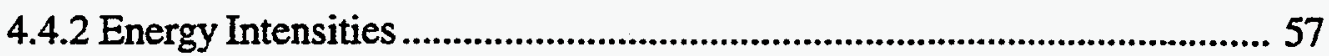

4.5 The Service Sector and Other Sectors ..................................................... 58

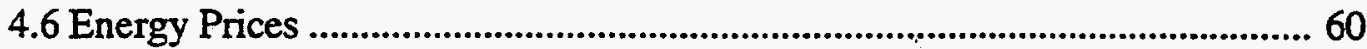

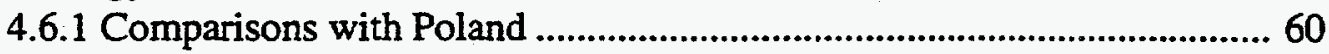

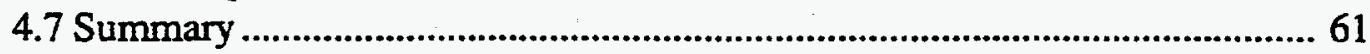

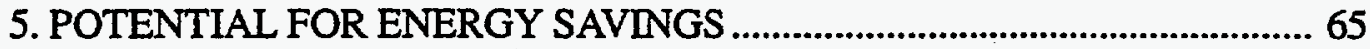

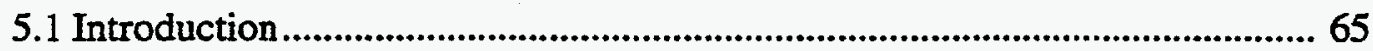

5.2 What is "Potential for Energy Savings"? .................................................... 65

5.3 Previous Overall Estimates of Energy Efficiency Potential ........................... 67

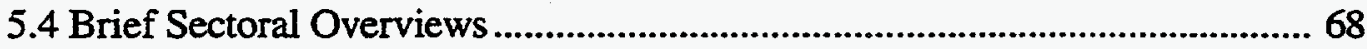

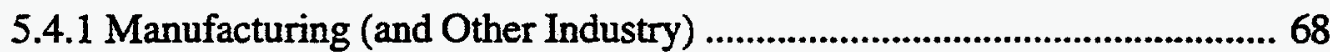

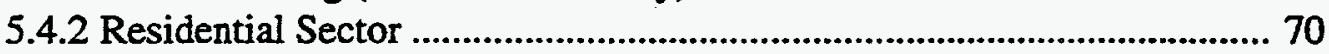

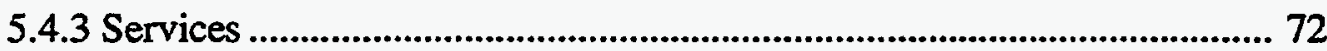

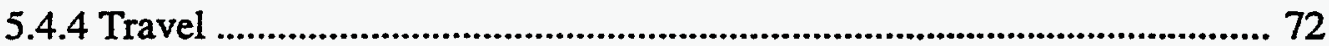

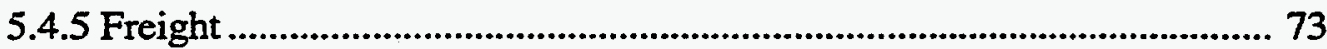

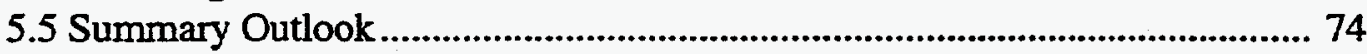

APPENDIX: EXPERIENCE FROM SPECIFIC PROJECTS

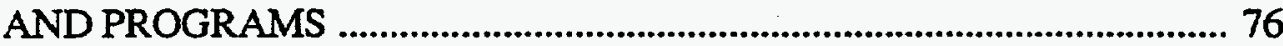

Building Retrofits in the Mustamaee District of Tallinn ............................... 76

Building Retrofits in the Oeismaee District of Tallinn ................................ 77

Heating Equipment in Buildings in the Viru Region of Estonia .................... 77

USAID Emergency Energy Program Audits and Technical Assistance ........ 78

World Bank District Heating Improvements ............................................... 79

6. IMPROVING ENERGY EFFICIENCY IN ESTONIA:

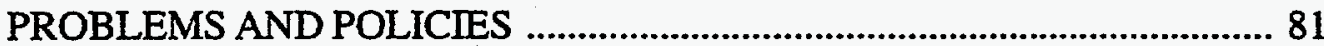

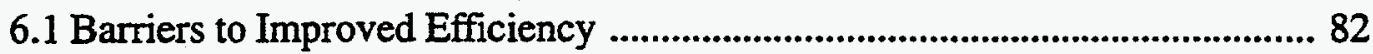

6.2 Some Key Issues in Housing and Heat Supply .............................................. 84

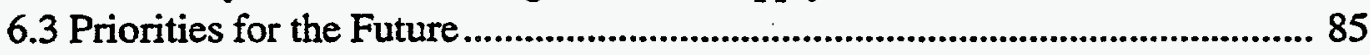

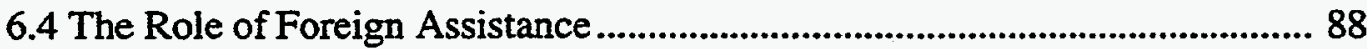

6.5 Closing Observations and Summary ............................................................. 89

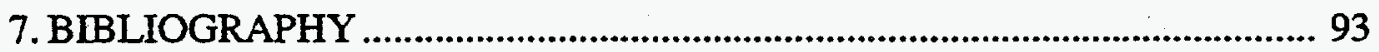




\title{
STRUCTURE AND EFFICIENCY OF ENERGY USE IN A REFORMING ECONOMY:
}

\author{
THE CASE OF ESTONIA
}

\author{
Lee Schipper and Eric Martinot," \\ Marta Khrushch, Jurgen Salay," Claudia Sheinbaum and Diana Vorsatz
}

Energy Analysis Program Energy and Environment Division Lawrence Berkeley Laboratory Berkeley, CA 94720
Stockholm Environment Institute

and
Box 2142, 10314 Stockholm

Sweden

\section{ABSTRACT}

We have analyzed the structure and intensities of energy uses in Estonia, a small independent state formerly a republic in the (former) Soviet Union. Our analysis covers the period 1980-1993, with the most detail for the years since 1990. While wedid not rigorously examine the structure of energy production and supply, we note that the reliance on oil-shale for electricity production and heavy fuel oil for heat supply contributed to very high per capita emissions of most pollutants, particularly $\mathrm{SO}_{2}, \mathrm{NO}_{x}$, and $\mathrm{CO}_{2}$. These problems alone, plus the recent reliance of Estonia on imported oil and gas sold at world prices, create an enormous incentive for improved energy efficiency in Estonia.

We analyze the structure of energy consumption, noting that while the industrial and freight sectors play a strong role (as they did in other centrally planned economies), the Estonian economy was somewhat less oriented toward production of energy-intensive raw materials than were most other planned economies.

We find that most energy intensities are high, indicating a significant potential for energy savings. Comparing Estonia with Poland and economies of Western Europe confirms this finding. Welay out in detail steps that could permit a reduction in energy intensities of 25-50\% in Estonia, depending on key factors such as timeframe, energy prices, overall economic reform, and a few important policy steps We hote, however, that there are many formidable barriers to improving energy efficiency. Some of these are related to the problems of Communist economies-lack of markets, lack of realistic prices, and lack of information-many of which have already begun to change. But other problems, particularly those plaguing the housing and building sector, hinder efficient use of resources in market economies as well. We call for policies that focus on accelerating the transition away from the older economy and those that address market barriers that are likely to remain.

Work sponsored by the Stockholm Environment Institute under the U.S. Department of Energy Contract Number DE-AC03-76SF00098. All opinions those of the authors.

- Also with the Energy and Resources Group, University of Califomia, Berkeley, CA. 


\section{ACKNOWLEDGEMENTS}

We are grateful to the Stockholm Environment Institute for its support for this project, and to Toenis Kaasik and his staff at SEI Tallinn for their hospitality during 1993. Karen Olson and Ted Gartner of LBL provided essential editing and production of this report. Marta Khruchsh and Diana Vorsatz acknowledge the support of the Central European University, Budapest. Eric Martinot acknowledges Carol Egan for her support and endurance of hardships during the research for this report.

We thank the following individuals for their assistance and cooperation. They have provided us with a substantial amount of information, unpublished data, expert estimations, and guidance which have all been invaluable to our results.

Murat Alekhodzhin, EC Energy Center Tallinn Jaan Anvelt, Ministry of Transport

Hanon Barabaner, Energy Research Institute

Kaido-Paul Boestrov, State Energy Department

Mauno Inkinen, National Housing Board

Karl Jaanimaegi, Energy Research Institute

Urmo Kala, Ministry of Economy

Arvi Kallas, Research Institute of Agriculture

Lembit Kiviloo, Ministry of Transport

Kjell Larsson, State Energy Department

Hillar Lauri, World Bank

Aarne Leisalu, A/S ESTIVO

Anu-Mai Levo, A/S ESTIVO

Endel Linask, Ministry of Economy

Franz Longhi, European Commission EC Phare

Kalle Maandi, Eesti Gaas

Vello Maeeots, Ministry of Transport

Jueri Maegi, A/S Hansab

Maert Moetus, Institute of Energy

Toenu Naestema, Ministry of Transport

Kuelli Neider, USAID

Georg Nielsen, European Commission EC Phare

Arvo Niitenberg, Minister of Energy

Asto Nummert, Ministry of Transport

Maert Ots, (formerly) State Energy Department

Andrus Pihkva, (formerly) State Energy Department

Mall Poeldmaa, Ministry of Transport

Alari Purju, Institute for Future Studies 
Valdemar Raidla, National Housing Board

Mart Randlane, Ministry of Transport

Priit Raud, Electrolux Estonia

Toenu Rohumaee, Estonian Building Research Institute

Jueri Sander, National Housing Board

Marika Sepp, National Housing Board

Sulev Soosaar, A/S EnPro Engineers Bureau

Ernst Tammemaegi, EC Energy Center Tallinn

Aarne Tihemets, State Statistical Office of Estonia

Uelo Toivere, State Statistical Office of Estonia

Jaan Viik, Ministry of Agriculture 


\section{INTRODUCTION}

The end of Communist rule in Central and Eastern Europe helped push aside the secrecy that had hidden both the energy sector and detailed patterns of energy use in the former centrally planned economies (CPEs). The secrecy may have been necessary for national security, i.e., good information about how energy was used revealed how poorly the economy was really performing. But the most important reason may have been the giant lack of information. Despite intensive scrutiny by planners, the quantitative structure of energy use in former CPEs was very poorly understood because user categories were poorly defined, meters were rare, prices meaningless, and few authorities actually bothered to see how much (or how efficiently) energy was being used.

Economic reform and rapidly falling demand in Central and Eastern Europe have collapsed industrial output in many regions. Other economic activities have experienced drastic changes. Energy use has declined, albeit at a slower pace, because authorities have tried to keep unprofitable factories running at low capacity, and because private citizens have imported large numbers of Western cars and kept their homes as warm as possible. Some decline is welcome because of the lessening of environmental damages from energy use and many industrial activities. The changes in energy use are dramatic, but their speed and end points are uncertain.

In this report we address that uncertainty. In doing so, we pursue answers to many important questions that have occupied energy planners around the world since the onset of reforms in Central and Eastern Europe:

- Just how inefficient is (or was) energy use in planned economies?

- What happens to energy use under conditions of rapid economic reform?

- How do the structure and efficiency of each sector or end use change when the very nature of each sector changes?

- What is the recent experience with improving energy utilization or switching to lower-cost fuels?

- In what sectors will market forces reshape energy use without intervention by authorities, and in what sectors might intervention be necessary to accelerate the adjustment to market conditions?

- What role can assistance organizations like the International Energy Agency, energy companies, non-governmental organizations (NGOs), or other interested parties play in accelerating the improvement of energy utilization or the reduction in pollution arising from energy production and use?

Using Estonia as a case study, this report ponders how energy efficiency and energy market reforms can succeed on their own merits and how new governmental policies can influence energy efficiency in a former CPE. Although a small country whose population is dwarfed by most capitol cities of Central and Eastern European countries, Estonia offers the opportunity to study a former CPE that seems to have 
avoided the disastrous economic collapse that threatens Russia or Ukraine and which is well on its way toward market-based approaches to energy efficiency. Estonia's small size enables an energy-efficiency project to have national impacts because of the accessibility of local and national authorities.

\subsection{Project Formation}

Several developments led the Stockholm Environment Institute to take up this project. First and foremost, SEI has a deep interest in all the Baltic countries because of the serious environmental problems connected to industry and energy use there, problems that affect other countries around the Baltic Sea. Then, following the dissolution of the Soviet Union, many authorities in the Nordic countries became concerned that the Baltics might lose their supplies of cheap heat, leading in turn to either misery and economic disruption or to a hasty substitution of local resources with their own environmental impacts. Finally, Estonia has always had an affinity with the Nordic countries through its language, which is related to Finnish, and through history-Estonia was once a province of Sweden and, at least until World War II, still had a small Swedish-speaking population.

In 1992, SEI established a branch office in Tallinn, Estonia, to research questions relating to environment, including energy. As concern over the Baltics mounted, it became important to know which strategies to reduce dependence on energy imports would pay off. This knowledge demanded a better understanding of the patterns of energy use than had been previously available, in spite of all the "data" from the era of the planned economy. In fact, many changes, ushered in by both economic reform and the new terms of trade placed on energy, were already underway.

During 1992 and early 1993, the International Energy Studies Group at Lawrence Berkeley Laboratory studied energy use in Poland and analyzed patterns of energy use in the Soviet Union in 1989-1991. ' Based on that work, SEI requested the Group to perform a similar analysis of energy use in Estonia to determine how closely energy use in the very process of economic reform could be studied.

\subsection{Goal of this Report}

Previous analyses of the existing energy situation in Estonia concentrated on the supply side. ${ }^{2}$ But little rigorous analysis or comprehensive discussion of the demand side has taken place. This lack could be attributed, in part, to poor statistical information. But beyond statistics, a detailed examination of energy consumption is not simply an "energy" question. Rather, it involves all sectors of the economy-manufacturing, transport, housing, services, and agriculture. Many existing reports mention "energy-efficiency potential" in very general terms. But likewise, future energyefficiency potential is not simply a technical question, but an economic, social, and institutional one as well.

The goal of this report is to contribute to a better understanding of the detailed structure of energy consumption entirely from a demand-side perspective. From this understanding, and from a comparison with energy consumption in other countries, we can begin to form recommendations and suggest priorities for future policies and investments which will result (directly or indirectly) in energy-efficiency gains.

1 These studies are included in the bibliography at the end of this report.

2 See, for example, Ministry of Industry and Energy, 1993, and Fenhann, 1992. 
Our work is arranged in three parts: analytical, comparative, and empirical. We combine statistical data, expert assessments and estimates, a specific set of assumptions, and analytical models to provide a detailed, quantitative picture of energy consumption. An important part of this analysis is a transformation of Estonian statistical categories (which portray energy use in the manner of the old Soviet statistical system) into standard Western statistical and accounting categories. With this transformation, we can compare the structure of Estonia's energy consumption with other Western countries and highlight potential energy-efficiency gains. Finally, we examine "real-world" experiences from energy-efficiency programs and projects in Estonia and try to extract useful information about energy-efficiency potential from these experiences. 


\section{ECONOMY, ENERGY, AND ENVIRONMENT IN ESTONIA}

\subsection{The Economy in the Soviet Period}

During the period of Soviet rule following World War II, Estonia was fully integrated into the economic and political system of the USSR. Characterized by rapid industrialization and urbanization, including the migration of workers from various parts of the Soviet Union (especially Russia) into Estonia, this period forced Estonia to become highly dependent on energy and raw materials from other parts of the USSR. Most Estonian companies were directly subordinated to central planning authorities in Moscow and were prohibited from conducting foreign trade directly with other countries. In the 1980 s, industry accounted for approximate $40 \%$ of Estonia's GDP; food processing and light industry each provided about one-quarter of industrial output; and agriculture accounted for some $20 \%$.

According to World Bank estimates, at the end of the 1980s, Estonia had the highest standard of living of the republics in the USSR, with a per capita income $40 \%$ above the Soviet average by the end of the 1980 s. Evaluated at purchasing power parities, in 1990 per capita income was slightly lower than that of Poland and more than four times smaller than that of the Scandinavian countries.

Using Western conventions, the Estonian Statistical Office has been trying to estimate the GDP of Estonia in the Soviet period. The Office estimates that GDP, in 1980 rubles, grew from 4.45 billion in 1980 to 5.45 billion in 1989 , but then fell to 5.25 billion in $1990 .{ }^{2}$ Between 1980 and 1989 the average, annual real GDP growth was only about $1 \%$. These calculations show that in 1990 the share of manufacturing in total GDP at about $40 \%$ and that of services at about 30\%. In Figure EC-1, we show the results of these calculations by major sectors of activity along with an estimate of the total 1992 GDP.

\subsection{The Onset of Economic Transition}

In 1990, one year before Estonia became independent, its newly elected government introduced economic reforms similar to those adopted in most Eastern European countries. Estonia was the first of the Baltic countries (and other former Soviet republics) to adopt market reforms. The Soviet tax system was abolished and replaced by a modern Western-type tax structure. Most consumer prices were deregulatedexcept basic ones like rents, electricity, heat supply to apartments, public transportation, and telecommunications-and state subsidies to enterprises were gradually canceled. In a successful effort to shield its economy from uncontrolled inflation in the collapsing Soviet economy, Estonia introduced its own currency, the kroon (EEK), in mid-1992. The EEK was fixed at 8 to the German mark and has remained stable and freely convertible with Western currencies ever since. According to World Bank estimates, real GDP decreased by $8 \%$ in 1990 and by $10 \%$ in 1991 . The decline in 1992 was even greater: estimates range from $15 \%-25 \%$. In 1991, the largest declines

I This section based on "Estonia: The Transition to a Market Economy," 1993, World Bank: Washington, D.C.

2 "National Accounts in Estonia." Statistical Office of Estonia. Tallinn, 1992. They indicate an unofficial exchange rate of approximately 1.6 rubles to the dollar, about $2 \frac{12}{2}$ times the "official" rate but probably less than the real exchange rate. Hence this "GDP" overestimates output for Estonia. 


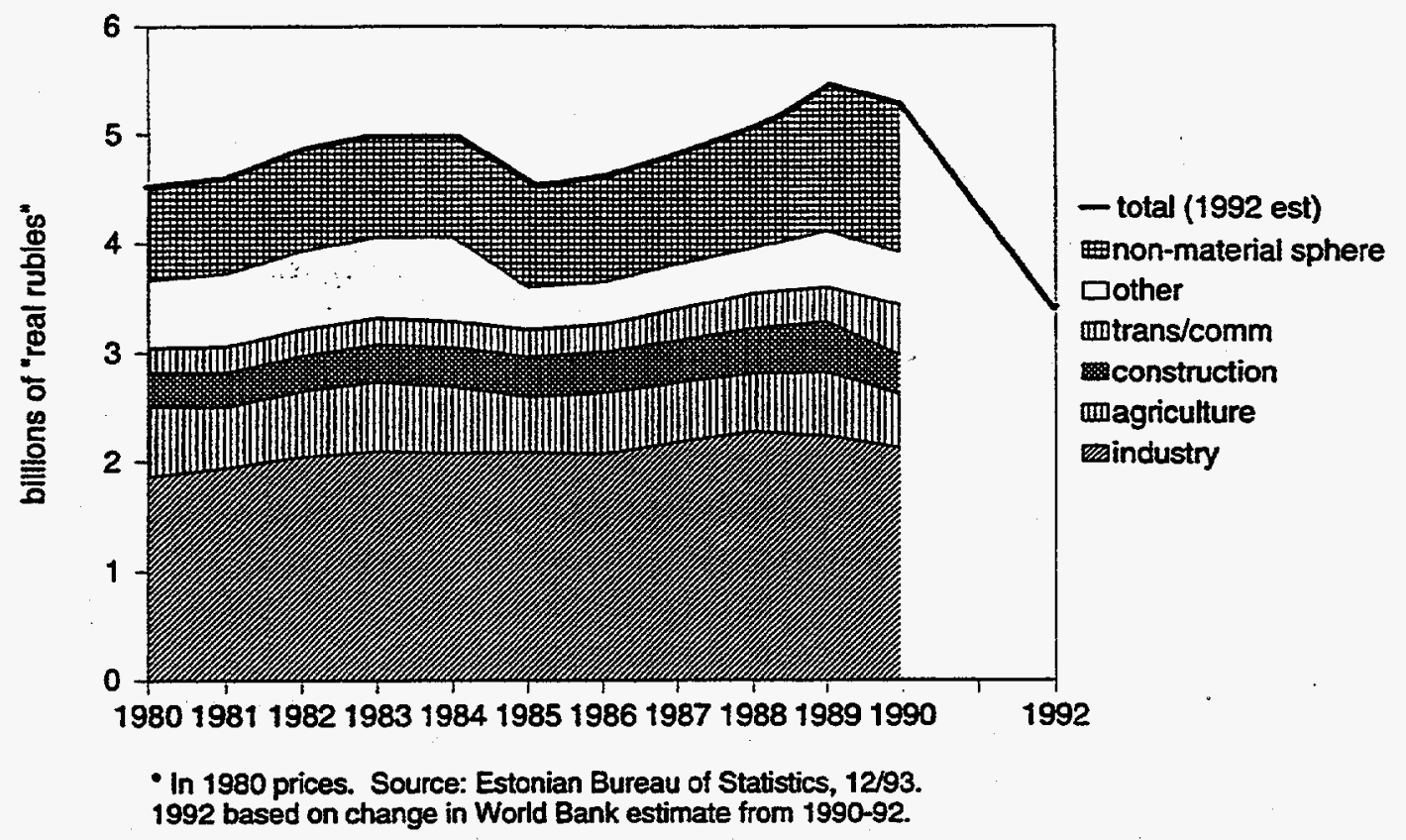

Figure EC-1. Estonian GDP*. Estimated according to western practice.

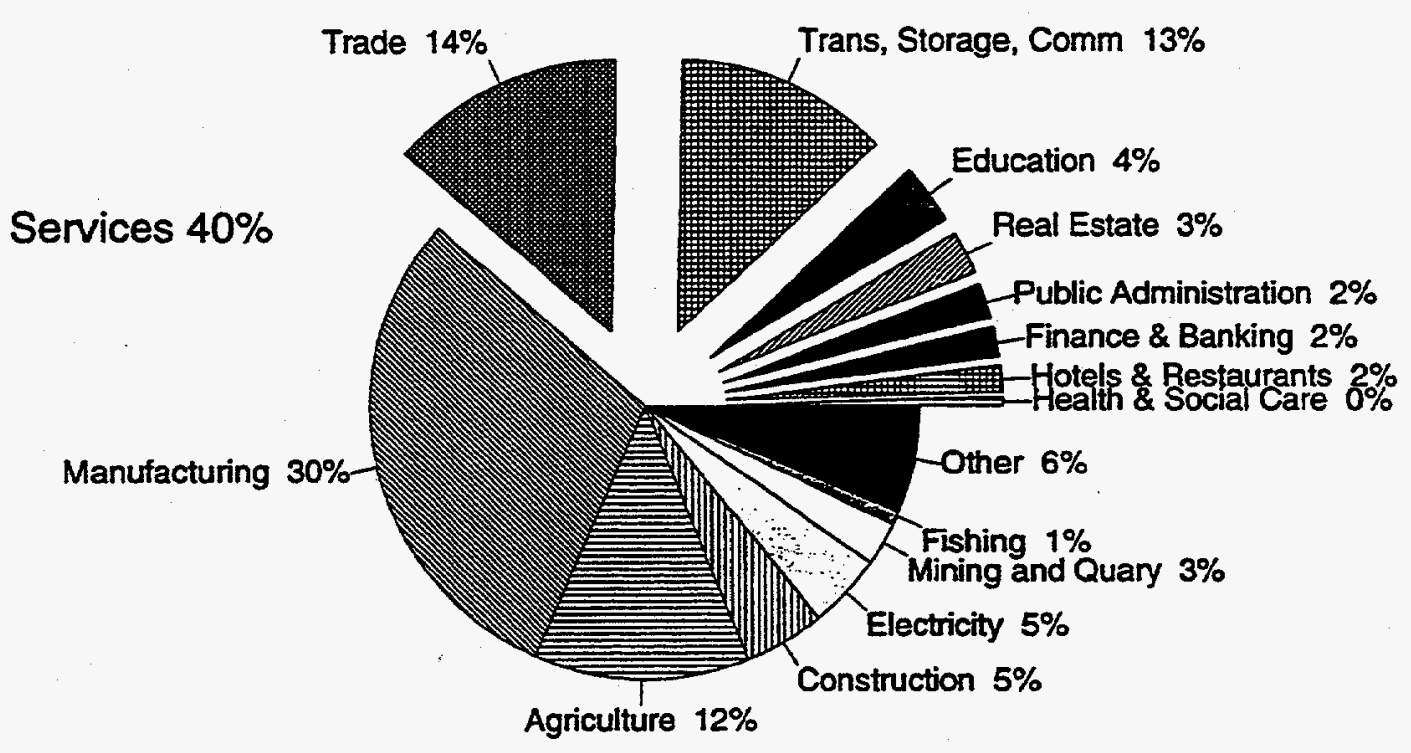

Millions of EEK for 1992

Figure EC-2. Estonian GDP. Economy branches. 
were in agriculture and construction, while output in industry declined by more than $30 \%$ in $1992 .{ }^{3}$ Figure EC-2 shows World Bank estimates for 1992 of sectoral GDP in EEK. ${ }^{4}$ It is notable that manufacturing comprises only about $30 \%$, mining less than $3 \%$, and services $41 \%$. While the two different measures of the structure of output (ruble in 1990 and EEK in 1992) cannot be directly compared, ${ }^{5}$ it is clear that the low share for manufacturing in the Bank's 1992 estimate represents in large part the collapse of that branch from 1990. The drastic fall in output may bottom out in 1994, but in late 1993 output was still declining. However, even accounting for a leveling or coming upturn, Estonian GDP will still be well below the 1990 level for the next several years.

A major reason for the drop in output has been the collapse of trade with the former USSR - a collapse that has made acquisition and finance of imports needed to maintain production extremely difficult for Estonia. Although trade with the West is still small compared with most Eastern European countries, Estonia has successfully expanded trade with Western Europe and other OECD countries since 1991. Coupled with the decline in output has been a high rate of inflation and high interest rates. Following price deregulations, inflation accelerated, reaching some $200 \%$ on an annual basis in 1991. Inflation rates stabilized in the second half of 1992 and declined to a few percent on a monthly basis in the second half of 1993 , or about $30 \%$ on an annual basis. ${ }^{6}$ Real interest rates have remained at about $15-20 \%$ and have seriously hampered capital investment.

\subsection{Energy Prices}

Energy prices have increased manifold since reform began. Sample energy prices (including sales tax) as of September 1, 1993, are shown in Table 2.1. The prices of oil and gas are now approximately equal to world-market prices, although with practically no energy taxes, they remain perhaps $10-15 \%$ below consumer prices in other countries. Because of low taxes, retail gasoline prices lie slightly under those in the U.S. and far below those in Western Europe. Also notable are the low prices of oilshale and electricity (in EEK/GJ) relative to other sources. Electricity prices are set by the government and are drastically less than those in Western countries for two main reasons: domestic oil-shale used for electricity production is cheap to mine and its price is kept low (the mining company was reported operating at a loss in 1993 and amassing huge debts), and electricity rates do not include any capital depreciation or investment elements. Prices for district heat and hot water are subsidized for some consumers and are determined by local municipalities after they account for their cost of fuel purchases. Two years after Estonian independence, energy prices still remain low on an international scale.

3 GDP estimates come from the World Bank ("Estonia: The Transition to a Market Economy," 1993, and a private communication by J. Hansen) and from the Statistical Office of Estonia. According to these estimates, Estonia's GDP in 1990, 1991, and 1992 were 6.6 billion, 5.9 billion, and 4.4 billion, respectively, in 1990 US dollars.

4 The total value, 13.34 billion EEK, compared with a figure of USD 4.40 billion, gives an implicit exchange rate using purchasing power of about 3 EEK to the dollar. This figure can be compared to the official exchange rate of about 12-13. Such divergences are not uncommon. Since the EEK is freely traded, there is virtually no black market exchange rate.

5 The reason for this is because the ruble to EEK exchange rate at the time of the introduction of the kroon did not necessarily reflect true values.

6 Inflation figures based upon the Consumer Price Index calculated by the Estonian Statistical Office. 
Table 2.1. Energy prices in Estonia (September, 1993). (Dollar Values at Approximately 12.5 EEK/\$)

\begin{tabular}{|c|c|c|c|}
\hline Form & Physical Units & Per Gigajoule & US\$/GJ (Approx) \\
\hline $\begin{array}{l}\text { Oil-shale } \\
\text { Coal } \\
\text { Heavy fuel oil } \\
\text { Natural gas } \\
\text { Diesel oil } \\
\text { Gasoline } \\
\text { Heat } \\
\text { Electricity }\end{array}$ & $\begin{array}{l}36 \text { EEK/ton } \\
405 \text { EEK/ton } \\
1000-1300 \text { EEK/ton } \\
1400 \text { EEK/1000m } \\
3310 \text { EEK/ton } \\
3927 \text { EEK/ton } \\
220 \text { EEK/Gcal } \\
0.150 \text { EEK/kwh }\end{array}$ & $\begin{array}{l}\text { 3.84 EEK } \\
\text { 16.9 EEK } \\
\text { 32.4EEK } \\
41.5 \text { EEK } \\
\text { 75.8 EEK } \\
\text { 92.4 EEK } \\
\text { 52.5 EEK } \\
\text { 41.7 EEKJGJ }\end{array}$ & $\begin{array}{c}0.30 \\
1.20 \\
2.80 \\
3.00 \\
6.00(0.24 \text { Aiter) } \\
7.50(0.30 / \text { iter }) \\
3.50 \\
3.25 \text { (or } 0.012 / \mathrm{kWh})\end{array}$ \\
\hline
\end{tabular}

Measuring price changes in real terms is difficult, especially between the periods when the ruble and the EEK were used. Nominal prices have increased one hundredfold or more since Soviet times, depending on the exchange rates. We can compare 1990-1993 prices using an index of consumer prices published by the $\mathrm{Bu}$ reau of Statistics. ${ }^{7}$ Making a comparison with Western prices is problematic because of the exchange rate problem, but using the World Bank's estimate that the purchasing power of the EEK was approximately three times its official exchange rate gives some realistic idea of the energy price level. Figure EC-3 shows prices for fuels for stationary use and Figure EC -4 shows prices for road fuels. The levels shown are far below typical prices seen in Westem countries. It should also be noted that the huge price increases of early 1992 were not followed by further increases, but slowly eroded by inflation. ${ }^{8}$

As the pressure to raise energy prices to world market levels has intensified, a central problem for the energy sector and consumers has been the effect of energy prices on personal income. In June 1993, the minimum wage was $300 \mathrm{EEK} / \mathrm{month}$ (about \$25) and the average wage was $800-900 \mathrm{EEK} / \mathrm{month}$ (about $\$ 70$ ). At these income levels, consumers could hardly afford to pay world energy prices. In the winter of 1992-1993, heat and hot water production costs were approximately 500$600 \mathrm{EEK} / \mathrm{month}$ for heating a three-room flat, more than half of which was subsidized by municipalities or by the state. In 1993 consumers were only required to pay up to $25 \%$ of their monthly income for heat. Heat purchases were also exempt from the $18 \%$ sales tax.

7 Prices obtained from M. Moetus, 1993, "Energy Situation in Estonia after Currency Reform and New Energy Saving Program for the Near Future," Institute of Energy Research, Tallinn. The price index was published by the Bureau. Additionally, A. Purju, Institute for Future Studies, Tallinn, provided us with indices of average wage levels and indices of purchasing power for the average wage. Combining these gave virtually the same relative price changes as indicated by the CPI. Of course, the prices for energy in 1990 and 1992 were only estimated in EEK based on changes in their ruble levels and the ruble/EEK conversion rate at the time the EEK was introduced in 1992.

8 By comparison, natural gas in Western Europe costs from \$5-10 per gigajoule in 1990 terms and automobile gasoline about \$25-35/gigajoule. Were we to use exchange rates, the Estonian prices would be even lower on an international scale than they otherwise appear to be. 


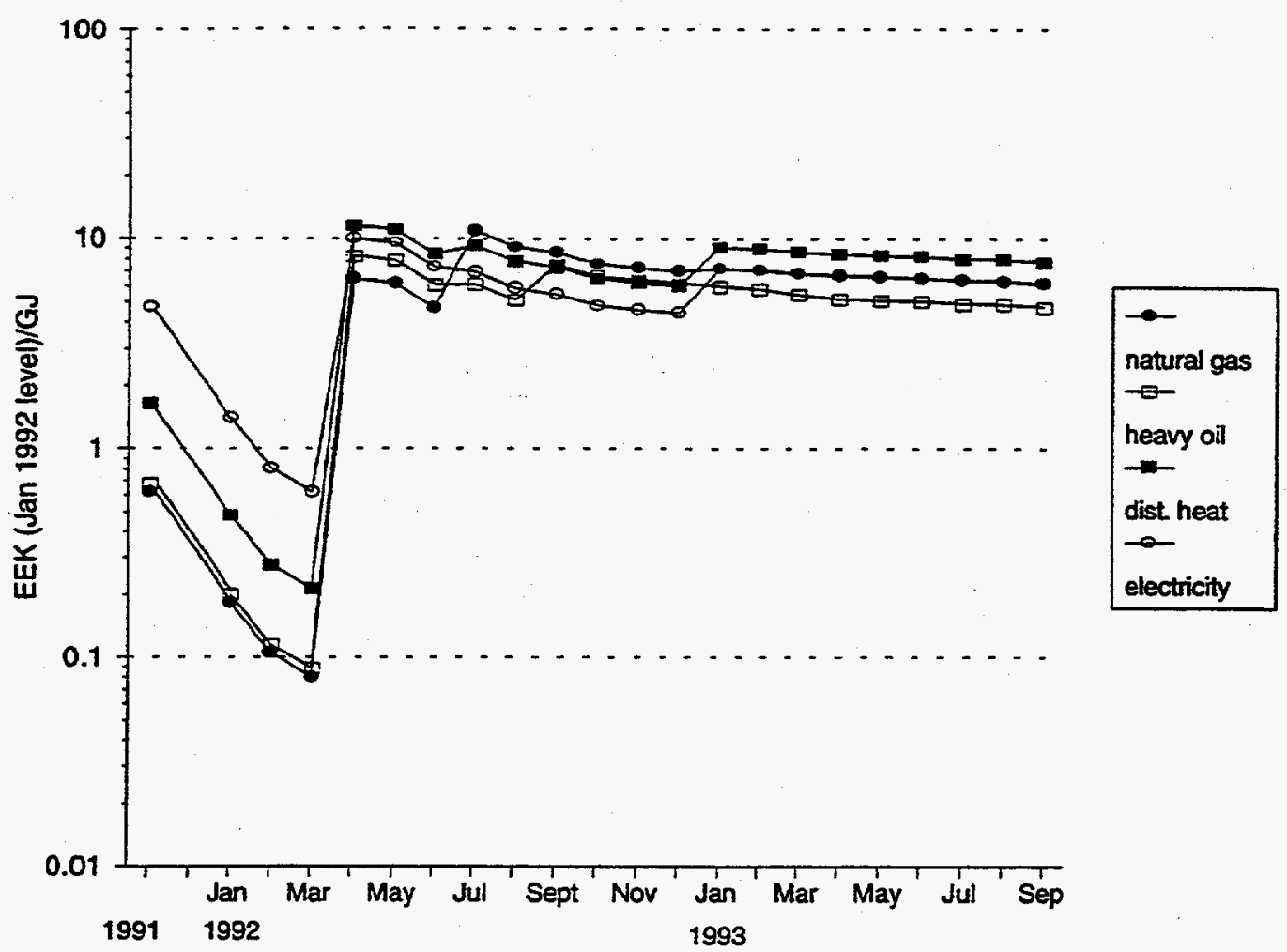

Figure EC-3. Stationary fuel prices in Estonia.

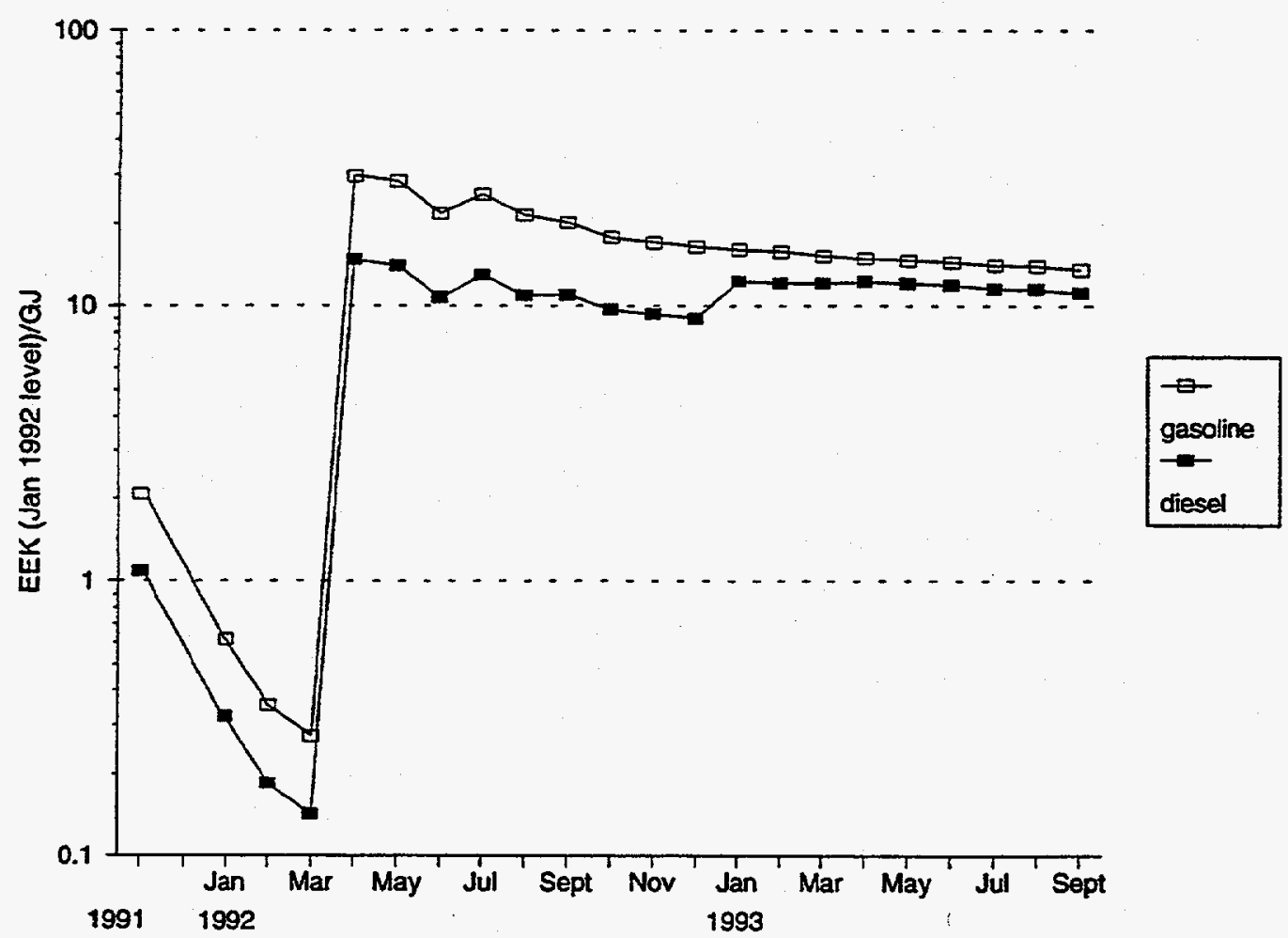

Figure EC-4. Road fuel prices in Estonia. 
Increased energy prices have created a secondary problem: that of unpaid debts. Debts to energy suppliers are mounting from energy customers who cannot afford (or simply refuse) to pay their bills. In 1993, district heating companies reportedly collected only about half of their billings; the rest went unpaid and were added to debt accounts or were paid by the state. Unwilling to offend foreign energy suppliers, the state has been forced to pay these debts to energy suppliers. Heat poses a special problem in revenue collection: while electricity to non-paying customers can be shut off, heat supply to individual consumers is mechanically (if not morally) difficult or impossible to stop. Industries struggling to survive add to the problem. As of August 1993, huge energy debts had accumulated within the energy sector among producers and consumers alike, with bleak prospects for settlement of these debts in the near future. State enterprises owed 260 million EEK to energy producers. In turn, these energy producers owed 320 million EEK to the state. ${ }^{9}$ The massive debts mean that little money has been available to invest in new capital. In fact, municipalities and energy suppliers could hardly maintain existing equipment, let alone fund new capital investments.

\subsection{Energy Supply}

Primary energy consumption lay around $460 \mathrm{PJ}$ in 1980 and 1985 , falling slightly to $450 \mathrm{PJ}$ in 1990 and then sliding to $416 \mathrm{PJ}$ in 1991 and $302 \mathrm{PJ}$ in 1992. Like most other East European countries, Estonia's energy supply is almost completely based on fossil fuels. In 1990, oil-shale accounted for 53\% of primary energy consumption, oil products for $29 \%$, natural gas for $6 \%$, and coal, peat, and wood, and other fuels for the rest. Oil-shale is used for electricity and some heat production as well is in the chemical industry. Although Estonia satisfied $44 \%$ of its energy demand from domestic sources in 1990, it imported all oil products and gas. Until recently, Russia and other parts of the former USSR provided all imported energy to Estonia. Given the infrastructure and competitive prices, Russia is likely to continue to be Estonia's main energy supplier for the next few years.

Energy supply considerations have an important impact on the environment. Estonia stands out as the only country in the world with an electric power systemabout $96 \%$ of the installed generation capacity-based on oil-shale. Located in the town of Narva in northeast Estonia, two thermal power plants with a combined capacity of $3045 \mathrm{MW}$ provide the bulk of the power. In Tallinn, a smaller combined heat and power plant producing $190 \mathrm{MW}$ burns oil and gas. The structure of electricity production in Estonia is a result of Soviet energy planning of the 1960s and 1970s. The two large power plants in Narva, close to the Russian border, were designed according to the needs of a much larger region. Electricity produced in Narva supplied not only Estonia, but also Latvia and the Leningrad and Pskov administrative areas of Russia.

Heat production is also based in part on oil-shale, but heavy fuel oil accounted for $40 \%$ of the inputs in the recent past, while natural gas surpassed oil-shale as the second most important source in 1985. These figures are misleading, however, because a significant share of this production takes place on industrial premises or in small boilers for groups of buildings. As a consequence, emissions from heat production, being dispersed over more than 7000 boilers, are difficult to control. With imported oil and gas becoming expensive in the post-Soviet era, many operators are

Debt figures from M. Moetus, ibid. 
switching to oil-shale, wood, peat, or other biomass, which will create their own emissions problems.

\subsection{Environmental Effects of Energy Use ${ }^{10}$}

Energy consumption in Estonia creates many environmental problems. Some, like local air pollution and acid rain, are common to many European countries, while others, like land degradation and ground water contamination from oil-shale mining and processing, are unique to Estonia. Air quality varies among regions of the country. Tallinn and the oil-shale mining region in the northeastem are most affected by air pollution. Although concentrations of some pollutants have been monitored at least since the 1970 s, only limited air quality data are readily available. Concentrations of several pollutants, including dust, carbon monoxide $(\mathrm{CO})$, sulfur dioxide $\left(\mathrm{SO}_{2}\right)$, and nitrogen oxides ( $\mathrm{NO}_{\mathrm{x}}$ ), are highest in Tallinn, in Kohtla-Jaerve (from oilshale processing and the chemical industry), and in Narva (from thermal power plants). ${ }^{11}$ Total national pollutant emissions can only be roughly estimated, since little monitoring of pollution sources takes place. Most industries appear to lack self-monitoring equipment. Reported emissions are calculated using emission factors and are consequently only approximate values of actual emission levels. In addition, the data for $\mathrm{NO}_{x}$ emissions are based on estimates of transport activity. Estimates for total $\mathrm{SO}_{2}$ emissions in 1990 vary from 208 kilotons for stationary sources only (Estonian Ministry of Environment) to 276 kilotons including mobile sources (Taehtinen \& Nurste). Estimates for total $\mathrm{NO}_{x}$ emissions in 1990 vary from 46 kilotons (Ministry of Environment) to 107 kilotons (Taehtinen \& Nurste). About half of the total emissions in these estimates were attributed to mobile sources.

The major sources of $\mathrm{SO}_{2}$ emissions are the electric power plants in Naria, which accounted for some $60 \%$ of all $\mathrm{SO}_{2}$ and particles emitted from stationary sources in 1990. Since these plants have high smokestacks $(150-200 \mathrm{~m})$, a substantial part of their emissions is carried away. Sulfur and nitrogen emissions contribute to acidification of soils and lakes in the entire Baltic region and are widely believed to be a major cause of increasing forest damage in Estonia. The second most important source of $\mathrm{SO}_{2}$ is heavy fuel oil used by district heating plants. Major sources of $\mathrm{NO}_{\mathrm{x}}, \mathrm{CO}$, and hydrocarbons are motor vehicles, which in 1990 accounted for at least $52 \%$ of all emitted $\mathrm{NO}_{x}, 55 \%$ of all emitted $\mathrm{CO}$, and $53 \%$ of hydrocarbons.

Total emissions of $\mathrm{SO}_{2}$ in Estonia are of the same order of magnitude as those from Scandinavian countries, but per capita emissions in 1990 were several times higher in Estonia. In fact, Estonia had one of the highest per capita ratios in the world (see Figure EM-1) because so much electric power was produced and exported to other regions of the Soviet Union. Per capita emissions of $\mathrm{NO}_{\mathrm{x}}$ in Estonia are higher than those in most other European countries as well (see Figure EM-2).

10 This section based on Estonian Ministry of Environment and Finnish National Board of Waters and the Environment, "Estonian Environment 1991," 1991, Helsinki, and Estonian Ministry of Environment, "National Report of Estonia to UNCED," 1992, Tallinn.

11 Average levels of $\mathrm{SO}_{2}$ in Estonian cities are in the same range as concentrations recorded in the 1980 s in major West European cities, and below typical average $\mathrm{SO}_{2}$ levels in comparable East European locations. According to an official report on the Estonian environment in 1991, the highest recorded concentration of $\mathrm{SO}_{2}$ in that year was measured in Kohtla-Jaerve, $0.258 \mathrm{mg} / \mathrm{m}^{3}$. The highest level of nitrogen oxide $\left(\mathrm{NO}_{x}\right), 0.36 \mathrm{mg} / \mathrm{m}^{3}$, was also recorded in Kohtla-Jaerve. 


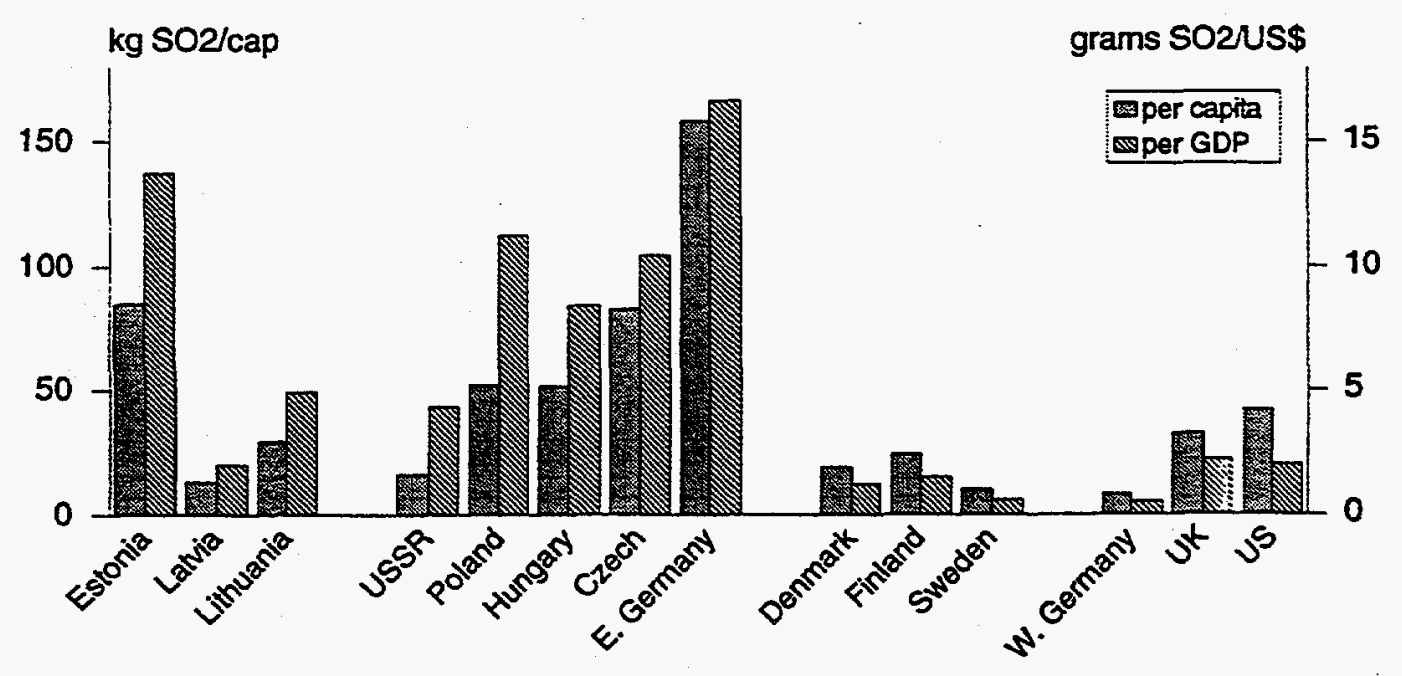

1989 emissions and GDP at PPP-values. 1990 emissions data for Estonia and Lithuania. 1991 emissions data for Latvia (likely to underestimate its emissions/income ratio by about 20\%).

Figure EM-1. Sulfur dioxide emissions.

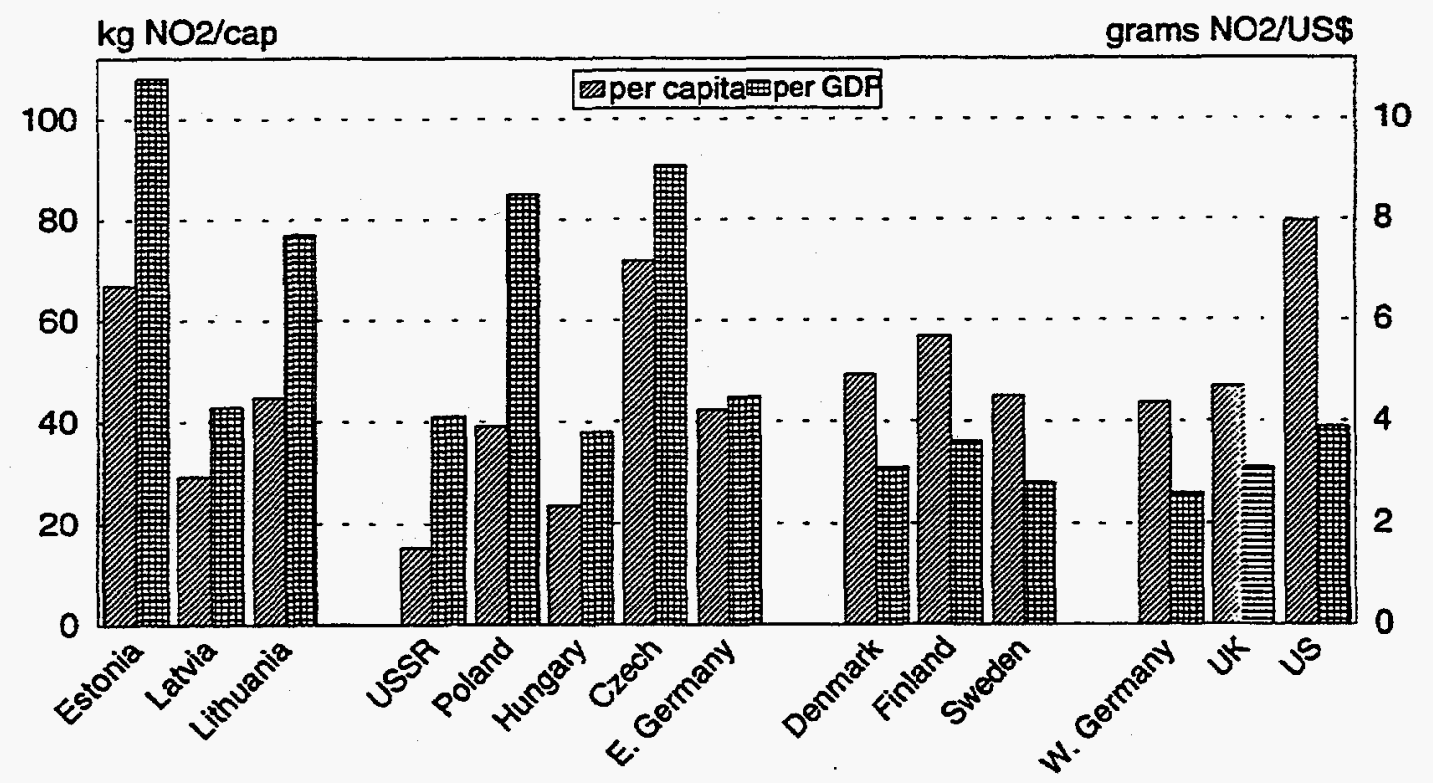

1989 emissions and GDP at PPP-values. 1990 emissions data for Estonia and Lithuania.

1991 emissions data for Latvia (likely to underestimate its emissions/income ratio by about 20\%).

Figure EM-2. Nitrogen oxides emissions.

Oil-shale mining and processing for electric power generation are also significant sources of environmental disruption. While oil-shale makes Estonia self-sufficient in electricity, it also burdens the country with high environmental costs. The use of oil-shale has created a severe ecological situation in the northeastern part of the country. The mining of oil-shale, which to a large extent takes place in open pits, requires about 350 hectares of new land every year, and the total land area used now 
comprises some $7.5 \%$ of the entire country. Of a total of about 10,000 hectares now spoiled by mining activities, some $70-80 \%$ has been subject to reclamation and recultivation, mostly with forest. The waste materials from oil-shale mining and combustion cover thousands of hectares, sometimes with 100-meter high heaps, and are washed out by precipitation. Leaking from those deposits are pollutants such as heavy metals and phenols that contaminate surface and ground waters. ${ }^{12}$ Oil-shale mining also lowers the ground-water level in the region. By the end of the 1980s, more than 8 million tons of residual ashes from the combustion process were accumulating each year. Some of it can be used for building materials and some for liming acid soils in agriculture.

In addition to repairing environmental damage within Estonia, national authorities have other incentives to reduce the environmental impacts of energy use. Health problems associated with the environment, such as increased rates of bronchitis and asthma, have been identified in Kohtla-Jaerve, Narva, and Sillamae. Emissions from the oil-processing and chemical industries in Kohtla-Jaerve contain hazardous pollutants like benzo(a)pyrene, formaldehydes, phenols, and various hydrocarbons. There is also international pressure on the Estonian government to reduce emissions of various pollutants that affect neighboring countries. Estonia is likely to join the International Convention on Trans-boundary Air Pollution, signed by most European countries, the U.S., and Canada. One of the agreements within the framework of this convention, the so-called Sulfur Protocol, stipulates a 30\% reduction of sulfur from the 1980 base-year levels by $1993 .^{13}$ The current status of environmental laws and regulations is a combination of administrative procedures, legislation, standards from the Soviet period, and some provisions adopted by the new Estonian government. Permits issued by local environmental protection boards stipulate limits on emissions of major pollutants. A system of environmental taxes, pollution fees, and fines, which apply to $\mathrm{SO}_{2}, \mathrm{NO}_{x}, \mathrm{CO}$, dust, and other emissions, was introduced in 1991. Fines are imposed for pollution exceeding certain ceilings. If the fines do not ensure compliance, plant closure is a potential final measure. Vehicles are currently only inspected for $\mathrm{CO}$ emissions. In the future, Estonia aims to adapt a program for environmental standards similar to those generally applied in Western Europe, in which laws provide operative requirements for the control of potential sources of environmental pollution. However, it is difficult to imagine how Estonia can reduce emissions without reducing the quantity of energy consumed. Certainly tighter emissions controls and enforcement of current regulations for existing and new facilities could help.

While reducing pollution through regulation, taxes, and incentives is important, future energy consumption will remain crucial to future environmental impacts. Particularly important is the oil-shale mining and electricity production complex in northeastern Estonia, which is a key issue for the future of both Estonia's environment and economy. This brief review of the environmental impacts of energy production and use in Estonia shows a huge, hidden benefit to strategies that restrain or even

12 van Arkadie, B. and Karlsson, M. "Economic Survey of the Baltic States," 1992, London: Pinter Publishers.

13 The Estonian government has declared that it intends to join the Convention but that it will need more time than Western European countries to comply with the reduction goals. 
reduce primary energy use. Reducing waste of electricity or heat lessens the burning of oil-shale and heavy oil or avoids the substitution of biofuels with their own special environmental impacts. Reducing waste of oil and gas alleviates the fiscal pressures on the Estonian economy to import these fuels. But can Estonia restrain or reduce energy use? In Section 3, we suggest the answer is yes. 


\section{ENERGY DEMAND OVERVIEW}

Appraising the potential for energy-efficiency improvements in any building, enterprise, or country requires a clear picture of how energy has been used in recent times. This picture must include both the quantities of energy consumed, by source, and the activities or output for which the energy is used. In this section, we develop such an understanding for Estonia. An appendix to this chapter lists our data sources and explains our assumptions about each sector of final energy demand.

\subsection{The Economy: Aggregate Structural Data}

Structural data for Estonia come from a variety of sources. The Estonian Statistical Office provided statistical yearbooks (including many from the Soviet period), national accounts (including the Statistical Office's reconstruction of GDP in the Western style), as well as housing and transportation data. Additional information was provided by the various ministries. However, since much activity is being privatized, the future role of authorities in collecting such data is uncertain.

The population of Estonia has grown slowly, from 1.48 million in 1980 to 1.58 million in 1990, after which a small decline may have occurred. The population was composed of approximately 450,000 families of two or more members and about 140,000 single-person households or individuals living in collective dwellings (barracks, dorms). ${ }^{1}$ In 1990 , there were approximately 590,000 dwelling units, which was increased to about 600,000 in $1993 .{ }^{2}$ This number lay close to the 530,000 dwellings reported in 1980. (This figure excludes a substantial number of units owned by the Russian army.)

The structure of GDP in former CPEs is hard to calculate. As a result, providing measures of output that can be compared to energy use is difficult. During the Soviet period, Estonia had the highest per capita income in the USSR, as evidenced by the housing standard, the high number of private cars, and other material indicators of the standard of living. As noted in the preceding chapter, however, the economy has contracted significantly since 1990 .

\subsection{Sectoral Trends in the Structure of Energy Use}

Our primary data sources are four sets of energy balances. The first (Balance 1) was produced during the Soviet period; Balance 2 is currently published by the Estonian Statistical Office. Balance 3 was provided by the Office and contains unpublished estimates of energy use by branches of manufacturing. The final balance (Balance 4), also unpublished, was prepared by the Estonian Statistical Office for the United Nations and accounts for the disposition of each fuel. ${ }^{3}$

Figure EU-0 shows total primary energy use in Estonia by type, with an indication of the share used to produce exported electricity. Figure EU-1 shows the "disposition" of this primary energy into various categories of losses and uses other than final energy use.

Data on the number of households and families, obtained by comparing per capita and per family ownership of household goods, are derived from Estonian statistical yearbooks from the Soviet period. The 1989 Soviet census gives similar indications.

2 National Housing Board.

3 We thank $\mathrm{U}$. Toivere for making all of these sources available. 
Figure EU-2 summarizes the manipulations used to convert original data from the various energy balances. The original sectoral data from the balances (marked "Original" in the figure) include all energy-conversion sectors under "Industry," which is usually not the case in Western energy statistics. (Other Estonian sectors were not defined as in Western statistics.) Instead, we used separate data on the use of each fuel to reconstruct the main final-demand sectors. Some fuels were excluded (peat briquettes, fuels derived from shale, aviation fuel), but we reinserted most by finaldemand sector from the original sectoral data. The main transformations (see the appendix to this chapter) involve moving transportation fuels to that sector from industry, services, and households; moving energy sources used for buildings from

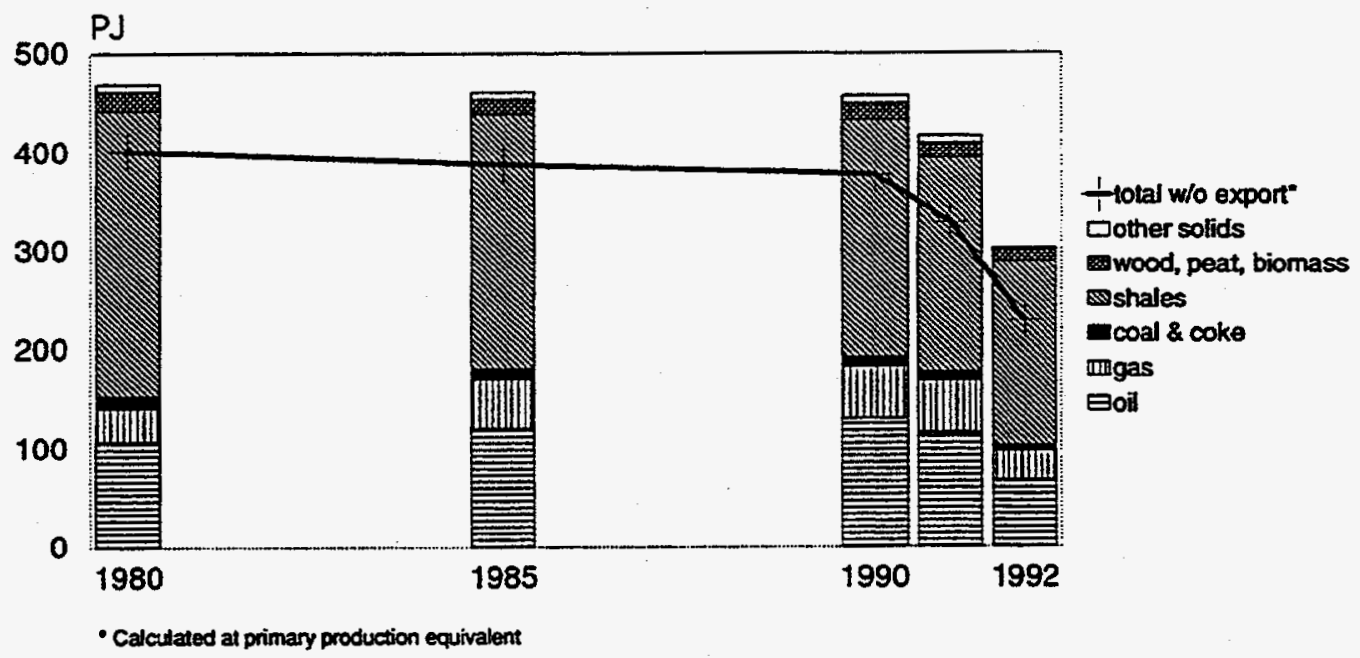

Figure EU-0. Estonian primary energy use. By type of fuel.

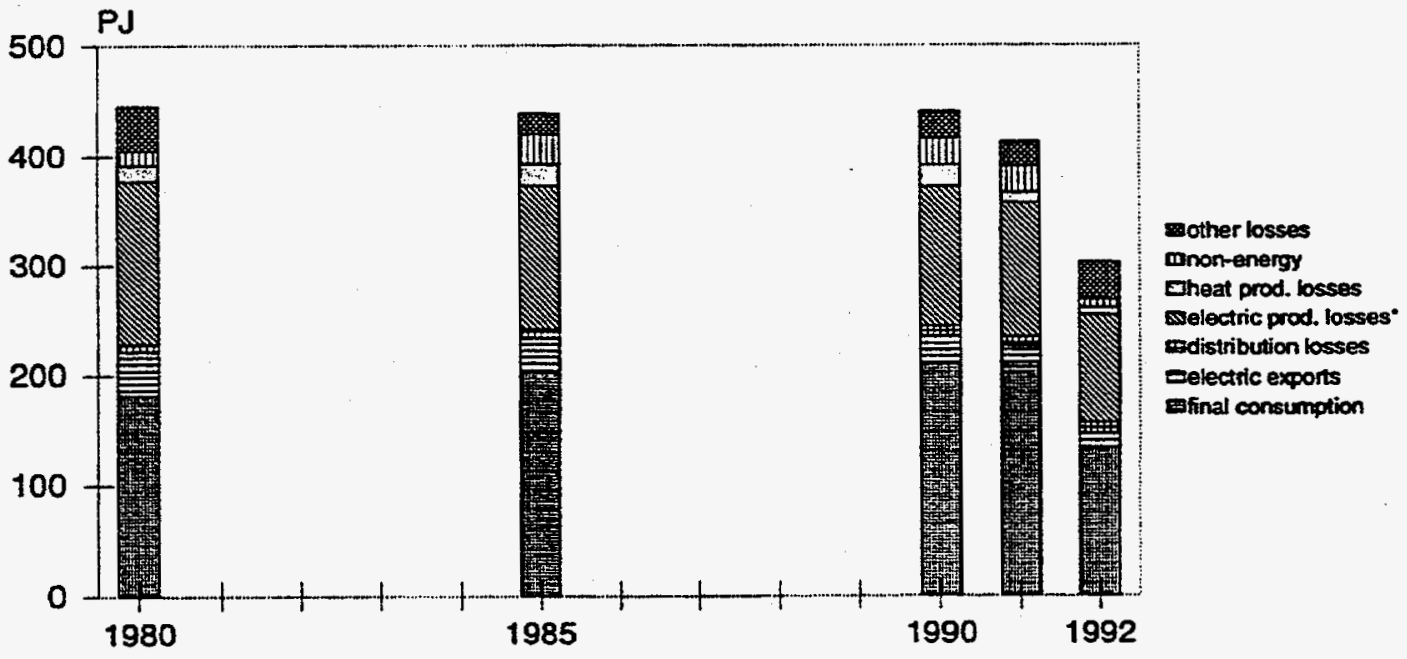

- Inciudes losses for production exponed electricity

Figure EU-1. Primary energy consumption in Estonia. Disposition. 
transportation or agriculture to households or services; and splitting transportation between travel, freight, and fuel for overseas shipping.

Figure EU-3 shows our estimate of heat produced in heat-only boilers in enterprises and the energy sector. Heat produced in final-demand sectors is shown by sector. The small "+'s" indicate our estimates of the fuel consumed in each sector to produce this heat. The deliveries from each sector to housing are also shown. Thus, we show our estimate of the heat consumed in each final-demand sector, the net trade in heat with other sectors (and the energy sector), the losses accounted for within each sector, and the losses implied by the difference between heat "sold" and

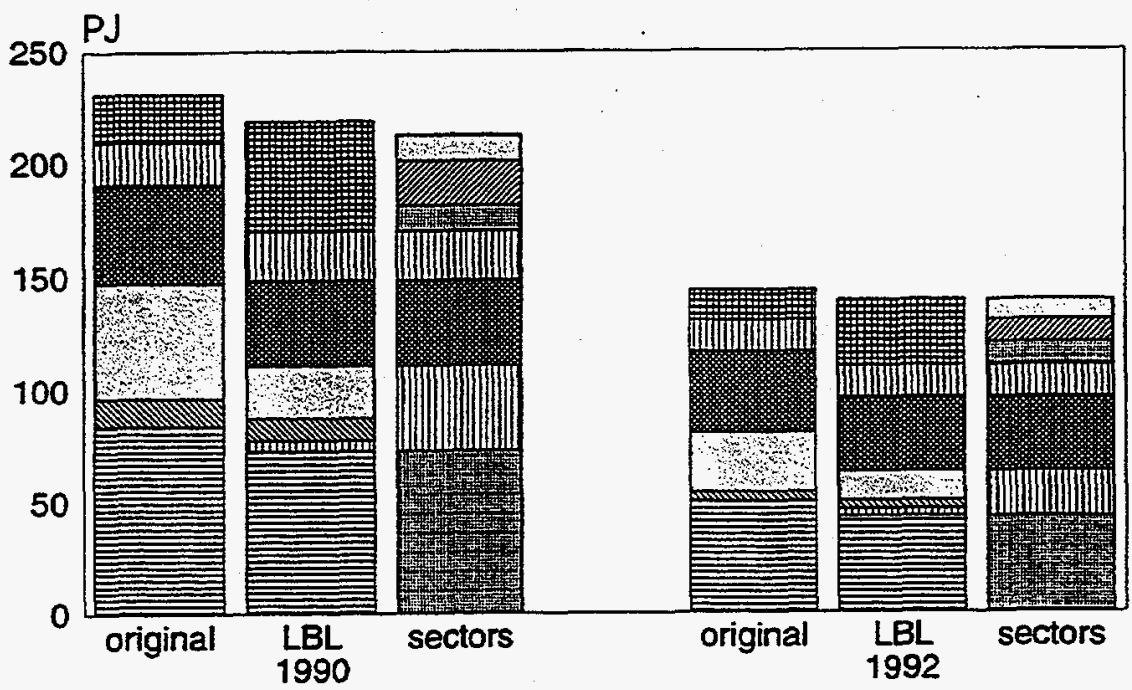

口bunkers freight travel mtransport mservice mouseholds urother ind. Đagriculture construction ammining manufacturing Eindustry

Figure EU-2. Energy use in Estonia. LBL transformations.

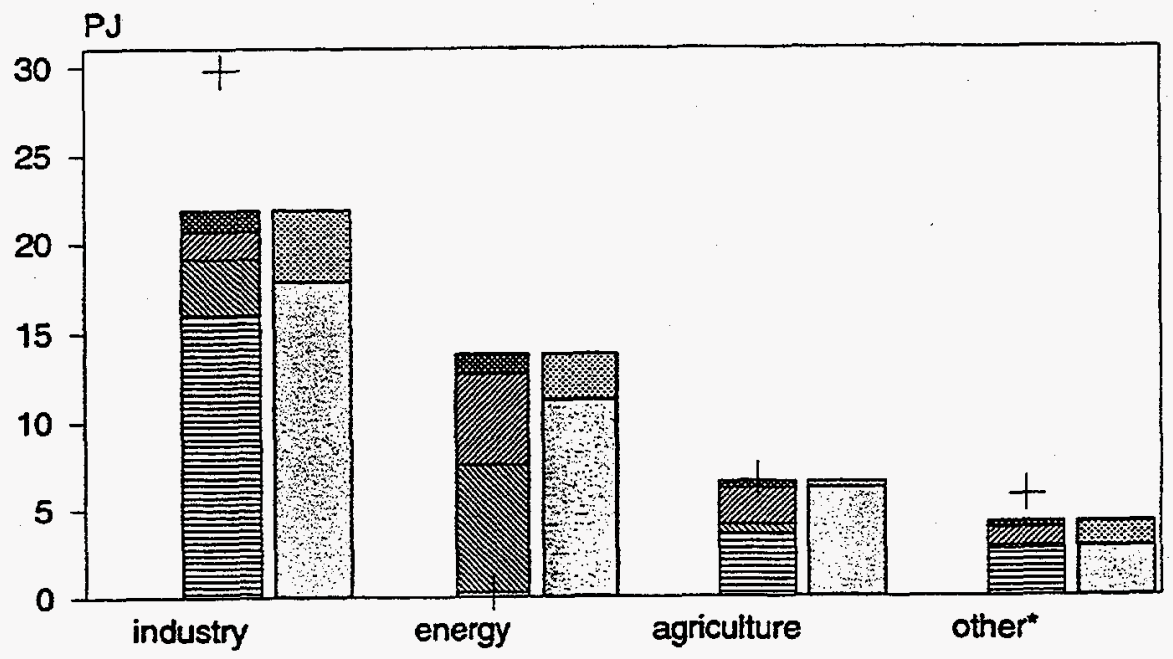

trel consurnotion"opurchase Dproduction - ilosses rato housing \$lo other enterprises -consumption Other includes mining, construction, transport \& semices - Indudes supplies from CHP

Figure EU-3. Estonian heat production and consumption. By economy branches. 
heat "received" among sectors. ${ }^{4}$ Comparison with the energy balances permits us to estimate how much heat is bought from other producers, mostly the combined heat and power (CHP) stations and a small amount of industrial cogeneration. CHP provided approximately $24 \mathrm{PJ}$ (petajoules) of heat (not shown) to industry and housing. The appendix to this chapter contains more details on how we have accounted for electricity and heat production.

Figure EU-4 shows the energy sources that we actually counted in final energy demand. The important role of heat is striking, as is the rising importance of oil products. In 1992, freight activity, which was very dependent on oil, fell dramatically.

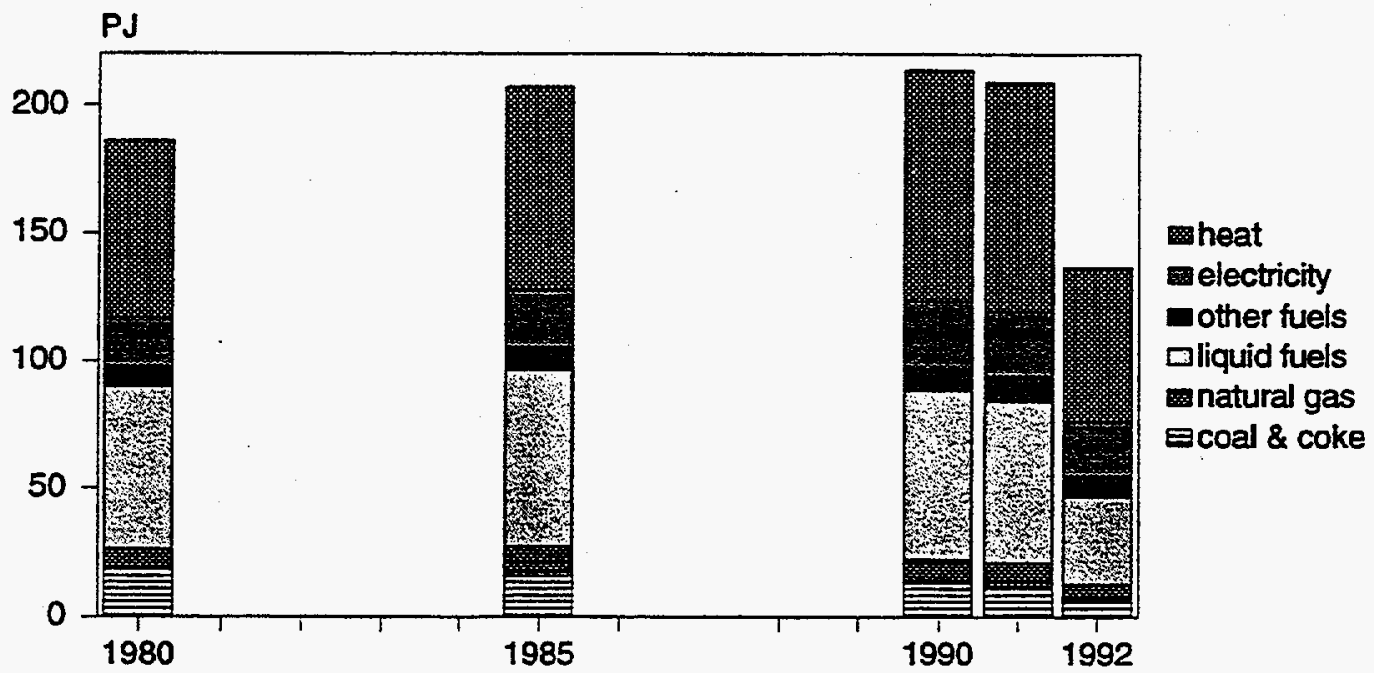

Figure EU-4. Estonia final energy consumption. By fuel.

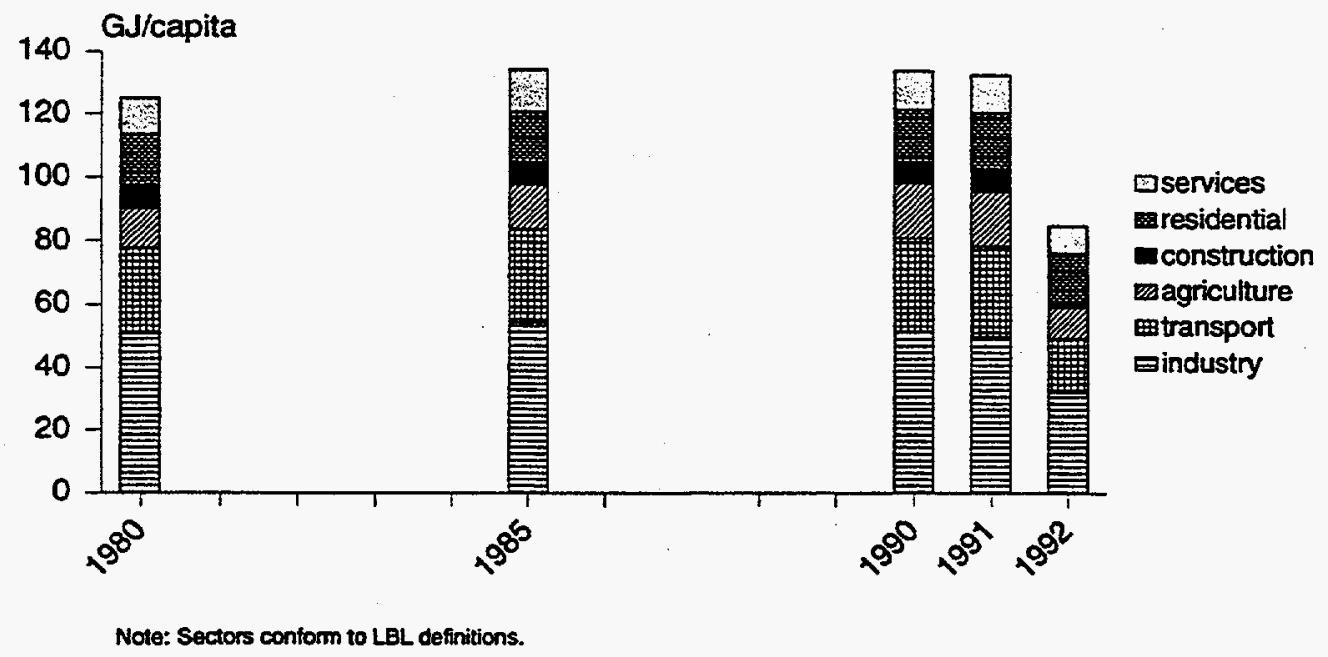

Figure EU-5. Per capita energy demand in Estonia. By sector.

4he estimated consumption of heat in each sector includes heat supplied to housing from enterprises or large heating plants. 
Once we decided on the allocation of each energy type by sector, we multiplied physical quantities of energy consumed by conversion factors supplied by the Estonian Statistical Office to obtain energy balances in PJ. Figure EU-5 shows the role of each sector in final demand on a per capita basis. ${ }^{5}$ The sharp fall in energy consumption for freight, manufacturing, services, and other industries contrasts with the slight decline in energy use in households and the nearly stable consumption of fuels for travel. Clearly the use of energy by private households has not yet seen the full force of the economic reform.

Figure EU-6 shows per capita sectoral electricity use, which plays a relatively small role in final demand, as is clear from Figure EU-4. The decline in household electricity use is small, while the fall in electricity use for manufacturing, other industry, and services is significant.

\subsection{Industry: Manufacturing}

Determining the structure of the manufacturing sector is difficult by Western standards because of a lack of market-based, value-added data or production figures that reflect what is made. However, information on physical production suggests that the chemicals, paper/pulp, and minerals sectors are important. Figure EU-7 shows per capita production of important materials, fertilizers, cement, paper, and pulp through 1992. The cement figure is huge by any proportions. While data are incomplete, indications are that production of these materials fell even more in 1993, when two principal paper mills closed.

Manufacturing energy use by fuel is portrayed in Figure EU-8 and by industry branch in Figure EU-9. The sharp decline in 1992 was brought about by the economic collapse. The importance of chemicals, paper and pulp, and, above all, minerals (building materials, like cement and bricks) is clear. In terms of volume of energy

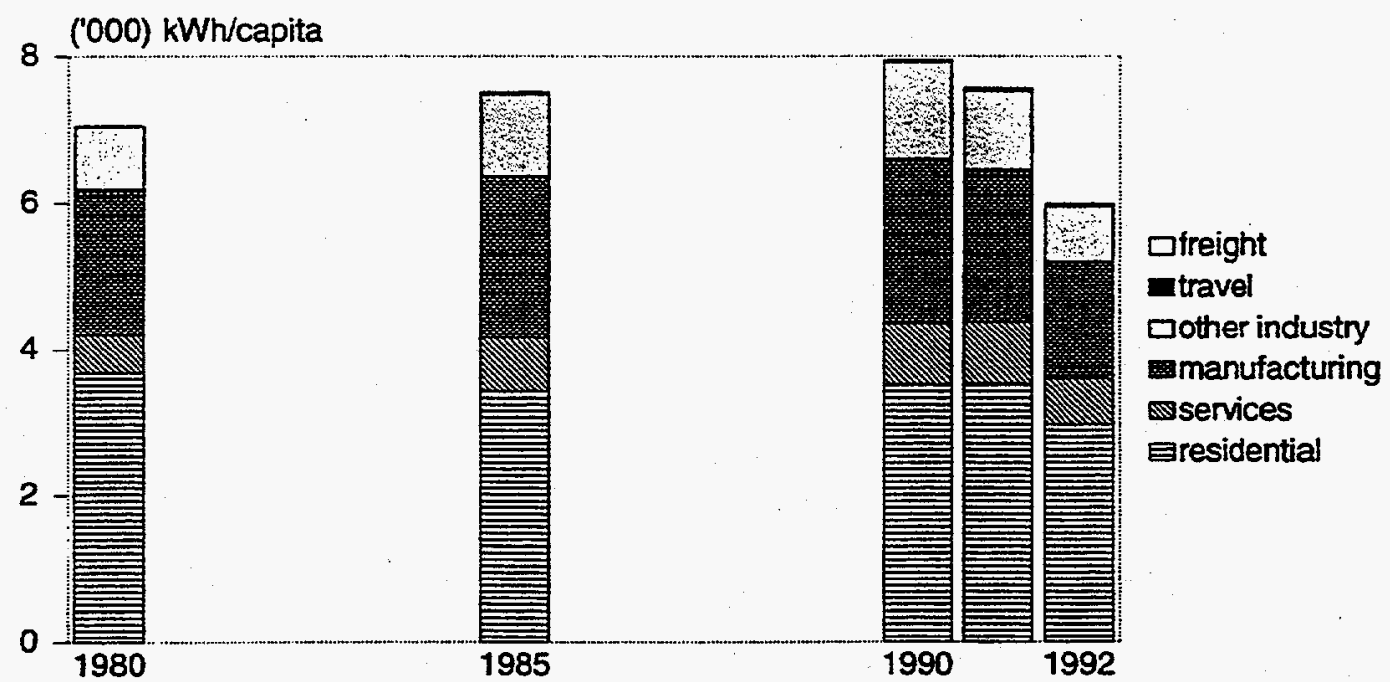

Figure EU-6. Estonian electricity use. Per Capita, by sector.

5 The appendix to this chapter also details the many adjustments we have made to each sector of final demand. These adjustments align the sectors more closely to Western-style ones. 
used, machinery and food are also prominent, but these tend to require less energy per unit of output than industries that process basic materials. Also notable is the absence of the iron and steel sector in Estonian manufacturing. Unfortunately, we have no accurate information on output by individual branch against which we can compare these figures.

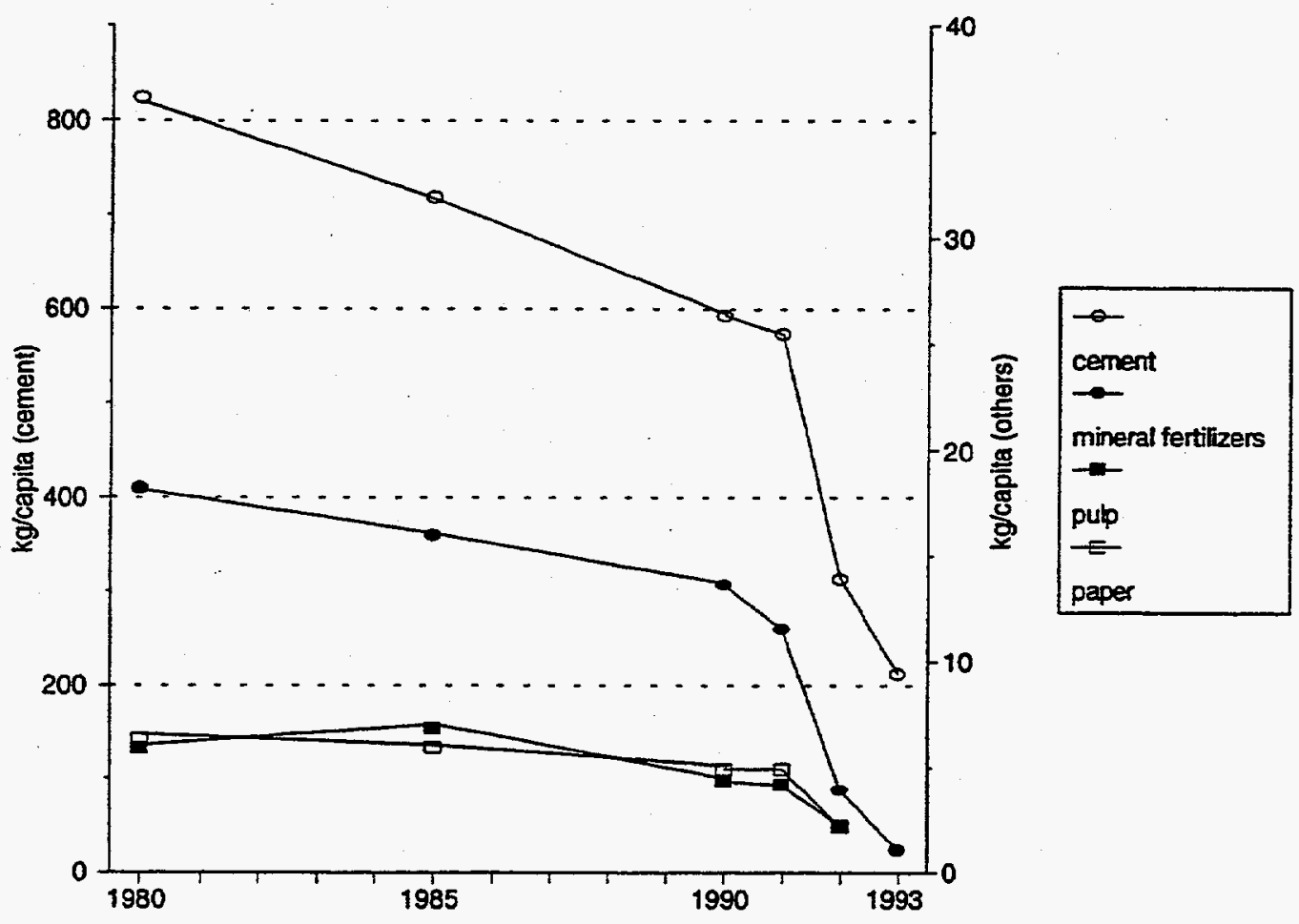

Figure EU-7. Estonian industrial production.

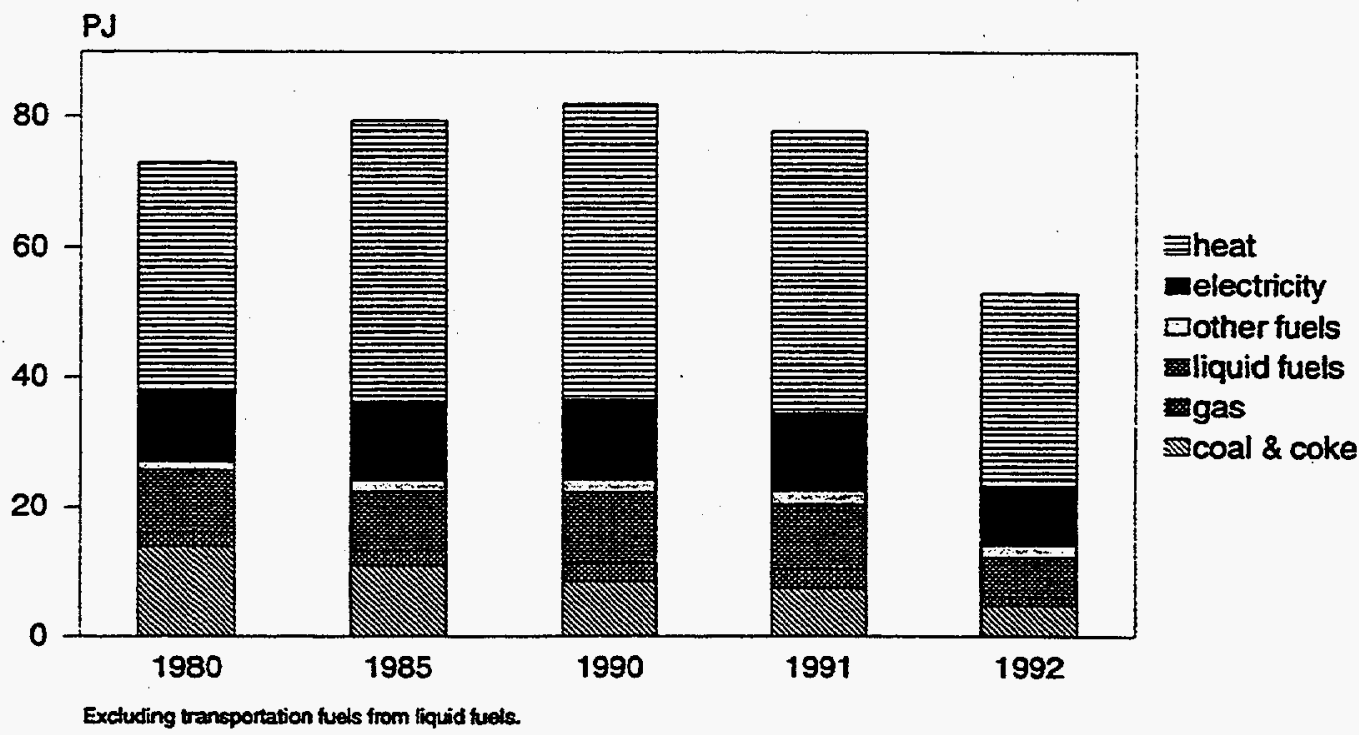

Figure EU-8. Estonian manufacturing energy use. By type of fuel. 
A large share of manufacturing energy use is listed in all balances as "heat" (see the appendix for further details). Our inspection of Balance 1 shows that in 1985 a significant quantity of fuel, about one-third as much as was consumed directly, was used to produce this heat within industry, with the rest apparently taken from the public supply. As noted, manufacturing produced approximately half of the heat it used, obtaining the rest from public supply or cogeneration. If we counted energy uses in Estonian manufacturing by Western practices, we would count the fuel actually consumed by enterprises to produce their own heat, not simply the heat itself. This would raise total manufacturing energy use by 10-20\%, depending on the exact amount of self-produced heat and the actual efficiency of production.

\subsubsection{Other Industry: Agriculture, Construction and Mining}

In 1992, agriculture, construction, and mining provided $13 \%, 4.9 \%$, and $2.6 \%$, respectively, or $21 \%$ total, of the estimated (by the World Bank) GDP in Estonia. Their share of energy use was slightly less, only $15 \%$ in 1992, having fallen from nearly $20 \%$ in 1990 . Oil and heat are the two most important final energy sources, a fact we find not surprising since agricuiture includes both vehicles and (until 1992) some food processing and at the same time dominates the sector we call "other industry." Figure EU-10 shows the full breakdown of energy sources in this sector; Figure EU11 shows the importance of each subsector for 1990-1992 with each energy source shown separately. What is notable is that even agriculture produces and consumes a significant amount of heat. ${ }^{6}$

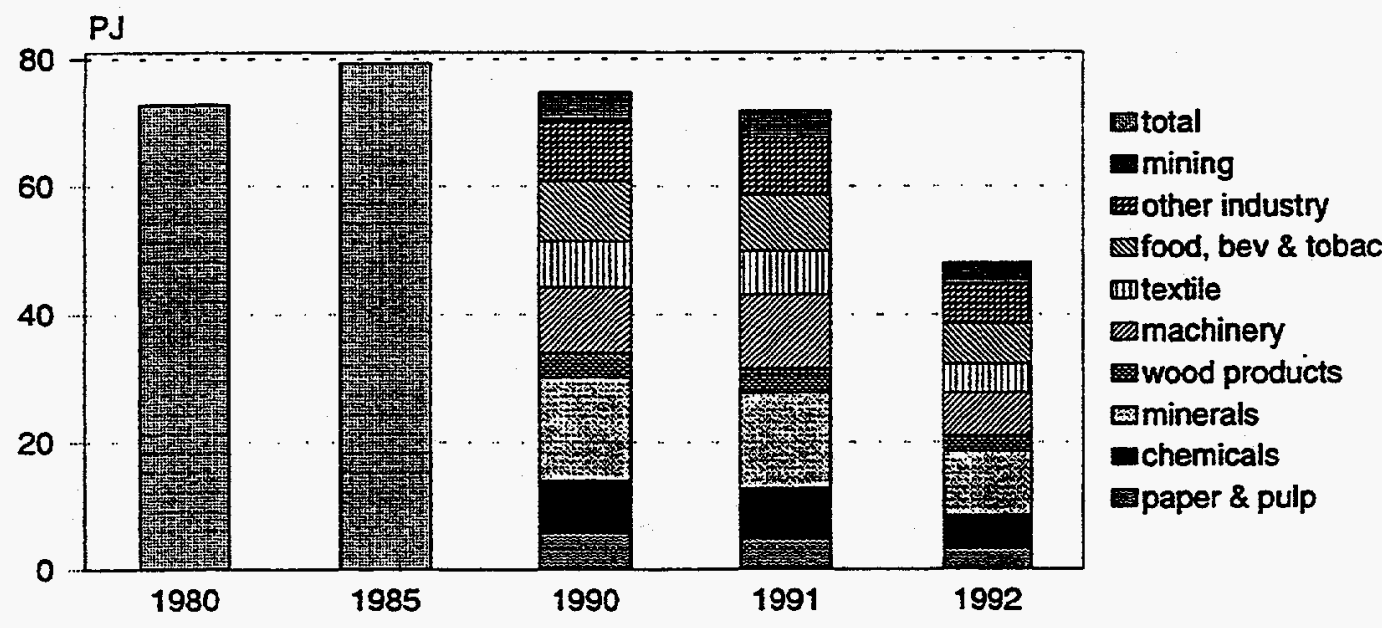

Excluding fuels used for transportation.

Figure EU-9. Estonian manufacturing energy use. By industry branch.

6 Some of the apparent decline in agriculture in 1992 occurred because food processing was counted in manufacturing that year. 


\subsubsection{Residential Sector}

Residential energy consumption figures are fraught with uncertainty because of the large role of district heat, which is allocated to the residential sector by the Estonian Statistical Office on the basis of billings, not metering or measurement. Figures for heavy fuel oil, gas, and solid fuels used in local boilers for residential buildings are reliable because of the system of allocation. Uses of heating oil, LPG, and peat briquette were estimated from sales data. Solid fuels used by consumers, particularly in single-family dwellings, are estimated by the Estonian Statistical Office. Electricity and gas are billed by customer, so these data should also be reliable. ${ }^{7}$ In

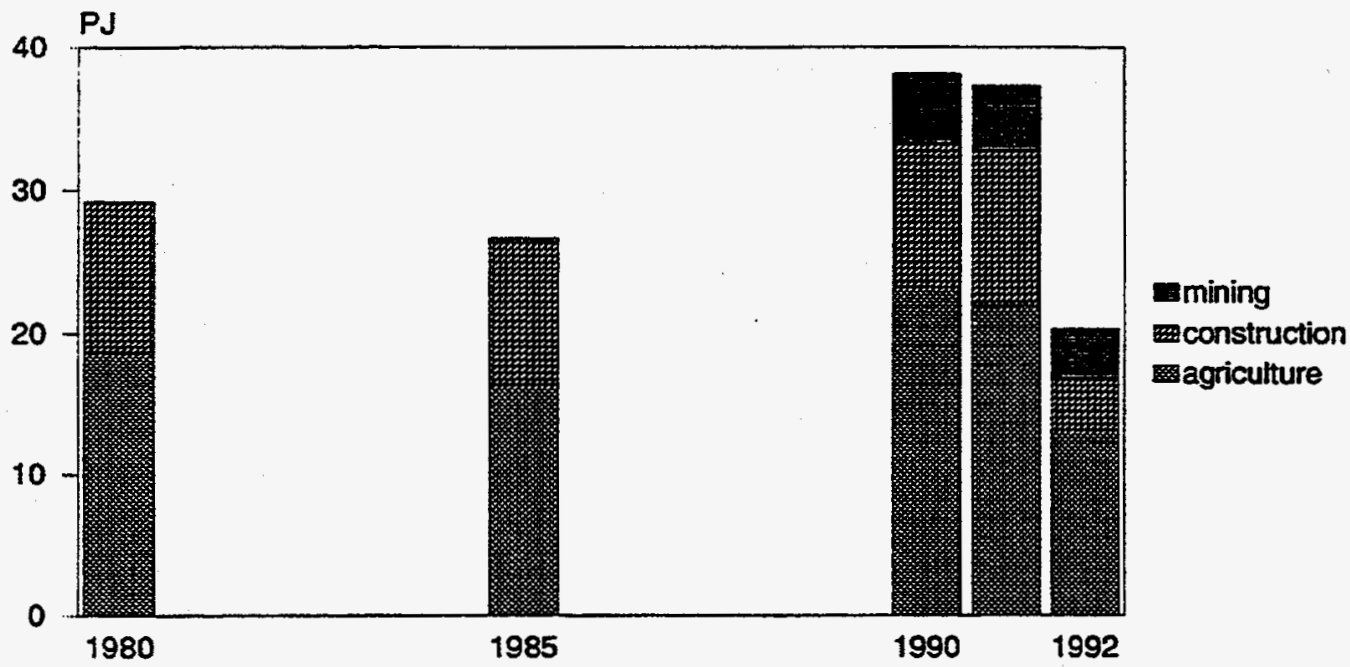

Figure EU-10. Estonian other industry. Total energy use by industry branch 1980-1992.

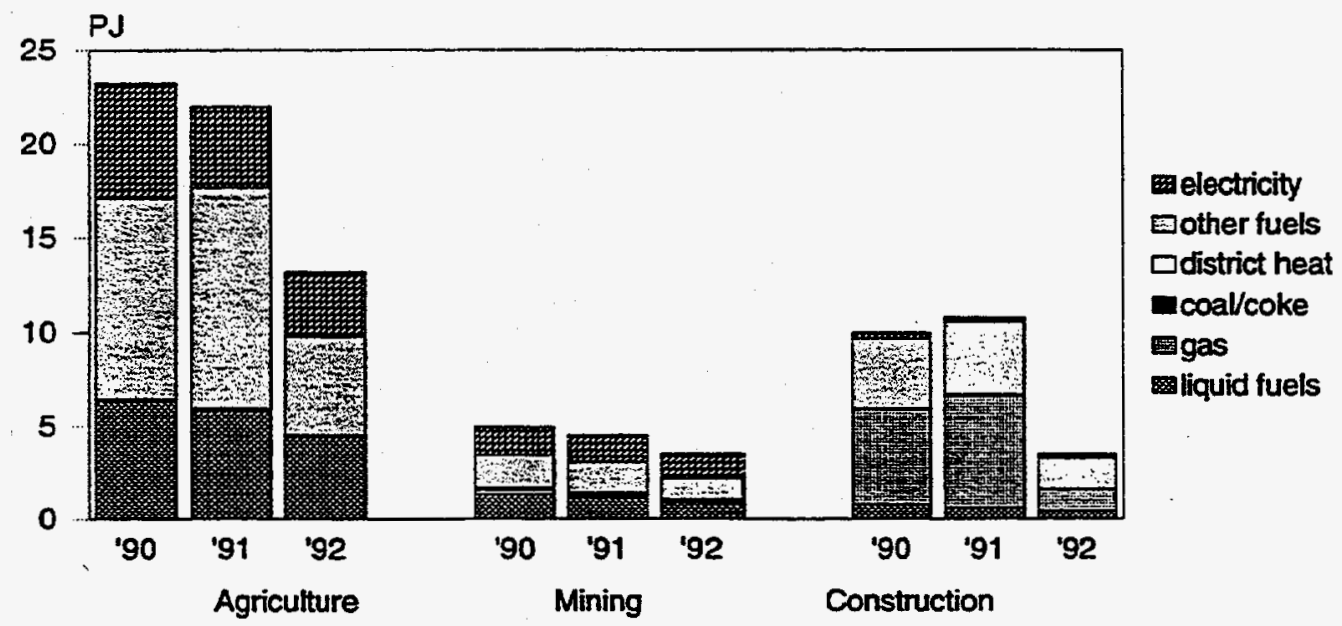

Figure EU-11. Estonian other industry. Energy use by branch and by type 1990-1992.

7 We have not been able to estimate how much heat is provided by enterprises to employee housing, but industry and other branches of the economy provide a significant amount of heat to housing in general. Data from the Ministry of Agriculture suggest that in 1991 about 0.7 PJ of electricity and 2 PJ of heat consumed in that sector were used for residential purposes. These figures are counted in our residential estimates, with similar shares of heat and electricity allocated for other years. 
general, the residual from these estimates, after other major production sectors are counted, is lumped into the "other consumers" or "service" sectors. Figure EU-12 shows the energy consumption figures, by fuel, from 1980 to 1992, we adopted for the residential sector.

The structure of the housing sector is measured by several important parameters. The extent of living space, in square meters/capita, measures the standard of living. However, the number of people per dwelling unit and the structure of the dwelling stock-single-detached, multiple in a large building, and so on-also affect the ways energy use can be reduced. Such data were hard to find from the Soviet period (although the 1989 census had some helpful information on the number of dwellings).

The 1992-1993 Estonian housing census, provided by the National Housing Board in advance of publication, revealed important characteristics of the present stock, including the number of dwellings by type and other information not apparent from the Soviet census. Figure EU-13 summarizes this information. Estonian households are small, around 2.6 persons. Dwellings average less than 62 square meters, but the small household size provides more than 20 square meters of space per capita.

The dwelling stock is dominated by apartments in buildings of more than four units. In fact, of the 190,000 residential buildings, about 160,000 contain one or two dwellings, while 25,550 contain most of the remaining 440,000 dwellings. Individual dwelling units total close to 600,000 . Approximately 160,000 of these are in free-standing houses, two-family houses, or row houses, most of which are privately owned. The remaining, about 440,000 dwellings, are in apartment buildings of various sizes or in non-residential buildings. Single-family dwellings are largely privately owned and account for $30 \%$ of the total area. Ownership of multifamily dwellings (and about 20,000 single homes) as of late 1992 was split among national authorities $(160,000)$, local authorities $(215,000)$, and various legal entities $(65,000)$. This distribution of owners will change with impending privatization, and the rate of change is uncertain. Until new ownership or administration structures are created, there will be little administrative or private incentive for improving the buildings to save energy.

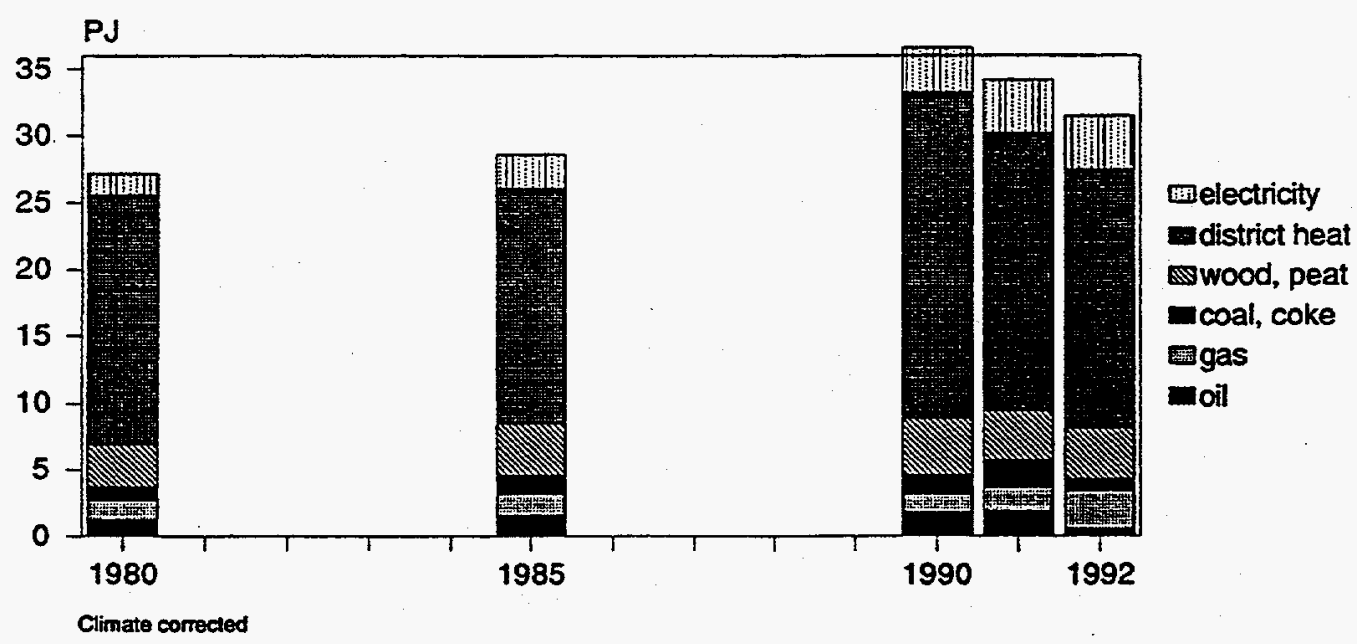

Figure EU-12. Estonia residential energy use. By fuel. 
The age distribution of the buildings is important. Older buildings are more likely to need rehabilitation for a variety of reasons, at which time energy-efficiency improvements are relatively straightforward. Of the public stock, 75,000 are buildings built before the end of World War II, only 51,000 are buildings from between 1946 and $1960,100,000$ from the 1960s, 119,000 from the 1970s, and 105,000 from the 1980s. By Western standards, the stock of apartments is "young," i.e., most were built after 1960. But our inspection revealed their quality and condition, while high by Soviet standards, was poor by Western standards. The stock is in need of improvements in spite of its young age.

Central heating-heating provided to most or all rooms by a hydronic (waterborne) central boiler in a dwelling or building or by public supply or boilers outside of the building-provides heat in $61 \%$ of all dwellings. ${ }^{8}$ The dwellings in publicly owned multifamily dwellings have far more central heating $(77 \%)$ than do the privately owned, single-family dwellings (17\%). We estimate that about one-fifth of these publicly owned dwellings rely on boilers in the same building (or those providing for a group of buildings); the rest depend on the public supply. Heat for the individual boilers is supplied by natural gas, heavy fuel oil, some light oil, and a variety of solid fuels. Heat for the district heating system is supplied by heavy fuel oil or solids. The remaining dwellings use small room stoves based on solids (including wood and peat), LPG, kerosene, or even small electric heaters. Figure EU-14 shows our estimates for the share of dwellings using each heating fuel as the main source.

Water heating is provided by the central heating system, in most cases, or by electric, gas, or LPG heaters in dwellings without central heating. Sixty-eight percent of the apartments have centrally provided hot water; most of the rest have gas water heaters. In private houses, there are also approximately 42,000 boilers for

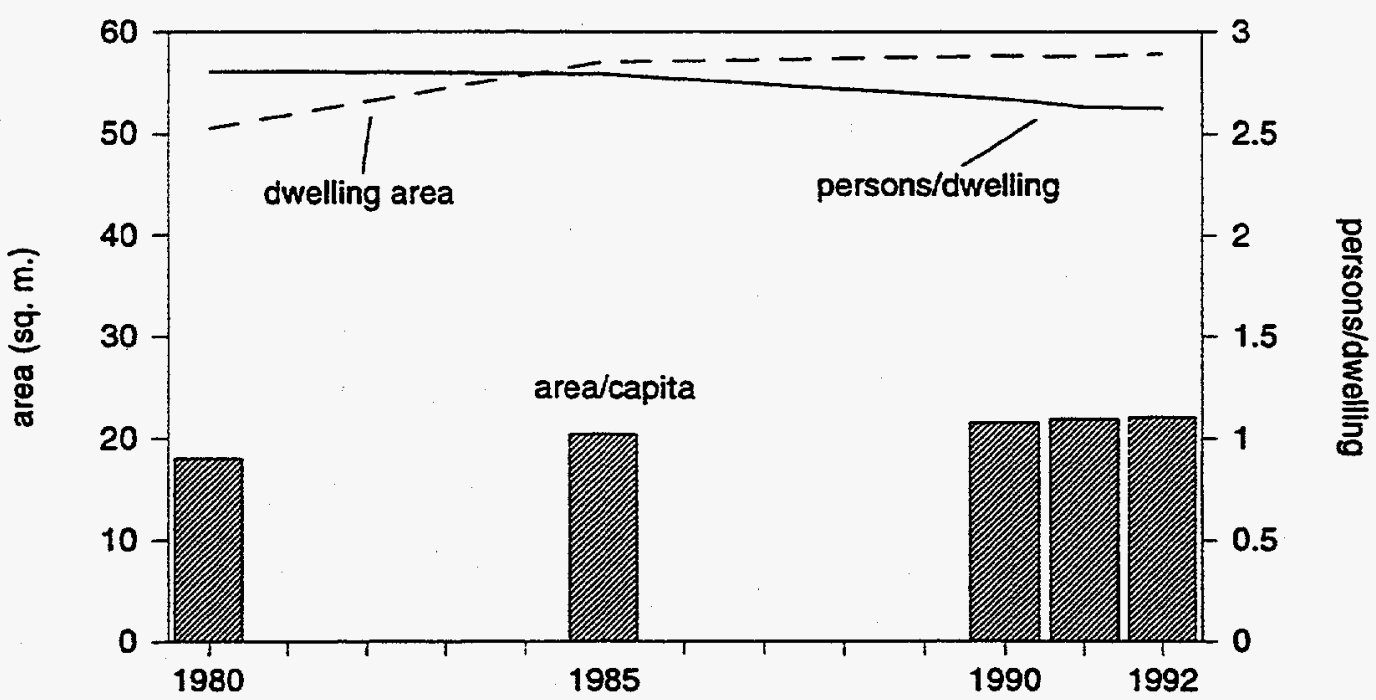

Figure EU-13. Estonia residential energy. Dwelling area.

8 This terminology is a source of confusion in many studies of Central and Eastern Europe, where "central heating" tends to refer only to what is called "district heating" in the West. Other heating systems (including electric radiators) are usually called "non-central," "room heating," or even "stoves." 
heating water, which we believe are fired with LPG, wood, or coal. We estimate that about $10 \%$ of dwellings today do not have running hot water. In 1980 this number was likely $25 \%$, based on our experience with Soviet data. Figure EU-15 shows our assumptions for fuel choices for water heating.

For cooking, most families rely on natural gas or LPG, but electric stoves have become popular in the last two years. Housing authorities say nearly $59 \%$ of all public dwellings have gas via pipeline. However, no one else finds that this many dwellings have either gas-based cooking or water heating. We surmise that this figure includes LPG for cooking as well. The remaining households utilize electricity (20\%) and wood (20\%). Figure EU-16 shows our assumptions for fuel choices for cooking.

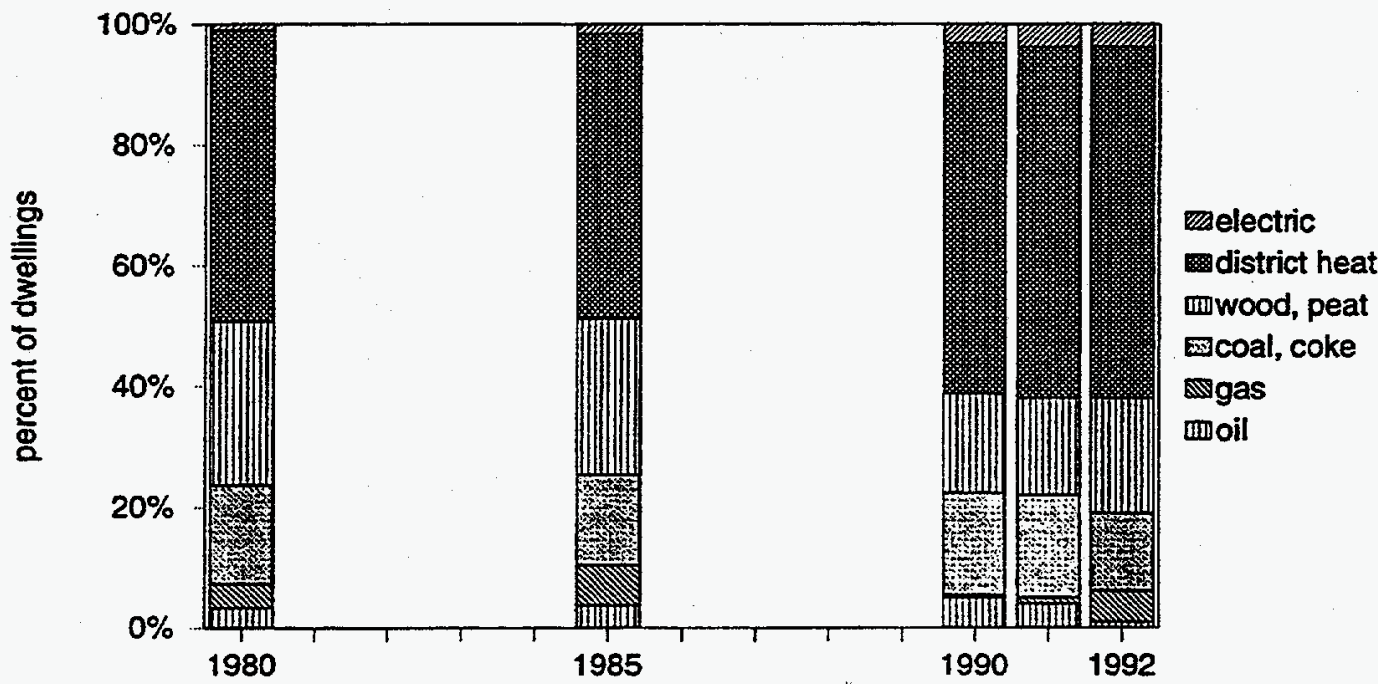

Figure EU-14. Estonia residential energy. Home heating fuel choices.

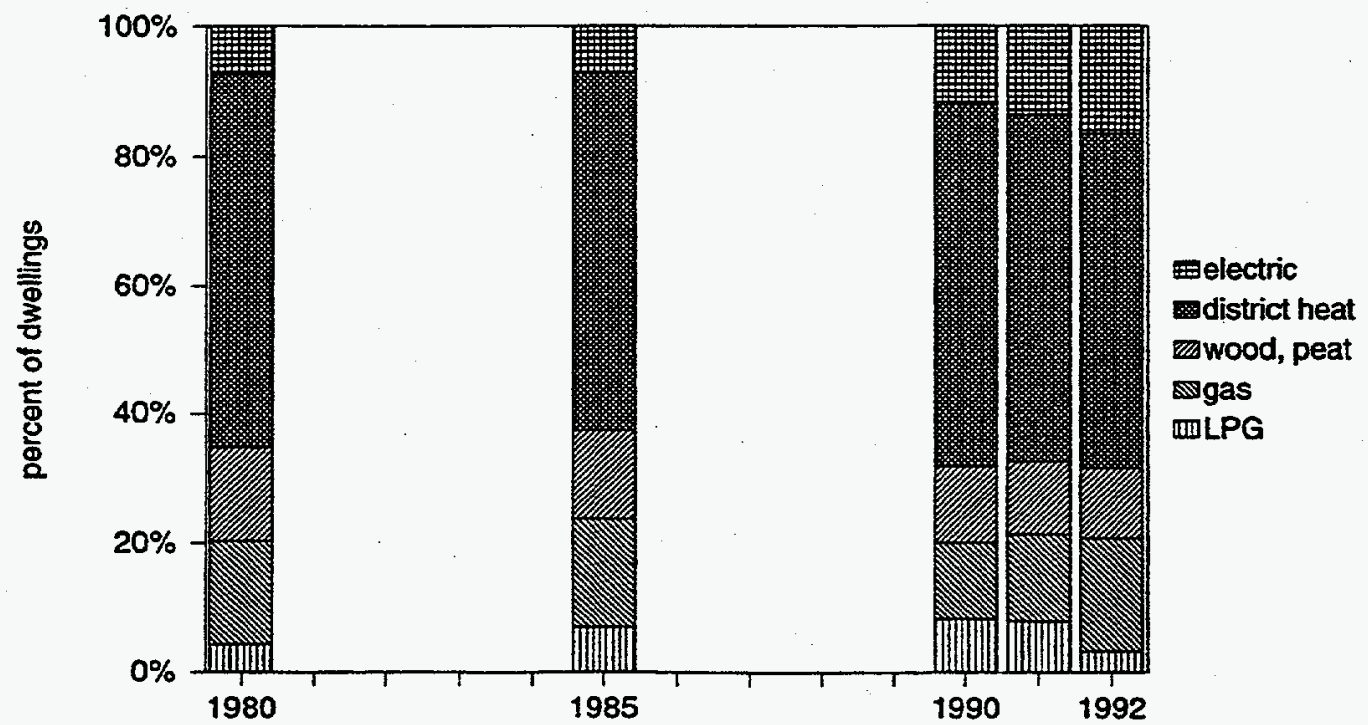

Figure EU-15. Estonia residential energy. Water heating fuel choices. 
Electric appliance ownership marks the other important set of structural data. From the older statistical abstracts we found figures for ownership of refrigerators, televisions, washing machines, and some minor appliances (see Figure EU-17 for household shares). Not shown is the central heating pump. From Western experience, we estimate that at least $150 \mathrm{kWh} / \mathrm{dwelling} /$ year are consumed for pumping heating water. We estimate an additional minimum of $25 \mathrm{kWh} / \mathrm{dwelling}$ for lighting common spaces in apartments.

Based on our experience analyzing similar end uses in a dozen other European countries, we estimate the unit consumption of energy by fuel and purpose. We mul-

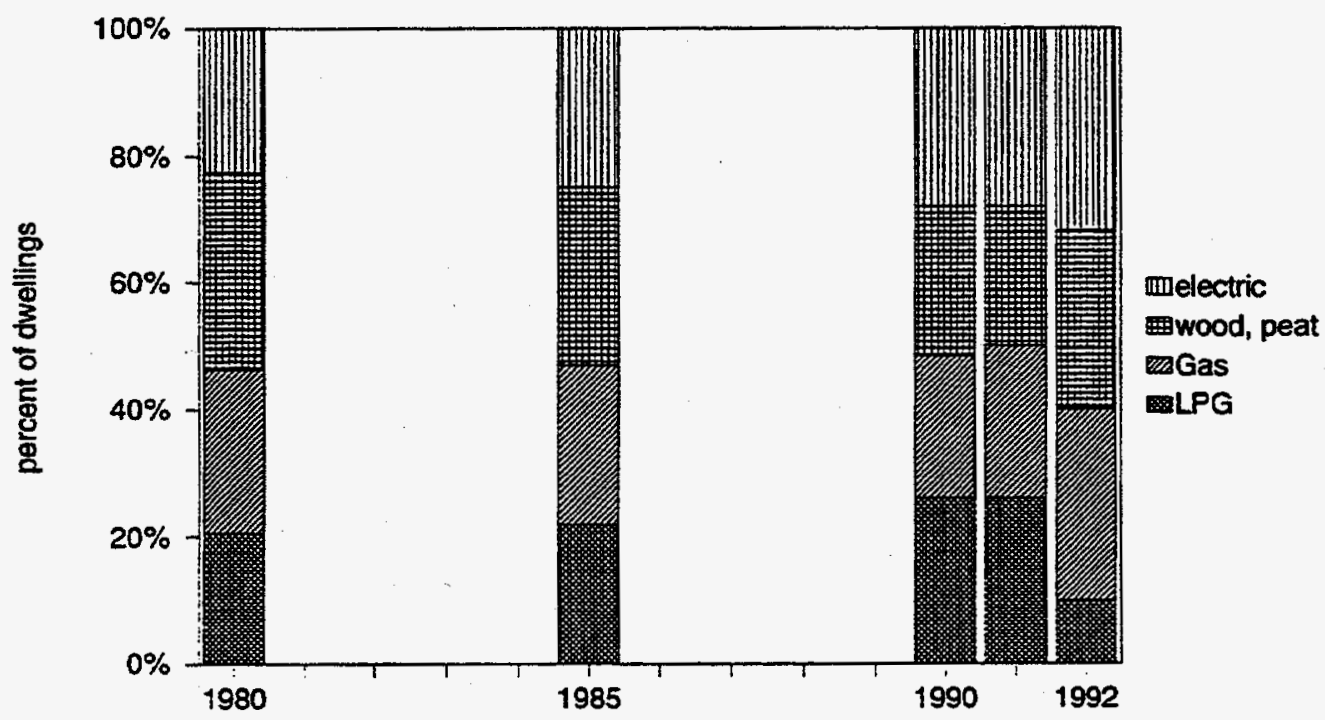

Figure EU-16. Estonia residential energy. Main cooking fuel.

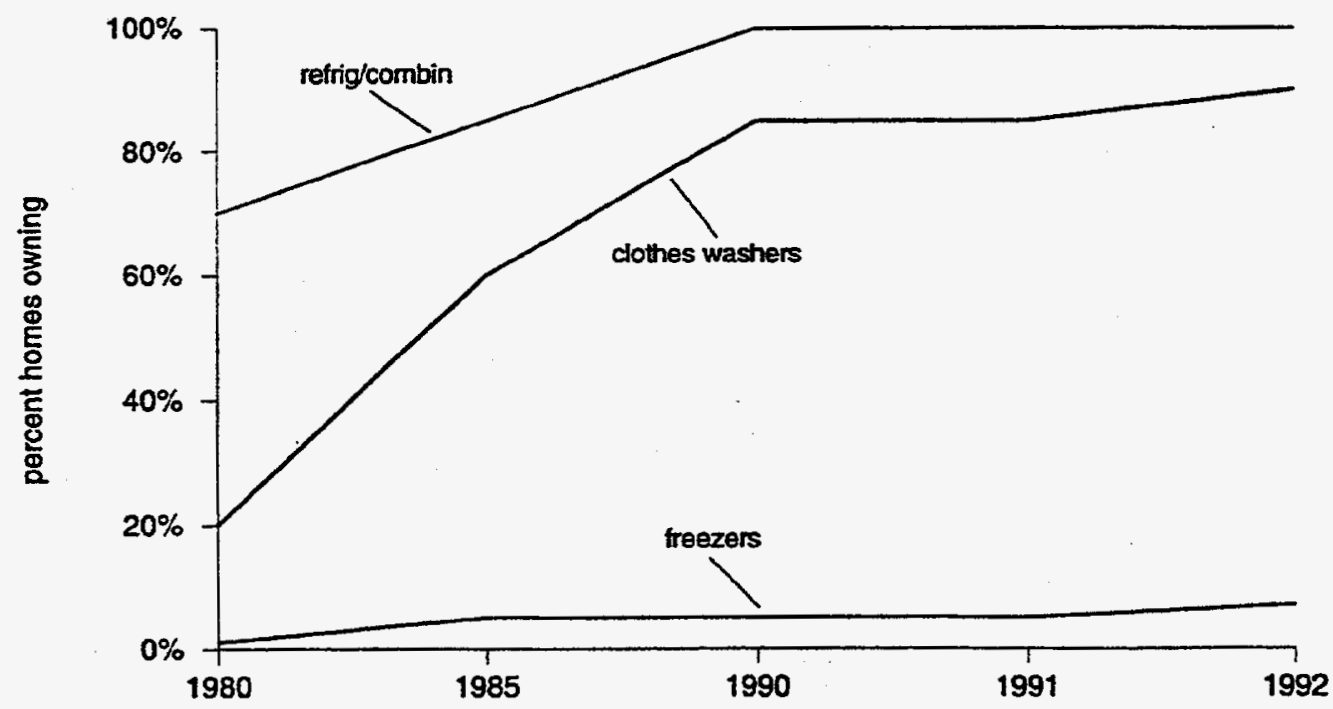

Figure EU-17. Estonia residential energy. Appliance saturation. 
tiplied the number of systems using a given fuel for a given purpose by the unit consumption for that purpose to obtain estimates of energy use for water heating, cooking, lighting, and major electric appliances. The residual of each fuel is allocated to space heating. (For solids and electricity, we know that these fuels are used both as principal heating fuels in a small number of dwellings and as supplementary fuels in a larger number of dwellings.) Our results for delivered energy use by end use are shown in Figure EU-18.

From these calculations, we can present estimates of energy intensities that combine information on how much energy was used with the service provided. To do this properly, however, we had to aggregate different energy sources that are converted with different efficiencies to useful heat. For purposes of simplification, which does not necessarily mean that we have made an accurate measurement, we counted $55 \%$ of the fuel value of solid fuels, $66 \%$ of that in liquids and gas, and all of that entering the building as heat or electricity as "useful" energy converted to space or water heating or cooking energy. This aggregation serves to remove most of the distortions that arise when we add fuels with combustion losses in the building to sources with no combustion in the building. ${ }^{9}$

Once these estimates of useful energy are made, we can present per capita use for each major end use, as Figure EU-19 shows. We further break down heating by dividing by area per capita and by the average number of degree days in a ninemonth season, base $18 \mathrm{C} .{ }^{10}$ The results of this calculation are then roughly compara-

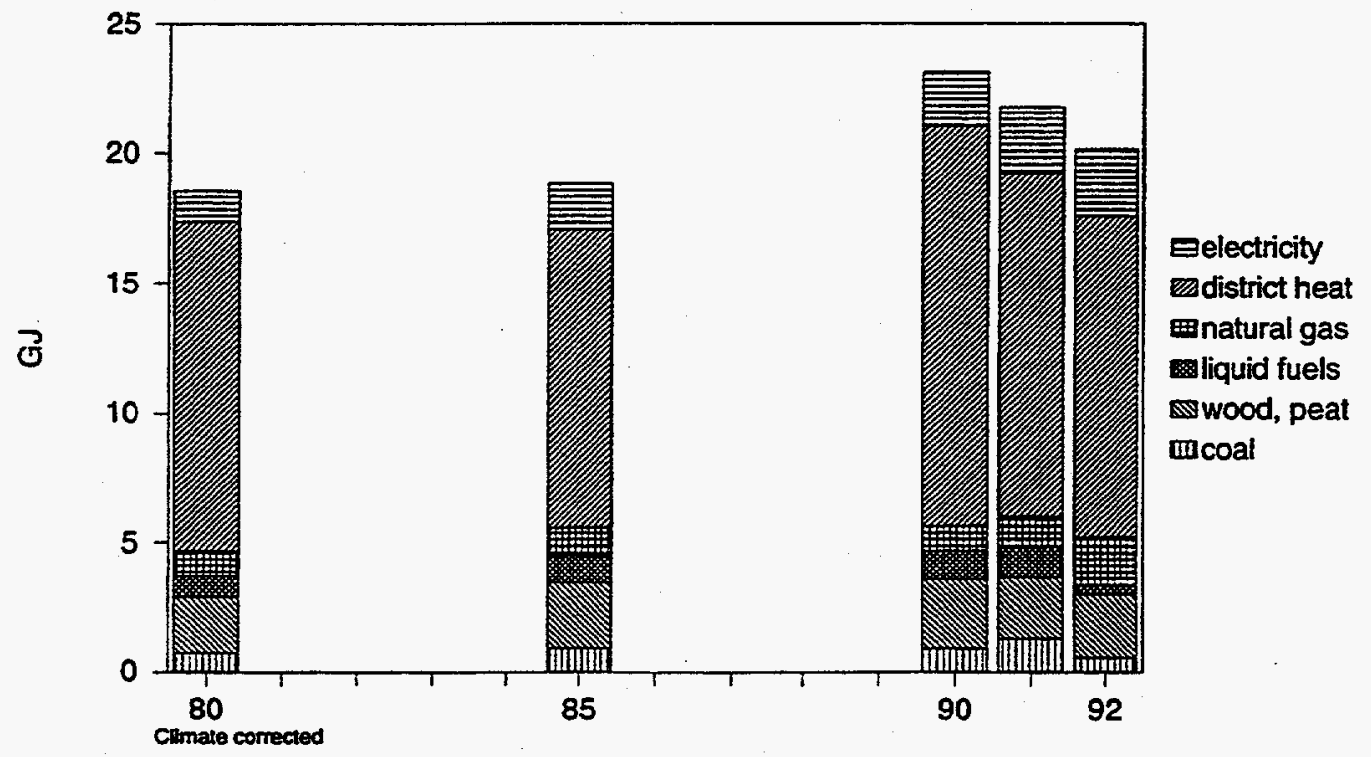

Figure EU-18. Estonia final energy consumption. Residential sector, per capita.

This method is fully explained in Schipper, Ketoff, and Kahane 1985.

to This was computed from data provided by the Institute of Hydrology and Meteorology for average monthly temperatures. We excluded June, July, and August. Degree days are then equal to the sum of $\left(18-T_{\text {averse }}\right) x$ the number of days in each month. This method gives results different from those used in Estonia, because we assume a longer heating season (September-May) for consistency with our calculations for other countries. The actual official heating season in Estonia last from October through April. This means we portray Estonian heating as less energy-intensive than it actually is. 
ble with those from other countries; more important, they are normalized by the intensity of the heating season, which allows comparison of 1990 and 1992, two extremely warm years, with 1980 and 1985, which were unusually cold. Failure to do this would overestimate the savings in energy for heating by nearly $20 \%$, which is the approximate difference between the number of degree days in 1985 and the number in 1990 or 1992 . We also corrected each year's consumption of energy for space heating in the residential sector by the ratio of the long-term average degree days to that for the year in question.

When we compute these various indicators, the picture that we obtain is consistent with that from many other countries. Per capita energy use increases for all pur-

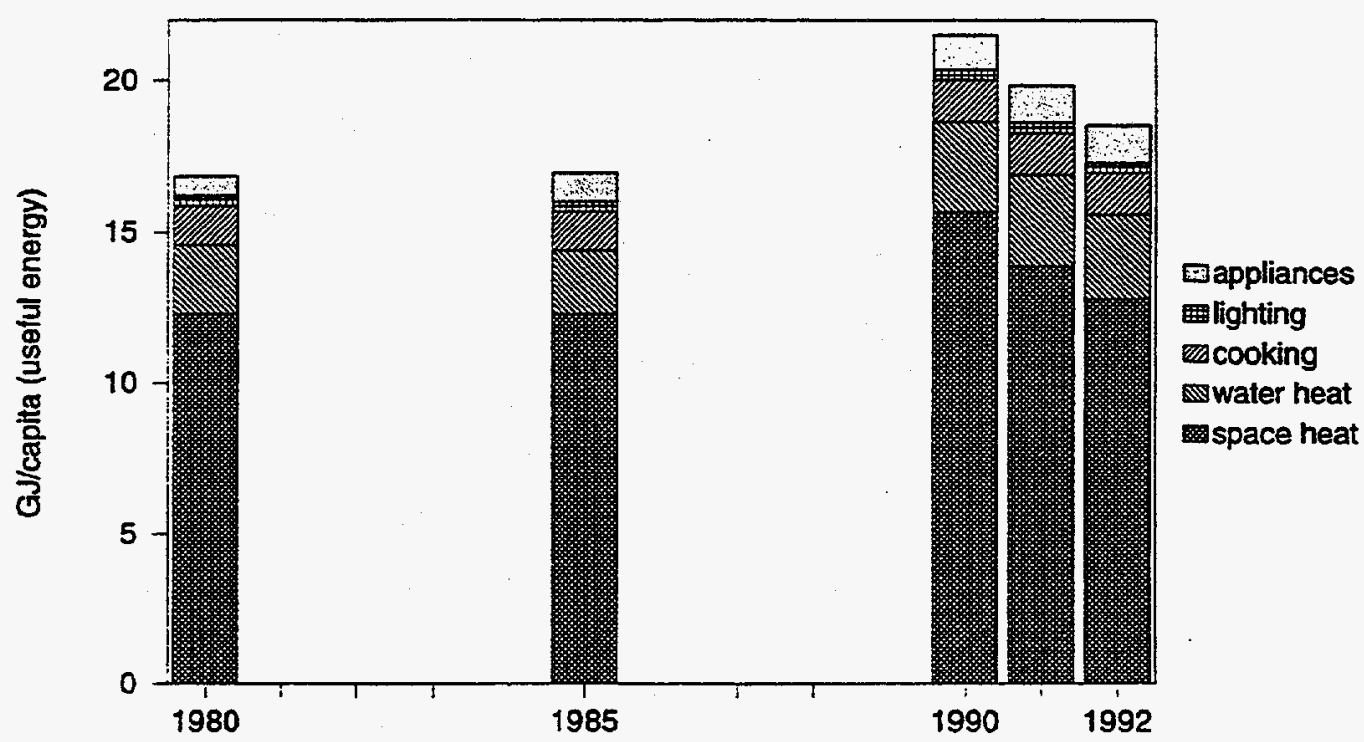

Figure EU-19. Estonia residential energy. Per capita intensities.

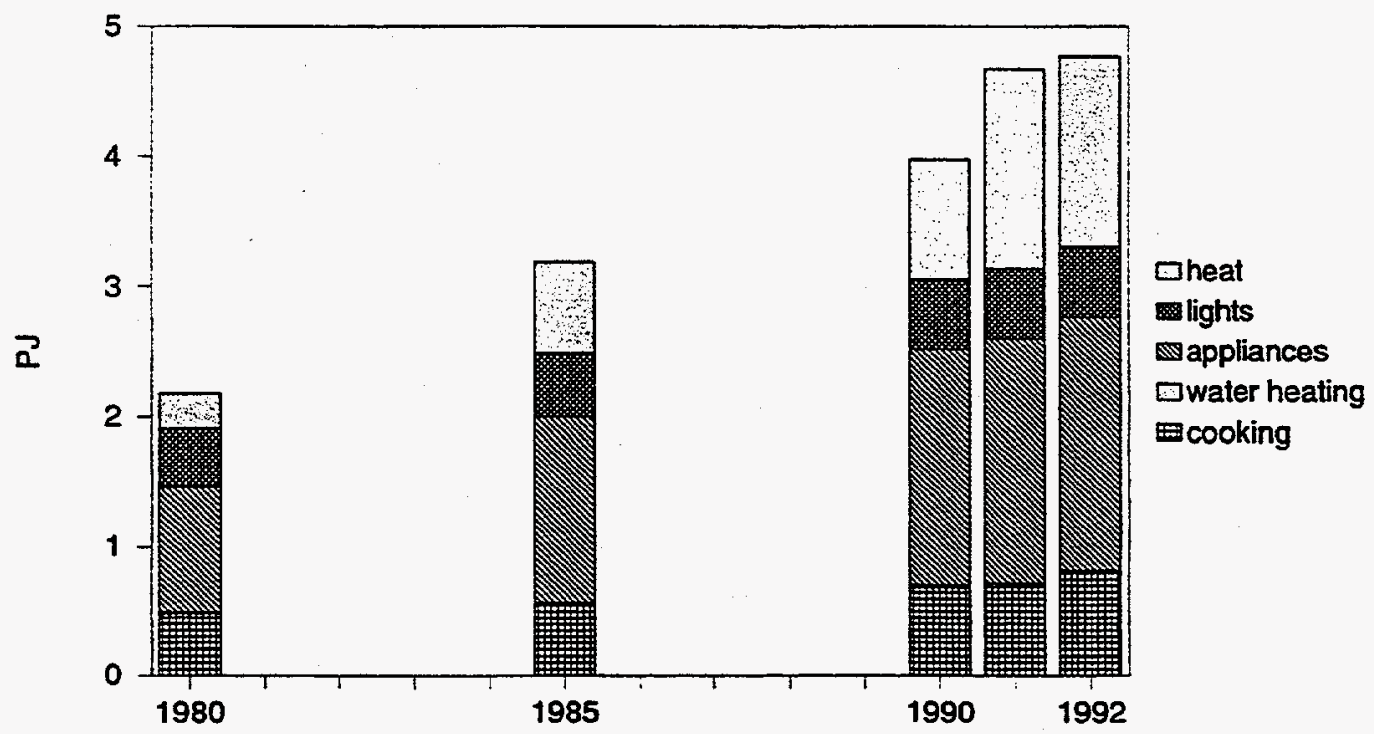

Figure EU-20. Estonia residential energy. Electricity use. 
poses, although cooking grows the least. When the economic crisis intervened, all energy uses were affected, but we believe space and water heating (in dwellings with central heat) were affected the most.

Figure EU-20 shows our estimate for the uses of electricity. Conversations with experts suggest electric space heating was not widespread until recently, although small heaters were common. The spike of electric heating in 1985 was caused by the very cold winter that year.

Are Estonian homes comfortable? We found no reliable data on indoor temperatures in Estonia (such data are also not common in Western Europe), but heard the usual anecdotes about homes being too warm most of the time, too cold sometimes, and drafty all of the time. On the other hand, it is likely that homes heated with room stoves using peat, coal, or wood have relatively lower average indoor temperatures, while those with large central systems are not always comfortable, even if the data indicate high energy consumption.

\subsubsection{Services ("Other Consumers")}

The services sector is not well documented in former CPEs. The sector closest to "services," is called "Other Consumers" in Estonian energy balances." It includes public administration, schools, health, and culture-sectors that are normally public in the West-as well as personal services, retail and wholesale goods, banks, insurance, real estate, hotels and restaurants, and other private services-socialized until recently and privitized in the West. According to the World Bank, $42 \%$ of Estonia's GDP in 1992 arose from this encompassing sector.

Unfortunately, no real energy-use data are available because "Other Consumers" is treated as a residual. Included are public utilities, street lighting, and miscel-

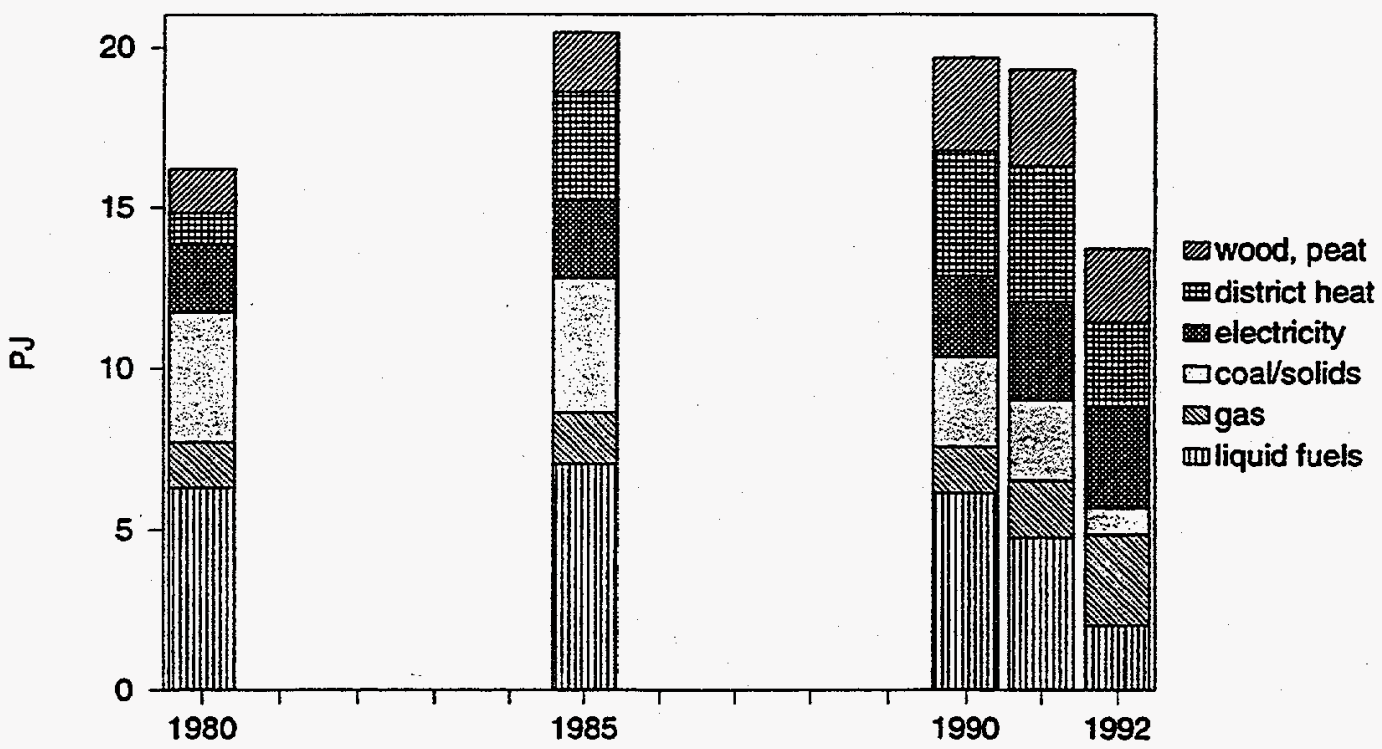

Figure EU-21. Estonian services sector. Energy use by fuel 1980-1992.

"In the accounting of CPEs, "Other Consumers" was often given the name "non-material sphere" or "non-productive" sector. 
laneous consumption not allocated elsewhere. Figure EU-21 shows energy uses by fuel. We accept the energy-consumption data as they are and limit ourselves to a few comments. First, the share of electricity is unusually small, particularly if we realize that it probably includes street lighting and pumps in buildings for district heat and central heating. Second, the share of oil is high, even after we remove the gasoline and diesel that are likely for motor vehicles. We suspect that a significant share of energy is consumed here apparently for purposes other than heating buildings and running building services.

\subsubsection{Transportation}

Countries have three kinds of transportation activities. Movements of goods is one, movement of people the second. The third is movement of special vehicles (including the military), for which no good measures of activity exist-fire engines, ambulances, cranes, tow trucks, and other utility vehicles. In Estonia, such movement requires little energy, but the energy-using vehicles constitute about $5 \%$ of the total stock. As noted in the appendix, we have no idea where fuel consumption for military vehicles is counted.

Structural data were provided by the Ministry of Transport, with some information contained in a questionnaire completed in 1992 by the Ministry of Transportation for the EEC Energy Center in Tallinn. ${ }^{12}$ This data included the number of private automobiles, distances driven, as well as estimates of fuel use for cars and city busses. Additional activity data came from various statistical yearbooks. We used data on the registered number of vehicles. The Ministry claimed that a large number of registered trucks are simply no longer in use; however, we assumed that every car registered is used, although there are undoubtedly registered cars that are no longer operable.

Energy data come from Balance 2, supplemented by Balance 4 for more details about the transportation sector and for the years 1987-1989. Additional energy data came from the EEC questionnaire. The Ministry provided other estimates of fuel used for state trucks and busses.

\subsubsection{Travel}

The most dramatic development in Estonian transportation in the last five years has been the rapid rise in the number of private automobiles. Doubling between 1984 and 1992 to approximately 270,000 , there is now more than one automobile for every 6 Estonians. In recent years, most have been Western-manufactured, used cars imported from the West or from Russia. Their numbers now swell traffic in Tallinn (and cities in other parts of Central and Eastern Europe). In 1980, there were about 12,000 state cars and taxis, a number that increased to at least 14,000 by 1992 . The average age of cars-13 years-reflects the long period cars are kept running, but it is very high considering the rapid expansion of the stock of cars since the mid1980s.

The EEC questionnaire results found that the average automobile was driven $6000 \mathrm{~km} /$ year; our estimate is that this figure was somewhat higher in the $1980 \mathrm{~s}$, 7000 (when there were fewer autos), but declined by $250 \mathrm{~km} / \mathrm{year}$ after 1988 to 6000 $\mathrm{km} / \mathrm{year}$ by $1992 .{ }^{13}$

12 V. Maeeots, of the Ministry of Transport, provided this information.

13 This drop is related both to the economic slowdown and increases in fuel prices and also to the rising number of cars. 
An equally surprising and perhaps troubling trend in the opposite direction is the decline in the number of diesel and electric busses and the routes themselves (both number and total length) since 1990 . Bus travel is still extremely cheap by Western standards; while trolleys (and trams) are found only in Tallinn, diesel busses run in 18 cities and between most towns as well. City transit in Tallinn is packed, giving no impression of the economic decline that has taken place. Intercity busses provide the backbone of intercity passenger transportation.

Figure EU-22 shows per capita travel by mode. Travel on city and intercity busses, in passenger trains and trams, and in international air and sea traffic, was recorded by the Ministry of Transportation. Travel in private cars was estimated by the Ministry in the EEC questionnaire. These estimates implied a load factor (people per car including driver) of about 2.5 in the early $1980 \mathrm{~s}$ and just over 2 in the early 1990s, consistent with estimates for other countries with as few cars as Estonia. We adjusted values for two years in the mid-1980s, using a load factor we interpolated, where the Ministry estimates for passenger- $\mathrm{km}$ appeared to be too low.

With all these data and assumptions, the picture of the mobility of Estonians is interesting. While bus and rail dominated travel in 1980, its importance (as well as the role of rail travel) fell dramatically with the onset of economic troubles in the early 1990s. Trams and trolleys are confined to Tallinn but form the core of the transit system. The automobile rivals the combined total of city and inter-city busses and likely surpassed them in 1992.

Estimates of energy use made for the EEC imply that passenger cars use between 10 and 11 liters of fuel per $100 \mathrm{~km}$, a high level but not impossible compared

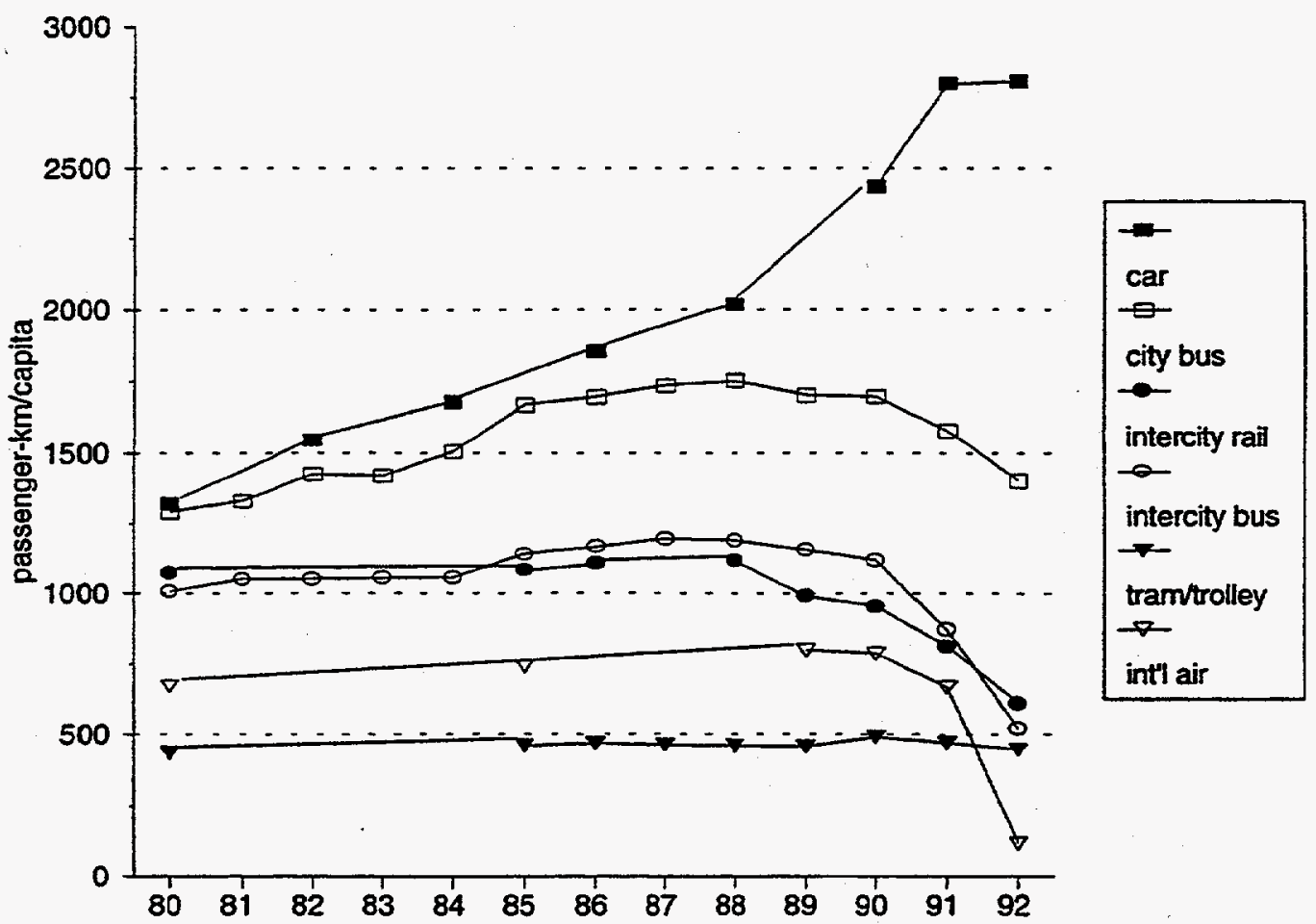

Figure EU-22. Estonia trasportation. Passenger travel by mode. 
to the rest of the former Soviet Union, ${ }^{14}$ since Soviet cars are notoriously inefficient. However, the large number of small private cars must reduce this figure below its Soviet value. We estimate therefore that fuel intensity was somewhat below 11 1/100 $\mathrm{km}$. We assumed that state cars and taxis required the same amount of fuel per $\mathrm{km}$ as private cars, but were driven somewhat more. Virtually all cars run on gasoline.

Fuel use for city busses and intercity busses was given for various years, from which we pieced together a picture of fuel use for each kind of passenger vehicle. We obtained data for electricity consumption for trams and trolleys for recent years, allowing us to extrapolate back to 1985 . For simplicity we counted this use with rail, for which electricity was a also an energy input.

Fuel and electricity uses by passenger trains are not known separately from that used by freight trains. Following an established practice, we partitioned both diesel fuel and electricity using a constant ratio of fuel use per passenger-km to fuel use per tonne- $\mathrm{km}$. While a passenger weighs considerably less than a tonne, the passenger's weight is almost irrelevant to that of the passenger train, while the weight of the freight dominates the weight of the freight train. As a first approximation, therefore, we set one tonne-km equal to one passenger- $\mathrm{km}$, a common approximation. ${ }^{15}$ Doing this yields an approximate value for energy consumed for rail passenger traffic.

When these data and assumptions are combined, we obtain the picture for energy use for passenger travel shown in Figure EU-23. It includes the energy used for international air travel, or more likely, fuel used for outbound travel of Aeroflot

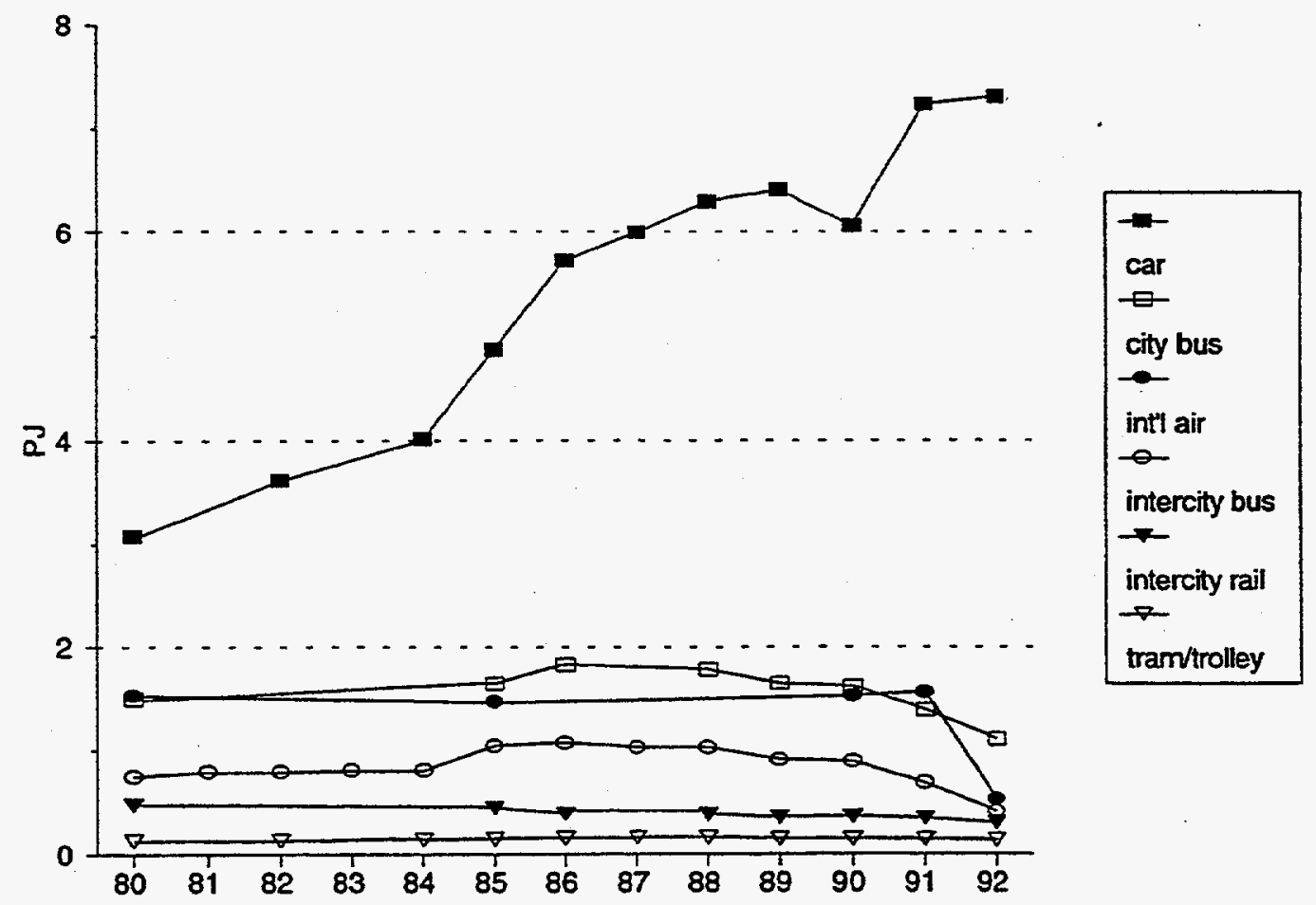

Figure EU-23. Estonia transportation. Passenger energy by mode.

14 Schipper and Cooper 1991.

15 To do this more accurately, we would need to know the precise load factors for both passengers and freight and characteristics of the trains themselves. 
aircraft, which until 1991 flew only to other parts of the former Soviet Union. We can seen that automobile energy use has become increasingly important, climbing as the number of vehicles increases, while that of busses for domestic travel drops to second, falling especially after 1990 .

Until now, cars have been easy to obtain in Estonia, at least for those with money. Until July 1993, when a 10\% tax was imposed, no tax was paid on used cars brought from the West. Taxes are also low on new cars sold within Estonia. Higher numbers of cars coupled with low gasoline taxes means greater energy consumption in this sector. But will the trend continue? Taxes on both fuel and cars are likely to increase, as more money is needed to maintain expand the transportation infrastructure. Higher car and fuel taxes should reduce both the growth in numbers of cars and the miles driven. Interestingly, there is still no tax differentiation by car weight or motor size. If such taxes are imposed, the largest, most gas-guzzling cars should incur the greatest taxes, which will favor smaller, less fuel-intensive cars.

\subsubsection{Freight and Others Energy Use}

The structure of freight has changed considerably as trucks overtake rails in importance. Data for common-carrier trucking (i.e., the state company) were found in several sources. Data for own-account trucking, i.e., provided by ministries or individual enterprises, were available for only two recent years. We extrapolated these to earlier years by assuming a constant ratio of own-account to common-carrier, a questionable assumption (but better than ignoring own-account). ${ }^{16} \mathrm{Data}$ for rail freight haulage were provided by the Ministry of Transport. Domestic water-borne trans-

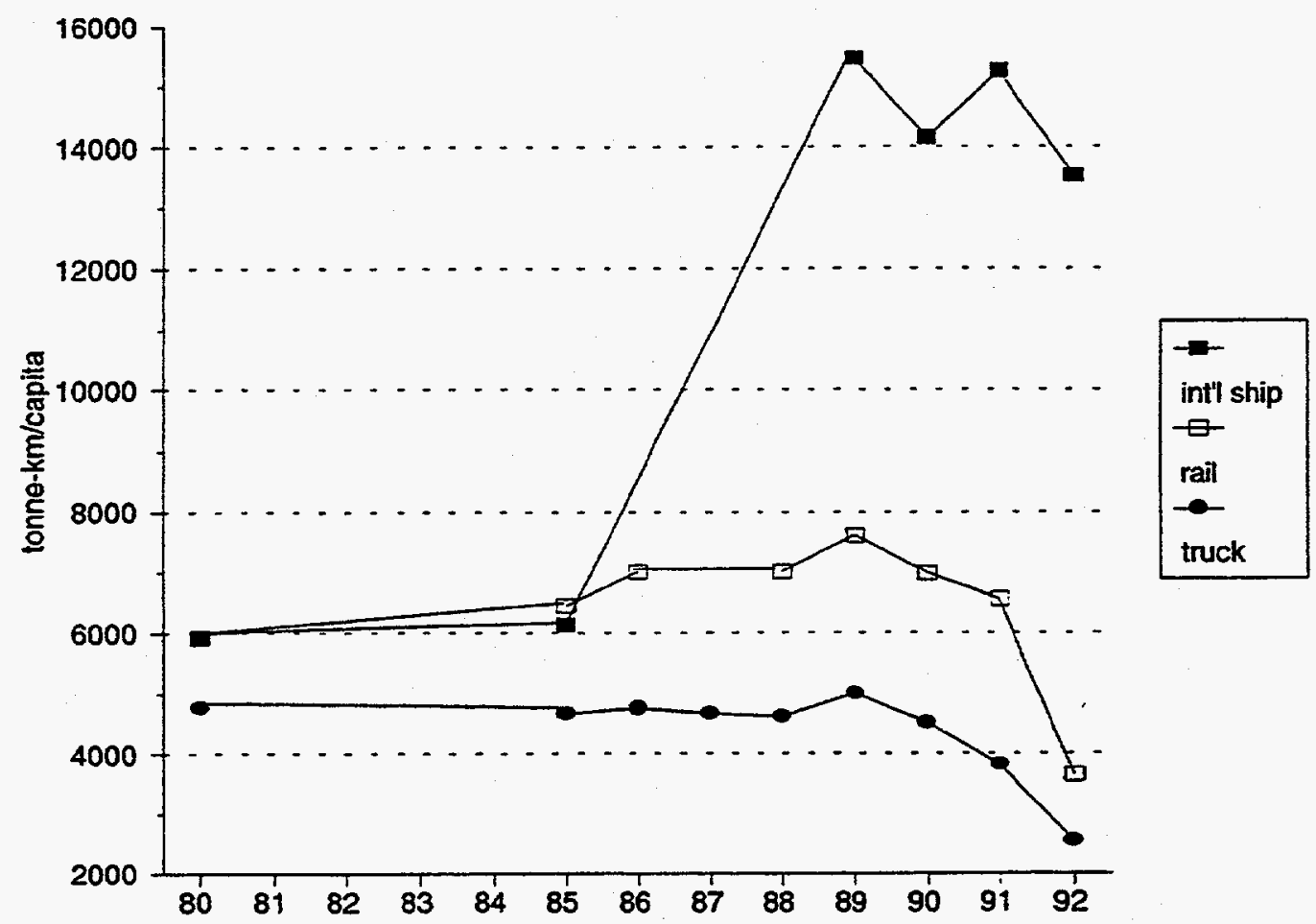

Figure EU-24. Estonia trasportation. Freight per capita.

16 Experience with Polish data suggests this approximation is good to the first order, but should be replaced with actual data. 
port was insignificant, but overseas haulage was very large, nearly equalling the total domestic freight haulage (includes transit freight sent to sea ports or rolling through Estonia between other former republics before 1992). Figure EU-24 shows the resulting patterns in tonne- $\mathrm{km}$. The dramatic drops in 1991 and 1992 are a result of the collapse of trade with the former Soviet Union and the shrinking domestic economy in Estonia. At the same time, it is worth noting that haulage by rail fell at a slightly greater rate than that by trucks. In 1993, a significant amount of freight hauled by private operators should appear. By contrast, rail freight is expected to continue to decline.

From data provided by the Ministry of Transport, which also estimates yearly $\mathrm{km}$-travelled by certain classes of trucks, we estimate that heavy trucks (greater than 8 tonnes capacity) required $9.5 \mathrm{MJ} / \mathrm{km}$ and about $2.5 \mathrm{MJ} /$ tonne- $\mathrm{km}$. Combined with the substantial fleet of light trucks that require (by Western experience) about $5 \mathrm{MJ}$ / vehicle-km but carry very little freight, we settled on an average truck intensity of $3.5 \mathrm{MJ} /$ tonne- $\mathrm{km}$ in 1992 and $3.25 \mathrm{MJ} /$ tonne- $\mathrm{km}$ for the late $1980 \mathrm{~s}$. This picture is roughly consistent with 10,000 diesel trucks of more than 8 tonnes capacity driven $80,000 \mathrm{~km} /$ year in 1992 and requiring around $10 \mathrm{MJ} / \mathrm{km}$. We also assume that light trucks (under 1.5 tonnes net capacity) require $5 \mathrm{MJ} / \mathrm{kilometer,} \mathrm{use} \mathrm{diesel} \mathrm{(60 \% )} \mathrm{as}$ well as gasoline (40\%), and are driven $18,000 \mathrm{~km} /$ year in 1990 and $15,000 \mathrm{~km} /$ year in 1992. With these parameters, we estimate energy use for trucking, shown in Figure EU-25 along with the resulting energy use for all modes of freight.

The truck fleet size has shrunk, as more than half of the existing fleet, especially those with gasoline engines, are not operating at all. Public freight companies will be privatized (as will some bus lines) but meanwhile, there is increasing use of 3-5

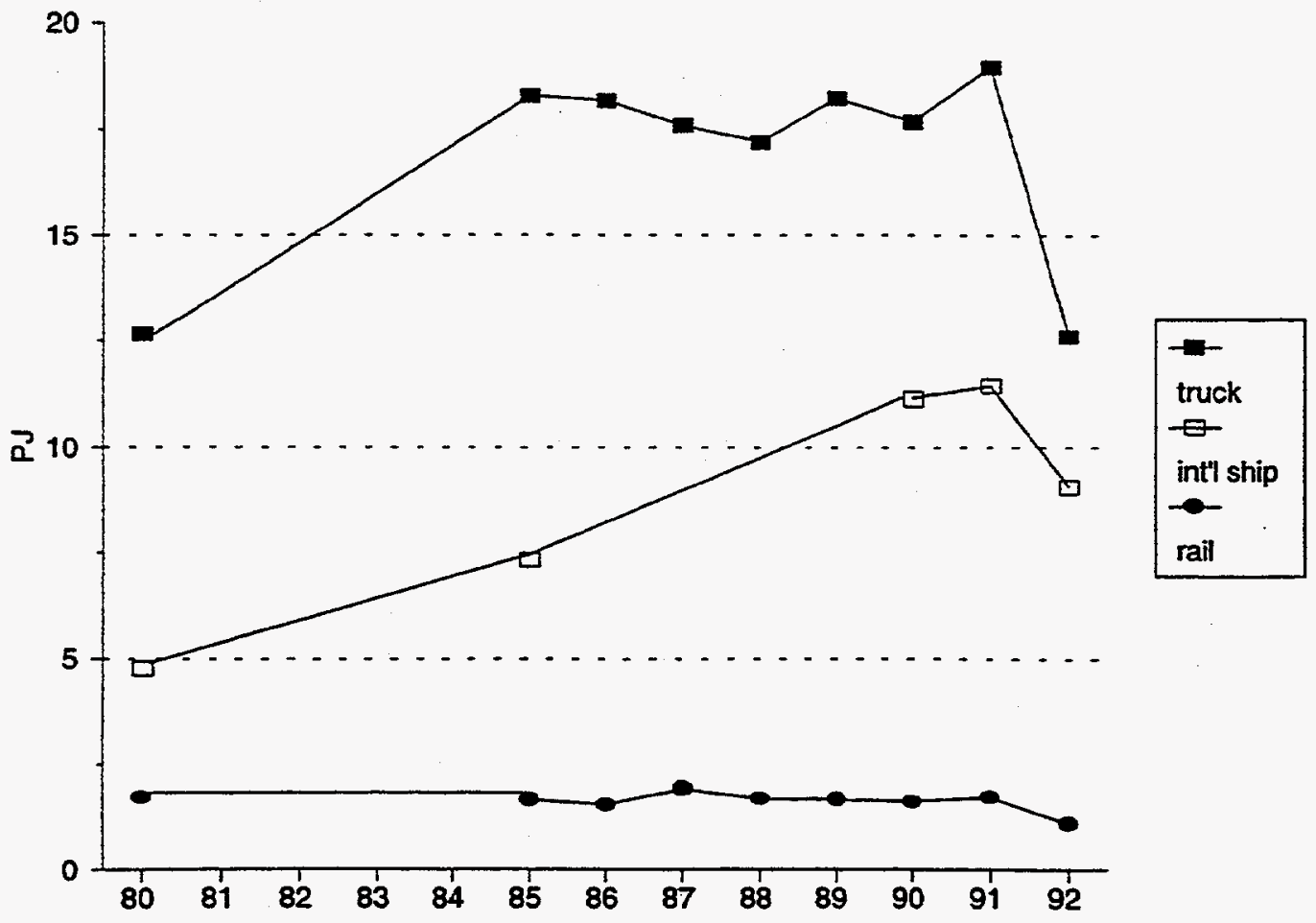

Figure EU-25. Estonia trasportation. Freight energy use by mode. 
tonne gasoline light tracks. Problems with rail freight are diverting freight traffic from trains to less efficient trucks.

\subsubsection{Other Uses in Transportation}

The remaining transportation energy uses are for miscellaneous vehicles. Although largely undetermined, we believe that this sector requires 1-2 PJ/year. ${ }^{17}$ Overall, our estimates for transportation energy use yield figures close to officially noted consumption in 1991 and 1992, but well below the reported consumption for previous years. It is possible that military vehicles or fuel purchases by visitors from Russia account for this discrepancy.

\subsection{Conclusions from the Demand Overview}

Since 1990, changes in output and activity have been responsible for most of the observed changes in energy use. While consumers paying directly for energy have somewhat cut back on use, there is little widespread evidence of increases in efficiency. The structure of the economy has changed too. Two paper mills have shut, by themselves reducing industrial energy use significantly. In both the travel and freight sectors, collective modes (rail and bus) have lost traffic relative to individual modes (truck and car). All else being equal, this change has increased sectoral energy use in both travel and freight, although the overall drop in freight volumes caused a net decrease in energy use for freight.

This brief overview and analysis lead us to reach several conclusions. First, the profound role of heat and the boilers that produce it places both the stationary finaldemand sectors and the energy sector at the center of any efficiency effort. Since most of these boilers run on heavy fuel oil or gas, the cost of running them with imported fuels is high. The present keen interest in converting as many boilers as possible from oil and gas to local (renewable) fuels is understandable, but it also carries environmental liabilities. Converting to cheap but potentially polluting fuels without improving the efficiency of utilization of the heat produced could be counterproductive.

Crucial to understanding heat production is the issue of shared heat production between enterprises and between sectors (like industry and residential). Heat supply in planned economies was developed according to maximal distribution of produced heat without regard to the inefficiencies or losses incurred. Nor did authorities care about the quantities of heat associated with specific producers or consumers, as long as the system as a whole met everyone's needs. Now, there are many opportunities to reduce energy costs by either substituting less expensive fuels or simply making boilers and heat-distribution systems more effective.

Second, energy use appears high for buildings and industry relative to activity or output. International comparisons (in the following chapter) will confirm this finding, which suggests by itself an important potential for saving energy through upgrading or replacement of equipment and better energy-use practices.

Third, it is also clear, on the other hand, that Estonia has no real shortage of electricity. Plentiful oil-shale provides inexpensive electricity, which seems to be

17 Recall that district heat, solid fuels, and electricity are also used in ministry buildings and other transportation facilities. We have moved the use of these fuels to the service sector. 
causing a boom in the use of electricity for space- and water-heating. However, this electricity is not really "cheap", because of the environmental impacts of oil-shale.

Consequently, many energy-reducing opportunities pose the real question for Estonian authorities: how to ascertain which energy end uses will undergo a transformation solely because of the enormous pressures of economic reform and higher energy prices, and which end uses can only be changed with significant intervention by the public sector. But before addressing the potential for improved energy efficiency in Estonia, we examine Estonia in an international context to better gauge the potential for energy saving. 


\section{APPENDIX: THE DATA PROBLEM}

Energy demand data come from four energy balances supplemented by information provided by experts from the various authorities in Estonia, especially the State Statistical Office and Eesti Energia, and the Ministries of Transport, Agriculture, Economy, and the State Energy Department. Structural data, quantities that describe the peopie, their private and economic activity, production, and the standard of living, come principally from the National Housing Board and the Ministries of Economy, Transport, and Agriculture.

Several basic dangers are inherent in interpreting data from a formerly planned economy.

1. FPE statistics are questionable. Not only do resources appear or disappear through black markets, but figures are also notoriously doctored such that reported consumption of a resource meets the "norm," i.e., consumption per unit of production or output.

2. Energy consumption data are particularly poor because of a virtual lack of meters in buildings and most industries. Use of liquid and solid fuels might be counted solely by the number of rail cars supplying fuel to a plant, not by the actual quantity; whereas electricity and gas use data derive from regular meter readings. Production and use of heat have been inaccurately reported because there are few real meters in industry and virtually none count how much heat enters buildings from the public network. Instead, buildings or tenants are "billed" according to their surface area. Consumption of fuels for producing heat in boilers in individual buildings is also poorly known.

3. Much structural data (production, housing stock, vehicle or transportation activity) should be viewed with suspicion. Some important, common economic activity indicators are simply hidden. For example, Soviet statistics never revealed the actual number of "dwellings," even in the 1989 Census; "families" in Soviet data do not include single-person households.

4. In the past, authorities collected far less data on "the private sector" (including private cars, free-standing homes) than on the public sector. The latter has risen in importance since the late 1980 s. Now authorities are revising their data collection methods.

\section{Energy Data Problems}

Energy data problems are formidable, as we noted in our earlier works on the former Soviet Union and Poland. However, we feel that by stating them, then showing which data we question the most, which approximations we make, and which results are clearly dependent upon the accuracy of questionable data or the reasonableness of our assumptions, we can link the observations to our conclusions in an open way. This invites further research into how best to understand the links between energy use and the Estonian economy in the future. 


\section{The Energy Balances}

The first data source is the old energy balance published by the State Statistical Office, in Russian only, for highly limited distribution ${ }^{18}$ covering the period 19701985. "Balance 1" was produced in the Soviet style. It includes (1) fuel consumption, heat use, and electricity use by ministry (i.e., industrial branch), with (2) a large residual for "other consumers" (households including private cars, and some nonministry buildings that produce materials, goods or services (including again some transportation)), and (3) rather detailed data on fuels used for producing heat and electricity. Represented are many solid fuels (oil-shale, coal, coke, wood, peat, peat briquettes) and most oil products, natural gas, shale gas and shale oil, electricity, and heat. However, consumption of fuels by each industry is not given. In these oldstyle balances, "industry" includes the energy industry. Gasoline and diesel for private cars are listed with households, while transport fuels for vehicles that belong to non-industrial consumers (stores, etc.) are listed with "other consumers." Energy consumed as steam or hot water (i.e., low-temperature heat) is called "heat" in the sector where consumed, counted at the calorific equivalent of that heat, with the losses incurred in producing the heat from primary resources allocated to the "heatproduction" sector. These balances were not published for 1990.

Balance 2 is now published by the State Statistical Office. It contains data for 1980,1985 , and 1990-1992, again presented in the old style, but then repeated in a slightly different way. In the newer style, the disposition of each fuel, electricity, and heat is listed according to whether the final use was in a transformation sector or in a final demand sector, of which the Estonians define six: industry, agriculture, construction, transportation, households, and "other consumers". Road diesel fuel and gasoline is further split into road, rail, water, and other modes. The sum for each sector of each energy source as listed in the second half of the new balances does not agree with the sum of each sector as listed in the first part of this energy balance.

A third set of balances, Balance 3, was provided by $U$. Toivere of the State Statistical Office. Balance 3 aggregates fuels into solids, liquids, gas, other (unspecificed) heat, and electricity. Sectors differ, because Balance 3 is supposed to follow the ISIC classification. Fuel types also differ slightly. Balance 3 removes transportation fuels from the industrial branches and places them in the transportation sector. Balance 3 disaggregates "industry" into mining and about eight other branches, consistent with the first Soviet-style statistics but giving all six kinds of energy noted here. In all, total final consumption in Balance 3 is within 4 PJ of that in Balance 2 (after our manipulations). However, the breakdown by fuels does not agree between these sources, probably because of varying definitions of "other fuels."

Balance 4 was prepared by the Statistical Office for submission to the U.N. Statistical Office. This balance give somewhat more detail about the transportation sector, splitting electricity into a road component, a rail component, and an unspecificed component (which we presume is transportation facilities and offices). There is some split of the industrial sector into chemicals, iron and steel, and construction. These balances provide estimates of energy use by fuel for 1987-1992.

From our comparisons of the energy balances, we present total primary energy consumed in Estonia (for all purposes) in Figure EU-0. Figure EU-0 also shows the

18 "Toplivno-Energeticheskiy Balans Estonskoy SSR", published by the Estonian Bureau of Statistics. 
implicit consumption of fuels (mostly oil-shale) for producing the electricity exported (net of imports) to other countries. Figure EU-1 shows how this primary energy is distributed to electricity production and transmission losses (with the part for exports shown), heat production and transmission losses, losses for producing other energy forms, feedstocks, and final demand. It is clear that these conversion losses" play a significant role in the disposition of total primary energy use in Estonia; reducing the losses represents a significant source of energy saving.

\section{Transformations of the Energy Supply Data}

Our experiences with Soviet and Polish data led us to make several fundamental transformations of the Estonian energy balances. First, we transform supply- and demand-side data to conform more generally to Western practices describing the uses of energy. Then we transformed the demand-side data as best as possible into final demands by industrial branch, final demands by mode of travel and freight, and by end use for residential and, if possible, services.

The energy and fuels industries are part of "industry" in Balance 1 and part of Balance 2. But Balance 2 also provides consumption defined according to Western practices to include ISIC 2 (mining) and ISIC 3 (manufacturing). After some manipulations we estimated shale and peat for manufacturing shale products (oil, gas, feedstocks) and peat briquettes.

\section{Fuels Industries}

The energy balances (Balance 2, page 10) are very unclear on the nature of the fuels industries. ${ }^{19}$ Fuels apparently used as inputs to conversion (oil-shale, peat) are listed in the same table as fuels that are likely products of this conversion (peat briquettes, shale products). Oil-shale for electricity and heat supply is also included in this table but not other fuels used for these two important conversion processes. Electricity and heat produced are also listed in these tables. While there is partial information on the quantities of peat briquettes and shale products consumed in certain sectors, this information not sufficient to reveal the net balance of primary energy consumed for secondary products. Moreover, the use of electricity or secondary energy forms (oil products, heat) in the energy industry itself is not identified on p. 10 of Balance 2. Curiously, the quantity of oil-shale "consumed" for the production of other fuels falls in 1985, but rises suddenly in 1992, while the quantity of oil-shale used as a chemical feedstock rises suddenly in 1985 but collapses in 1992. Together, the two uses of oil-shale are almost constant, suggesting that changes in the definitions of categories distort some of the elements of Balance 2. While these uncertainties are small in relation to total primary energy use, they may suggest other uncertainties hidden in Balance 2 or the other balances.

\section{Electric Supply}

At first glance, the balance of energy in the electric power sector looks straightforward. Approximately 3-3.3 units of primary energy, mostly oil-shale, are consumed for every unit of electricity produced. But upon closer inspection, this simplicity is misleading.

19 Normal practice is to show (a) all fuels consumed for secondary fuel production excluding heat and electricity, (b) net fuels produced by type, and (3) net consumption of all energy and fuels for secondary fuel production. 
- Cogeneration and CHP. While the exact role of these two forms of combined electricity and heat production is uncertain, these practices permit reductions of the primary energy allocated to electricity production because much of the waste becomes heat utilized in a local industrial process ("cogeneration") or in a combined heating and power network (CHP). About one-third of heat supply in 1992 came from "electric power stations," i.e., CHP plants. But only a small amount of electric power capacity lay in industrial premises or within agriculture, and not part of Eestii Energia. Unfortunately, a balance of fuel consumed and electricity produced for the CHP or these small sources could not be found.

- Power Production from Oil-Shale. Oil-shale, the main source of electric power use in Estonia, is difficult to handle and burn, with much pollution arising with its use. It may not be possible to count the "real" amount of heat released when shale is burned, but it is likely that the energy balances undercount this heat. Since we do not expect oil-shale power plants to produce electricity with the same efficiency as modern coal-, oil-, or gas-fired facilities, we are surprised at the overall system efficiency implied by the primary energy to electricity produced ratio of 3-3.3 noted above.

- Exports of Electricity. Roughly half of Estonia's electric power has been exported in the past, although this figure tumbled with the collapse of the Russian economy. Since these exports represent an important financial gain for Estonia, the primary energy used to produce and transmit this electricity should be counted in Estonia's "consumption," even if the electricity exported is not. This primary energy is so large compared to total consumption that we note it wherever possible as "losses for producing exported electricity," since it swells total Estonian per capita energy consumption relative to total use in other countries. In making this calculation, we do not subtract the small imports of electricity, since any extra electricity used in Estonia (and not imported) would have required the 3 to 3.3 units of fuel for production.

With these problems in mind, we treated all production of electricity uniformly. We partitioned fuel consumed to produce electricity into two parts, that corresponding to production for domestic needs and that for exports, noting the fuel consumption that would have occurred (at the average production efficiency) to produce what was imported. For this partition we used the shares of electricity consumed domestically and exported. We partitioned "waste," as listed in the Balances, in the same way. We consider the losses for domestic consumption and imports of electricity as part of domestic primary energy consumption for provision of electricity, while those losses in transmission of exports part of the "exports." We noted that the electricity use of the power sector itself is counted in "industry" ( $\mathrm{K}$. Jaanimaegi). For consistency with data from other countries, this was subtracted from "industry" and put in the power sector as losses.

\section{Heat Supply}

Heat supply is an important part of Estonia's balance because virtually all conversion of fuels to steam or hot water is counted at the end use as "heat." Since "heat" also includes district heat from public plants provided principally to the residential sector and public or commercial buildings, this confusion tends to play down the role of industrial boilers in converting primary resources to heat. More important, each major consuming sector produces some heat, consumes some or most of what 
it produces, sells or supplies to other sectors, receives from other sectors, and receives from the energy sector. While the net consumption is known, the ultimate location of production is hard to determine exactly, yet important for fuel substitution or energy efficiency strategies.

Overall, 64.8 PJ of heat were produced in 1992. Figure EU-3 shows an approximate accounting of the production, sales, and consumption of this heat. About twothirds of it was produced in heat-only boilers (40.5 PJ), the rest in CHP stations or industrial cogeneration plants. Of the heat-only boilers, the public stations of the energy sector proper accounted for $11.2 \mathrm{PJ}$, while boilers in enterprises accounted for the rest. The total consumption of heat in each sector from these heat boilers, also shown, was approximately 34.7 PJ. The difference between production and consumption is losses that arise both from transmission from the energy sector and in trade among enterprises.

Balance 2 shows a considerably larger amount of heat produced than is accounted for by these heat-only boilers. The difference in heat production between these two sources is supplied by CHP, and to a smaller extent, by cogenerating industrial plants. (Local boilers for the residential or service sector are not included in these totals.) Similarly, the difference between heat consumed, as listed in Balance 2 (60 PJ), and heat consumption from heat in heat-only boilers, 35 PJ, must have been supplied by CHP plants. Again, there are losses in transmission.

Estimating the primary energy consumption (i.e., fuels) used to make this heat, by sector, is difficult. Balance Two reports that only 71.7 PJ were consumed in 1992 for all production of heat (including that produced in CHP plants using some unspecified scheme for allocating losses in CHP [and cogeneration] between heat and electricity production). Officials indicated conversion efficiencies of 55-85\%, depending on the sector. If we assumed all heat boilers had an $85 \%$ conversion efficiency, then 48 PJ of fuels were used to make 40.5 PJ of heat, and approximately 24 PJ of fuel were used to supply the 24 PJ of heat from CHP. While this "efficiency" of $100 \%$ appears impossible, it is obtained by simply counting the heat produced in CHP as without losses, since much of this waste heat would have been lost were the electricity made in electricity-only plants.

Socialist statistics include heat supply in industry, i.e., steam and hot water, as if the heat plant is part of the heat sector. (The same is true of production in other sectors.) This is an important inclusion, because it appears that industry in Estonia produces roughly half of its own heat, which in turn accounts for as much as $40 \%$ of final energy use in industry. Approximately 17.9 PJ were produced by "industry" in 1992 (including 1.1 by mining), but 16 of these were "consumed" by industrial enterprises (and 1.13 consumed by mining) and 2.56 were losses. Since Balance 2 shows $29.8 \mathrm{PJ}$ consumed by industry (including mining), approximately $12 \mathrm{PJ}$ came from other than heat plants, in this case cogeneration or CHP plants. But in all the energy balances, only heat consumed is counted with "industry" or other self-generating consumers, while the losses associated with production of this heat are allocated to the heat supply sector. Unfortunately, this mixes industrial heating plants with those for public heat supply, i.e., district heat. ${ }^{20}$ Data provided by the Bureau of

20 While Polish statistics clearly disaggregated these two main producing branches, Estonian data do not. The 1985 Soviet-style balances for Estonia show how much fuel each industry consumed to produce heat but not how much heat was produced. Conversely, material supplied by the State Statistical Office showed how much industrial heat was self-produced in 1992, but not how much fuel was consumed for this production. 
Statistics for 1992 only give a disaggregation that helped us estimate sources of heat, but these data were still imprecise in allocating losses between heat and electricity production As a result, we cannot allocate fairly the losses incurred in production of low-temperature process heat and steam to the industries using the heat, except using the average ratio of fuel consumed to heat produced for all heat plants in Estonia.

This means that figures for energy use in manufacturing, mining, construction, and agriculture underestimate the real consumption of primary resources as counted by Western practices. If it takes 1.25 units of fuel to produce 1 unit of district heat (including losses in both production and distribution), and at least 1.2 units of fuel in an industrial boiler to produce 1 unit of heat at the boiler, every unit of "heat" in Estonian manufacturing (see preceding paragraph) could be thought of as $0.33 \mathrm{x}$ 1.25 units of fuel supplied through district heat/CHP, and $0.67 \times 1.2$ units supplied locally, making about 1.22 units of fuel for 1 unit of "heat" from all sources actually consumed in industry. ${ }^{21}$

Proper accounting has another important impact on analysis of energy efficiency potentials. As presented, the figures obscure the flow of fuels through heat boilers. These may be large or small but are nevertheless decentralized, and their utilization is tied to the fate of a factory or enterprise. Efficiency strategies aimed at converting boilers to new fuels will differ if the boiler is part of an industrial facility rather than part of a large district-heating network. Worse, we lose track of the amount of heat produced in industries that may become victims of economic reform.

The Estonian balances are unclear on another matter, the distribution losses in district heat. We assume that large customers (industries, etc.) have devices for counting the heat they consume from the public network, while buildings, which are unmetered, do not. That is, no one knows how much heat is actually consumed by buildings, only the total amount of heat in the "system" once all other users' consumption is estimated. In essence, all heat not ascribed to major consumers is either consumed in buildings or lost. ${ }^{22}$ To account for these losses, we removed $10 \%$ of the heat listed as consumption in households or "other consumers" in the Estonian balances.

With these adjustments made, it is possible to estimate primary energy consumption implied by the final energy demand of each sector. We could do this by multiplying electricity consumed by each sector by the ratio of (fuel used for all production)/(production - self use - distribution losses allocated to local production and imports). Similarly, we could multiply district heating by the ratio of fuel used to (heat produced - listed and estimated distribution losses). But the same imprecision in allocating primary fuel losses between electricity production, heat production, and combined production makes these calculations uncertain. (Unfortunately, electricity consumed by fuels industries and district heating plants themselves cannot be allocated to the energy sector.)

There is a simple-and logical-reason why statistics in Estonia (or Poland) counted heat in this convolved manner in the past. Since virtually all production fell

21 According to some accounting practices, cogenerated heat and CHP could be counted with a production and efficiency of greater than 1 . This would somewhat lower the losses. But Estonian practice seems to give credit to electricity for the gains to production efficiency arising from CHP or cogeneration.

22 This was the case for Poland as well. 
under state control, the method of counting, or indeed whether there was any counting at all, was immaterial. What mattered was that the state, in its own way, maximized efficiency by producing heat wherever practical and sharing heat between enterprises or among sectors. Inspections of industrial areas in Estonia or Poland confirm this practice: endless pipes, mostly above ground and many with little or no insulation, connect factories and buildings. Adding cogeneration to this system increased efficiency even more, at least in the eyes of the theoreticians who designed the system. ${ }^{23}$ With modern methods permitting inexpensive metering and controls, this system could easily be profitable to operate as individual firms (or boiler houses) are modernized and possibly privatized. That is, a kind of "bourse" for heat that resembles the rapidly growing electricity market of independent producers in parts of the U.S. could be developed.

\section{Adjustments to End-Use Categories}

We started our analysis of energy demand in Estonia with the patterns of energy use in Balance 2 ("Balance of Shale", etc.) for each fuel, electricity and heat. We made some use of Balance 3 and Balance 4 where noted, as these sometimes provided more detail than Balance 2. We then made an important series of adjustments explained and justified below. Each transformation was carried out starting with the data from Balance 2, as modified or clarified by Balance 3 (for manufacturing by branch) or Balance 4 (for somewhat greater detail on the use of fuels in transportation).

There is a fundamental problem with Balance 2. The initial set of tables that list fuel consumption of each sector simply do not match the tables that list energy consumption of each fuel by sector. Part of the problem is that some fuels listed in the sectoral tables (such as shale oil, shale gas, peat briquettes) are not listed under the fuel consumption tables. Another problem is that "Industry" as defined in the first section of tables includes virtually all energy-conversion activities. In the set of tables listing the use of each fuel, however, a different definition of industry is used. Large quantities of diesel and gasoline (petrol) listed under "Agriculture" and "Construction" are missing from the corresponding sectoral rows in the tables for "Balance of Petrol" and "Balance of Diesel." Even natural gas does not balance from one set of tables to the next. While there are some changes in accounting after 1991, these changes cannot account for the inconsistencies in the

way these tables are presented. U. Toivere provided us with much helpful information on how the balances were defined and constructed. But it is important that future editions of this important document contain these definitions.

Manufacturing is industry without mining (i.e., ISIC 3). Since we had no separate data for mining for 1985 and 1980 , we only show manufacturing explicitly in comparisons with other countries in 1990 or 1992 . Where aggregate manufacturing

23 The senior author visited Minsk-4 in Belorus in 1990. This huge $750 \mathrm{MWe}, 2000 \mathrm{MWth}$ plant provided heat to the inner part of Minsk from $15 \mathrm{~km}$ away. On a hot day in the summer, the plant provided hot water to downtown buildings like hotels. Asked whether this practice made sense, the directors replied both that it was efficient (relative to individual water heaters, something they had not considered for years), and, besides, it was not their responsibility: their task was to produce cogenerated heat and electricity, not to worry about whether the products were efficiently used! 
energy consumption data are required, however, we estimated mining at $4 \mathrm{PJ}$ in both 1980 and 1985 . We removed gasoline and half of the road diesel from industry in Balance 2. The figures for individual branches of manufacturing supplied in Balance 3 already excluded these transportation fuels. Figure EU-2 shows the original Estonian sectoral data, our "first" transformation (as outlined below), and then our final allocation into six final demand sectors that are comparable with those in other countries.

"Other Industry" is our category in which we place agriculture and construction and mining for 1990 and 1992 for comparisons with other countries (ISIC 1, 4, and 2 , respectively). We make every attempt to hold the energy sector (which includes utilities, ISIC 5) separate.

Transportation. Because socialist statistics counted the use of transportation fuels by industrial ministry vehicles under the consumption of fuels for that ministry's industry branch, we moved all gasoline and $50 \%$ of diesel from industry/manufacturing to transportation. ${ }^{24}$ And since these statistics count household, i.e., private, use of gasoline (and even diesel) for cars under households or services, we moved diesel and gasoline from households and services to the transportation sector. Finally, we removed peat, district heating, and residual electricity (that which remained after we accounted for trams/trolleys and the railroads) from transportation to the service sector. This consumption represents energy used for transport-related buildings. However, we overlooked the use of transportation fuels for on-road trucking in agriculture, which appear to be small compared with fuel for vehicles used on farms.

Socialist countries count energy used for overseas shipping and air traffic as domestic consumption, since the state company is usually responsible for the transportation service. Because of the problem of counting energy and travel or freight activity for both outbound and returning directions however, we had to ignore foreign shipping and air travel. This was unfortunate, since these two account for a substantial portion of total transportation fuel use. Other countries consider these uses as "bunkers."

Service ("Other Consumers"). We moved gasoline and diesel fuel from services ("other consumers") to transportation. We moved from transportation to services district heat, peat, and a small amount of electricity (after accounting for rail and trams) that was clearly used in buildings belonging to the transportation ministry. We moved a small amount of heat from services to the residential sector (1985, 1990, 19912 PJ; 19921 PJ) because of an apparent inconsistency that left the service sector with an unusually high share of all district heat in these years. We moved a small amount of electricity and heat from agriculture to services, based on information provided by the Ministry of Agriculture about the kinds of users of these two energy sources in 1991. We compared the consumption indicated by the Ministry for services (or residential) as a fraction of all consumption of heat or electricity recorded by agriculture in 1991, and moved the same share in 1990 and $1992,80 \%$ of that share in 1980 and $90 \%$ in 1985, reasoning that the service sector grew in importance relative to the agricultural sector over that period.

Residential. We moved approximately 260 gwh of agricultural electricity used in farmhouses in 1991 and about 2 PJ of heat provided to farmhouses in the same

24 The 50\% figure is a rough estimate, grounded on our belief that some vehicles provide transportation around enterprises but not freight or travel outside of the premises. 
way we moved heat and electricity from agriculture to services. ${ }^{25}$ We moved gasoline and diesel fuel from residential to transportation. We moved coal and wood from agriculture to residential, as these uses likely represent heating of homes. We overlooked the provision of heat to homes by industries if that heat was provided directly by industrial boilers to factory-provided housing.

Agriculture. The Agriculture Ministry indicated to us that a significant fraction of the electricity and heat counted as consumption in that sector was really used by homes or buildings. Accordingly, we made certain adjustments from agriculture to these sectors. We examined the data provided by the Ministry for 1991 to judge the proportions of the total amount of each of these sources listed under "Agriculture" in Balance 2, and moved similar fractions for 1992 and 1990, but smaller fractions in earlier years, reasoning that the residential and service sectors have grown faster than the agriculture sector, and that energy use for these purposes grew as a share of total heat or electricity listed as consumed by agriculture. We also moved coal and wood consumed by agriculture to residential, reasoning these fuels were most likely used to heat homes.

Uses of Energy for Military Purposes? It is no surprise that fuels used by the military are not identified anywhere. In Western countries, barracks and similar facilities are counted in the service sector, while transportation fuels are shown (or lost?) in that sector. We suspect, but cannot prove, that the residual of road fuels for 1980 and 1985 and 1990 represents the military. For 1991 and 1992, this residual is gone, which may be an artifact of our analysis. However, Soviet military activity fell off in these years and was not likely replaced by that of the new Estonian army. An alternative explanation is that the consumption of fuels by the Soviet army was not counted in Estonian statistics at all, the fuel being brought in by the Soviet authorities.

25 This data was kindly provided by J. Viik of the Department of Energetics, Ministry of Agriculture. 



\section{ENERGY USE IN ESTONIA: AN INTERNATIONAL COMPARISON $^{1}$}

Placing a country's energy patterns into an international context enhances understanding of that country's energy use. Careful comparisons can shed light on why use patterns differ and how they may evolve. International comparisons also help in formulating energy policies. Understanding how one country arrived at a pattern may stimulate implementing change in another. International comparisons reveal energy-saving technologies as well as key policies that promote energy efficiency; they help identify why certain energy uses are efficient and help explain the role of specific policies. In the case of Estonia and other CPEs that are moving toward market economies, comparisons with current and historic Western patterns can aid with projections of future energy requirements.

International comparisons provide a way of "calibrating" the structure of energy use in a country that previously lacked energy markets with the structures in countries that do have energy markets. Some of the gross differences that arise can be traced to the structure of the economy during the former period. Some or even most of these differences, which resemble distortions, can be expected to disappear as economic reform occurs. But econometric analysis of changes in energy use would be difficult, since there is no period for which one could estimate energy price and income elasticities. Here international comparisons can help. While revealing little about the speed at which the structure and efficiency will change, comparisons give us insight as to where the end points lie.

Comparisons of energy use between Western and former CPEs at an aggregate level are problematic. Unfortunately, finding comparisons of energy/GDP ratios between these countries, despite dollar estimates of GDP in the former CPEs being subject to considerable uncertainty, is not uncommon. Obtaining GDP estimates in national currency units is one problem, although for most CPEs the error margins for national-currency GDP are considered to be within 10-20\%. ${ }^{2}$ Problems are much greater, however, when converting GDP in national currency to dollars. Exchange rates in the former CPEs were characterized by large deviations between official rates and the actual rates for various transactions. Although official exchange rates have become more meaningful in most of the countries, including Estonia, which introduced a unified EEK-deutschmark/dollar rate in 1992, they are still poor measures of the domestic purchasing power of the currencies. Considerable effort has gone into developing so-called purchasing power parities (PPP), but the measures that have been calculated for the former CPEs suffer from problems that tend to lead to overvaluation of GDP. This is the case for Estonia, i.e., defining a "GDP" from the Soviet era is difficult, since so much of the activity that took place there was controlled by Soviet, not republican, ministries.

This chapter is based on Meyers, Schipper and Salay 1993, Chapter 7.

2 P. Marer, et al., "Historically Planned Economies: A Guide to the Data." The World Bank, Washington D.C., 1992. The Material Product System traditionally used in the CPEs excluded socalled non-productive services (such as administration, the military, education, and health) and depreciation. Prices, set by central planning authorities according to certain political and economic objectives (e.g., cheap housing, low prices of raw materials and energy, high prices on luxury goods), did not reflect the relative resource costs of production and services. 
Since considerable differences exist between dollar GDP values calculated using exchange rates versus those using the PPP method, the range of values for primary energy use per dollar of GDP is also great. ${ }^{3}$ Estonia's energy/GDP ratio in 1992 was five times higher than that of West Germany using PPP values (Figure I1). ${ }^{4}$ Including the energy lost in producing electricity for export (as well as the exports themselves) increases the energy/GDP ratio even more, as shown. While there are uncertainties associated with these comparisons, no one doubts that Estonia's economy is energy-intensive by Western-and even "Eastern"-standards.

Even if the problems of expressing economic output in a common unit could be overcome, the fact remains that comparisons of energy/GDP ratios reveal little useful information. ${ }^{5}$ Rather, it is necessary to look carefully at energy use and the fac-

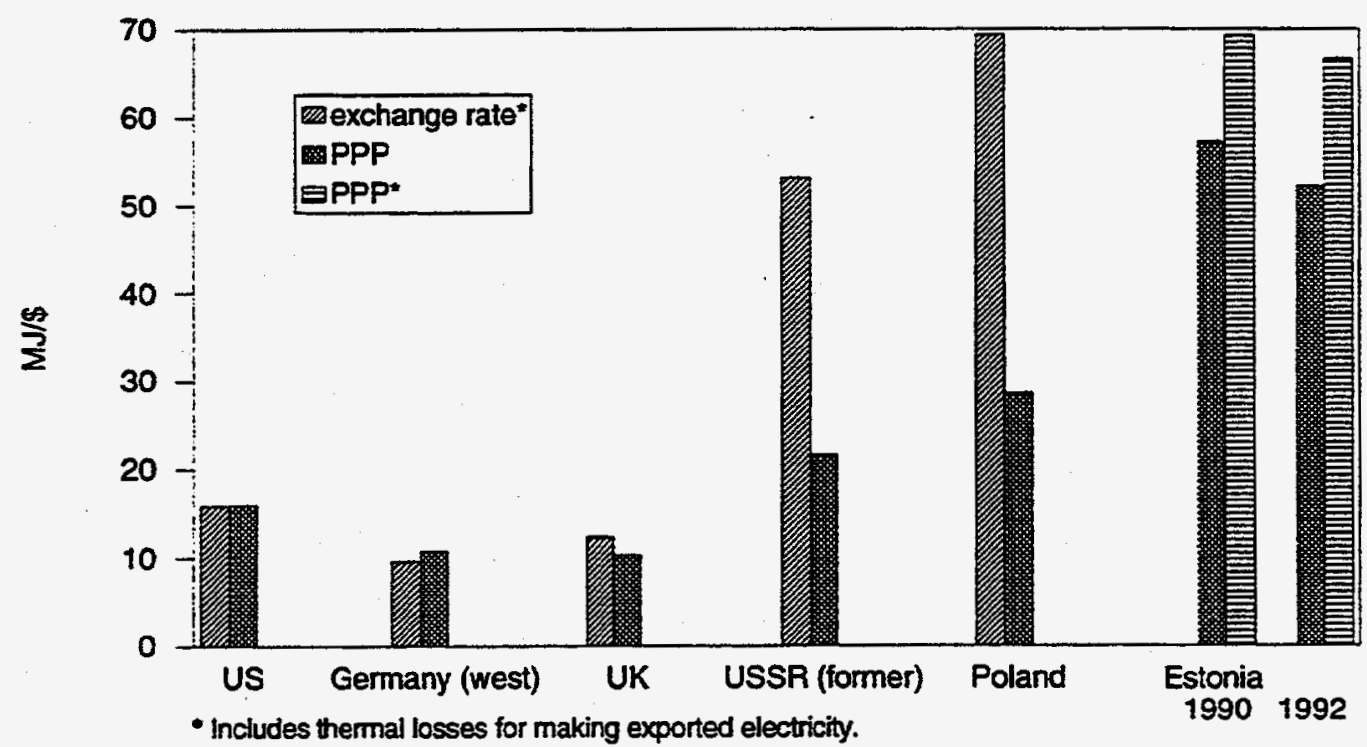

Figure 1-1. Primary energy use per unit GDP.

3 The difference between the two methods for Western countries is much smaller, but not trivial. For example, GDP calculated with exchange rates is higher than PPP-based values for West Germany, and especially for Japan, because of the premium placed on these countries' currencies in the international trading system.

- The source for the exchange rate-based values is the World Bank, which uses a three-year adjusted average of a country's exchange rate to smooth fluctuations in prices and rates. Sources for the PPP-based values are the OECD national accounts and Marer et al. (1992) for Poland and the former Soviet Union. The World Bank provided estimates of the real Estonian GDP in 1990 and 1992 in 1990 US dollars. Other data in Figure I-1 are derived from the World Bank 1991, OECD 1992 (purchasing power parity values), and Marer et al. 1992 (values for PPP for the USSR and Poland). The 1989 GNP for Poland is in current US dollars according to the World Bank Atlas method. The 1988 GNP for the USSR is in current US dollars. We have adjusted all values to approximate 1990 US dollars.

5 For a discussion of this point, see Schipper and Meyers et al., 1992. 
tors that shape it in each sector. The analytical framework that we present, which we have applied in other international comparisons, involves an assessment of three key elements in each sector: (1) a measure of aggregate activity, (2) the structure (composition) of activity, and (3) the energy intensities of key activities.

In the following sections, we show how these elements differ between Estonia and several Western countries. We also compare Estonia to the former Soviet Union and Poland, where LBL conducted similar studies in 1989/91 (USSR) and 1993 (Poland). We use 1990 to represent Estonia before the economic collapse, and 1992 to represent it after the onset of a period of transition that includes the economic collapse. We display Polish data from 1988 (and 1991) to represent energy use under the former system and during the period of transition. Unfortunately, we are limited to 1988 and 1989 for the Western countries. ${ }^{6}$

\subsection{Manufacturing}

Per capita final energy use for manufacturing in 1990 (prior to the economic collapse) was almost as high in Estonia as in the U.S. (see Figure I-2). Assuming 30\% of the estimated 1992 GDP arises from manufacturing (World Bank estimate; see Chapter 2) implies an output or value added of roughly $\$ 1,000$ US/capita. This figure indicates an extremely high ratio, approximately $35 \mathrm{MJ} / \$$ in 1992 dollars, of primary or final energy used to real output for that year. By contrast, aggregate manufacturing in the U.S. required only $15 \mathrm{MJ} / \$$ (in 1987 currency), and that value was higher than those for Japan and Germany. This comparison shows that energy use in manufacturing in Estonia is horribly inefficient.

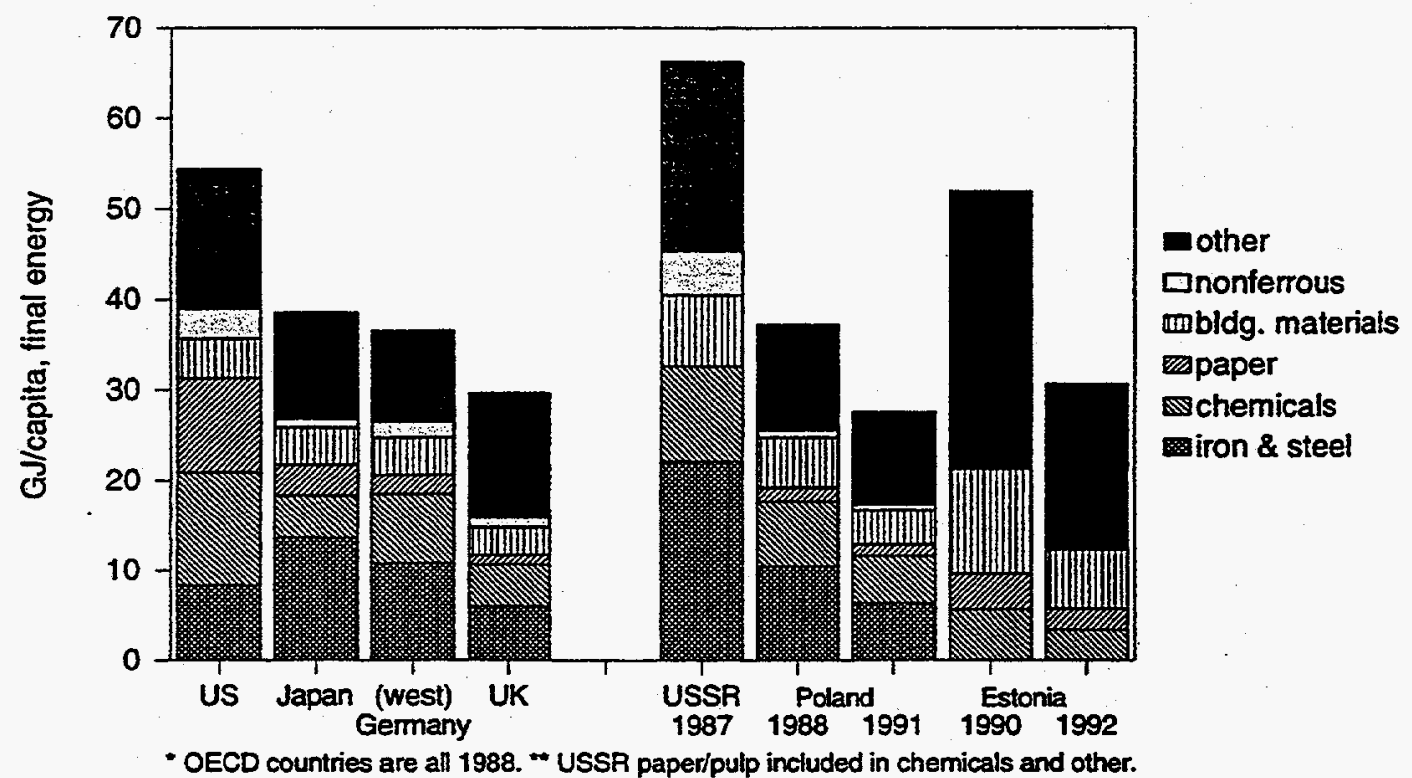

Figure 1-2. Manufacturing energy use per capita.

6 The data for the U.S., Japan, and Western Europe are from ongoing research by the authors and their colleagues at Lawrence Berkeley Laboratory. The data for the Soviet Union are from a study by Schipper and Cooper (1991). The Polish data are from Meyers, Schipper and Salay (1994) and Meyers, Salay, and Schipper (1994), both based on Meyers, Schipper and Salay (1993). 


\subsubsection{Structure of Manufacturing}

Structural factors are important for comparing energy use in the manufacturing sector. Five energy-intensive subsectors accounted for about $70 \%$ of total energy use in Poland in 1988, a similar share as in West Germany and the U.S. However, the energy-intensive industries in Estonia account for a smaller share of total manufacturing energy use, in part because of the absence of the primary metals industries in Estonian manufacturing. Nevertheless, as Figure I-3 shows, cement production per capita in Estonia was the highest of the countries shown. ${ }^{7}$ Paper and pulp production, while low compared to some Western countries, was very high by East European standards, doubtlessly reflecting Estonia's rich endowment of forests.

\subsubsection{Energy Intensities}

Unfortunately, data on the physical energy intensities of materials produced in Estonia are lacking. Because of the difficulties comparing output in monetary units, one cannot easily contrast the energy intensities of key industrial subsectors in Estonia with those in other countries. Judging from inspection of one of the two paper mills (both of which have since closed), we suspect technologies are old and very energyintensive. In future work, we hope to obtain energy-use figures for paper and cement production in Estonia.

\subsection{Passenger Transportation (Travel)}

Total energy use for domestic travel in Estonia in 1990 was around $5.3 \mathrm{GJ} / \mathrm{capita}$, below that in Japan and far below the level in Western Europe or the U.S. (See

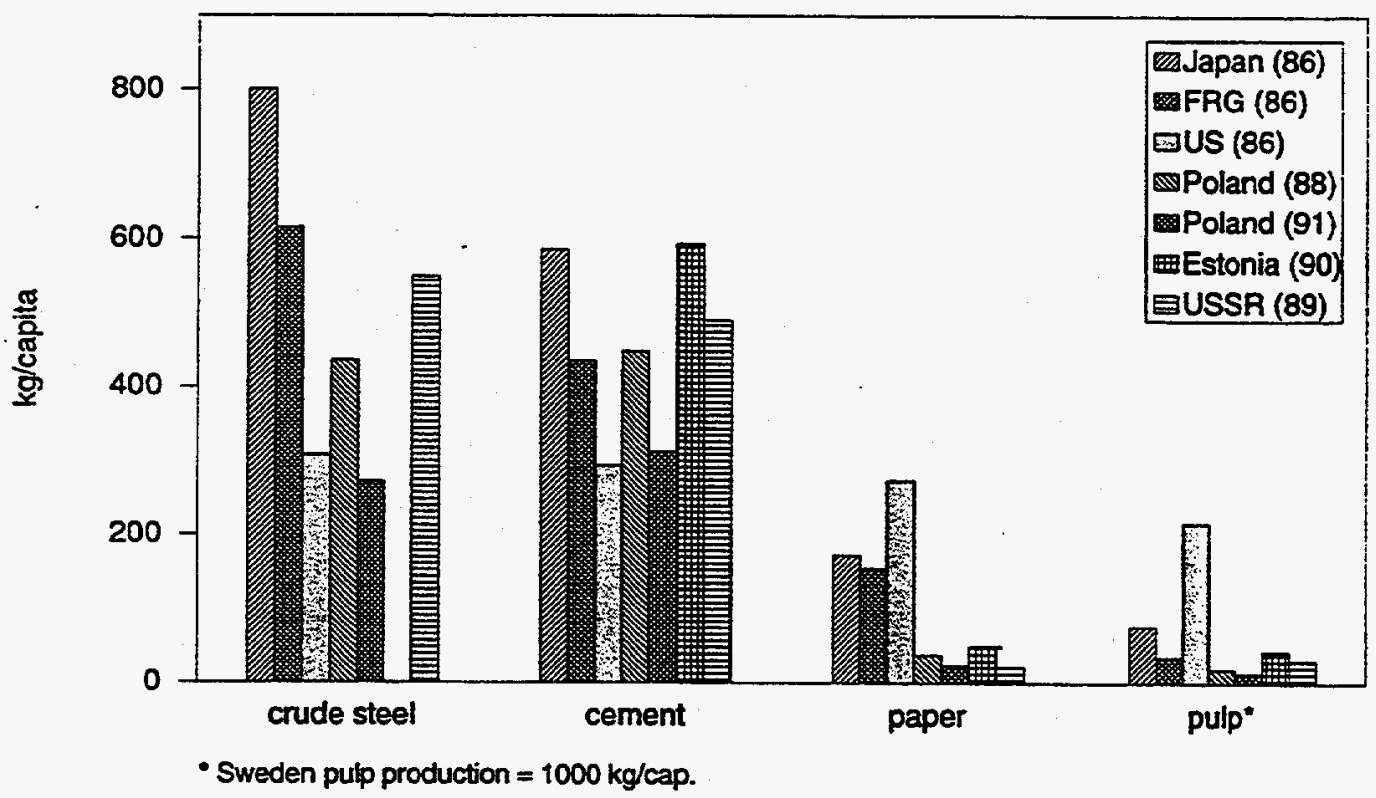

Figure 1-3. Energy-intensive materials production. Late 1980 s.

7 Data for the first three months of 1992 show considerably lower production, at an annual rate, than $1991 ; 1993$ is even lower. 
Figure I-4; to expand the scale, the U.S. is not shown, but lies at over $55 \mathrm{GJ} / \mathrm{capita} .^{8}$ Energy use for travel was also less than in the USSR, mainly due to the higher use of air travel (which is very energy-intensive) in the latter. For all of the countries except the USSR, the automobile dominated travel energy use, in part because it is more energy-intensive (in MJ/pass-km) than either rail or bus. ${ }^{9}$

\subsubsection{Activity and Structure}

Figure I-5 shows the modal structure of travel, measured in passenger-kilometers (excluding walking and cycling). Estonia lies well below Western Europe and even Japan. ${ }^{10}$ Estonians traveled as much as citizens of the Soviet Union in the late $1980 \mathrm{~s}$ however, in spite of Estonia's small size. This fact reflects the better condition of Estonian roads and the higher number of cars there than in other parts of the former Soviet Union. Air travel of Estonians, almost exclusively within the USSR in 1990, but probably balanced between the former Soviet Union and European countries in 1992 , is also shown in the figure. Including this as "domestic" travel boosts the total by $10-15 \%$, but still leaves Estonia below the levels of Western Europe.

While travel in the U.S. and Western Europe is dominated by the automobile, less than one-half of travel in Estonia took place in cars in 1990 (Figure I-5). (Note how the 1992 pattern shows a rise in travel in cars and a fall in other modes over 1990, as was the case for Poland between 1988 and 1991.) The wide disparity in automobile ownership partly explains the differences in the structure of travel be-

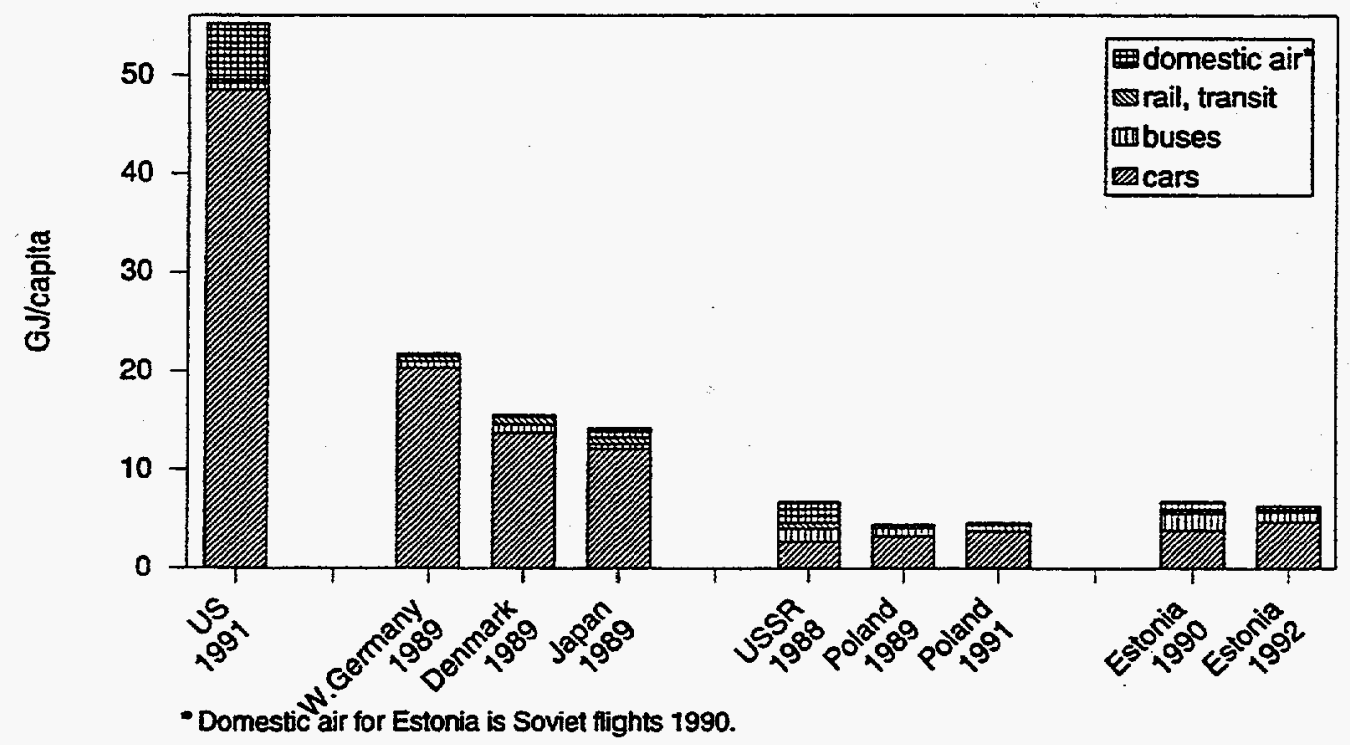

Figure 1-4. Per capita energy use for travel.

8 We estimated the passenger and freight portions of rail energy based on the assumption given in Chapter 3.

9 Automobiles include personal light trucks, buses include intercity and city, rail is heavy and light rail. Air travel is domestic only.

10 "EU-T" in Figure I-5 and other figures refers to the weighted average of Sweden, Norway, Denmark, West Germany, France, Italy, and the United Kingdom. 
tween Estonia and Western Europe (Figure I-6). By 1990 the ownership of cars in Estonia (180 cars/1000 persons) reached the level of Japan in 1978, but this level had been reached in Western Europe in the mid- to late-1960s. Nevertheless, Estonia

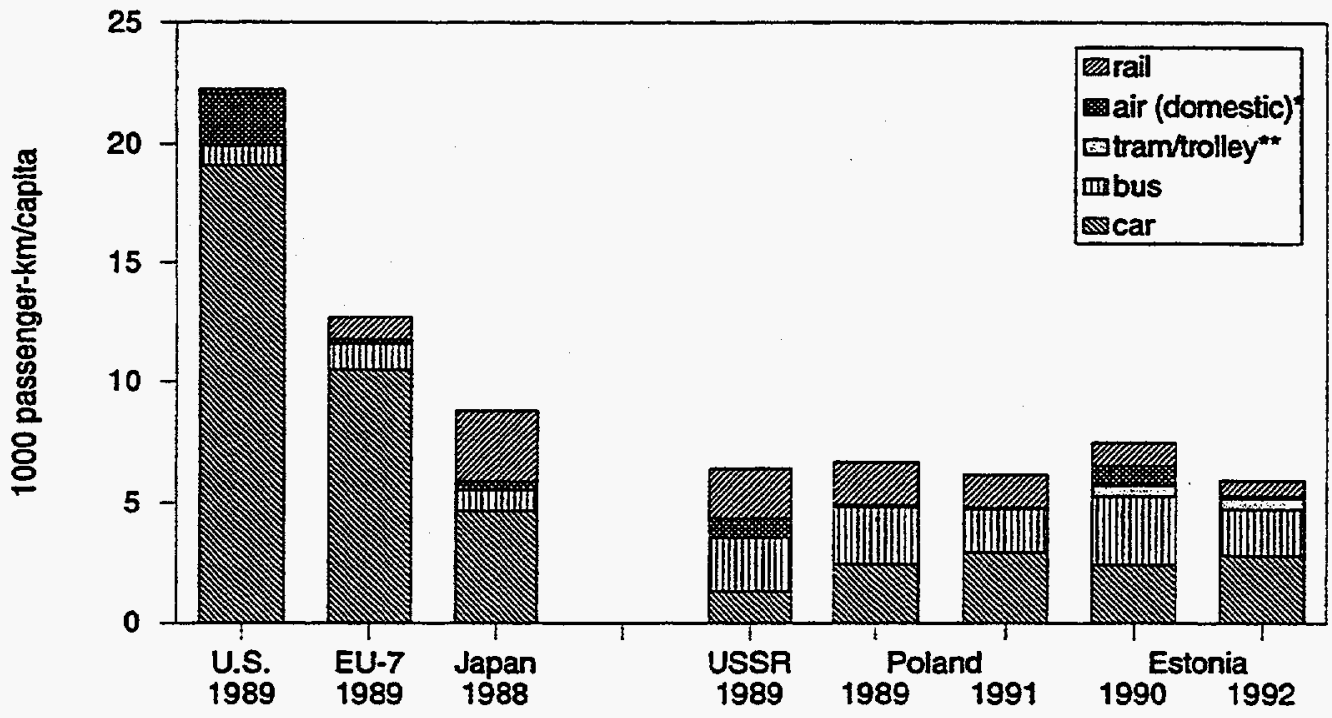

- Air transport in Estonia is Soviet domestic flights 1990.

- Tram/trolley countes with bus in Poland, with rail in other countries.

Figure 1-5. Passenger travel per capita.

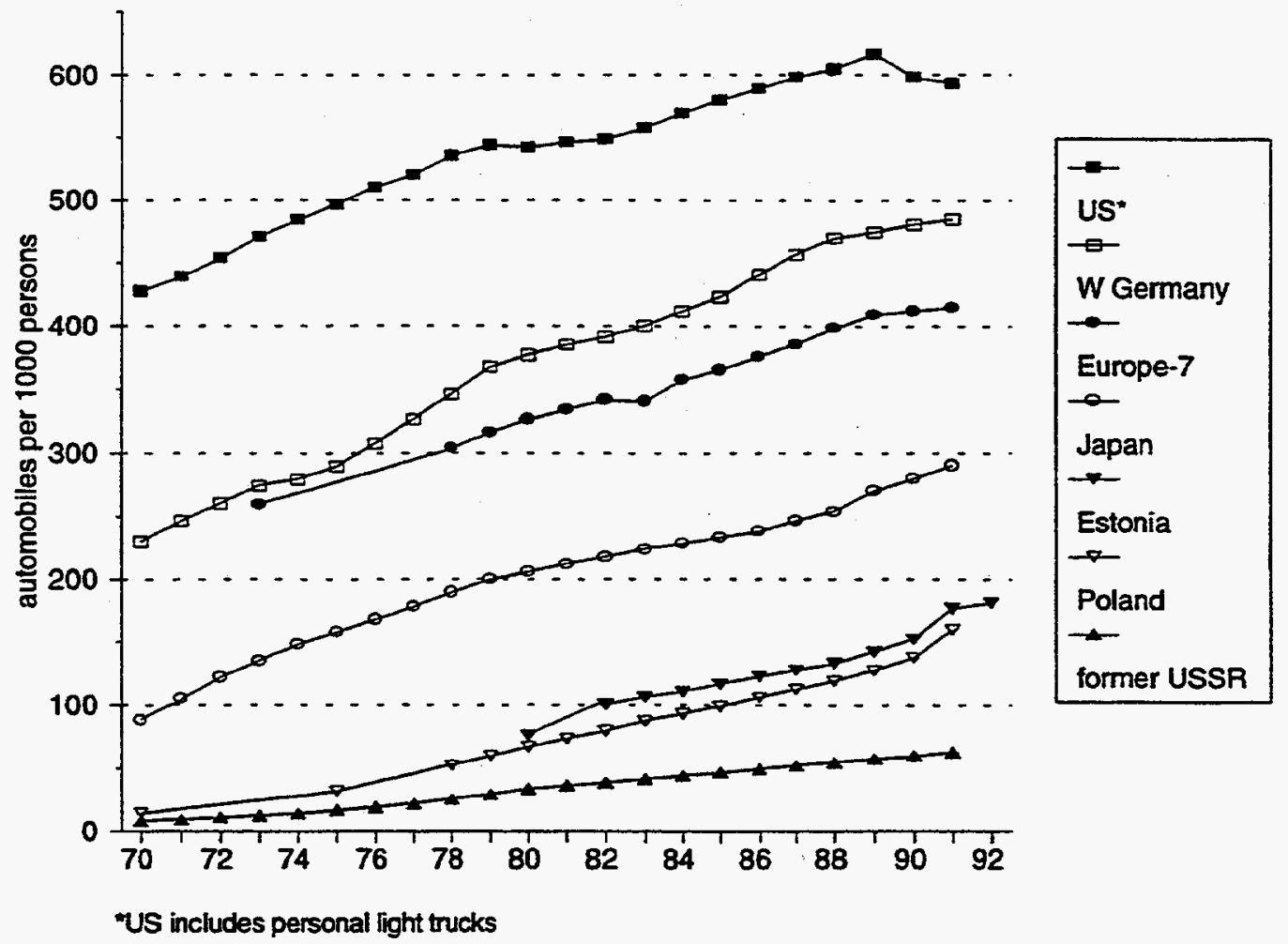

Figure 1-6. Automobiles per 1000 persons. 
(like Poland) appears to be rapidly closing the gap. By contrast, auto ownership in the rest of the Soviet Union was well below that in Estonia. Not surprisingly, Estonia's automobile share of travel was higher than that of the Soviet Union.

Because of its small size, intercity busses have proved somewhat more important relative to the railways in Estonia. This explains some of the differences between travel there and in Poland, which has an extensive rail network. Use of busses and trams in cities appears similar to patterns in Poland. Like other Soviet citizens, urban Estonians often faced long commuting distances between available housing in "planned" communities and their jobs.

\subsubsection{Energy Intensities}

Because of the data uncertainties, caution is required when comparing estimates of energy intensities of Estonian vehicles with those in Western Europe or elsewhere. For automobiles, it appears that the average gasoline car in Estonia in 1990 required approximately $10-11$ liters $/ 100 \mathrm{~km}$ (21-24 mpg). In the U.S. the comparable figure was close to 12 liters $/ 100 \mathrm{~km}$, while in Western Europe it varied from a low of around 8 in Denmark and Italy to 10.5 in West Germany. The relatively high fuel intensity of Estonian cars reflects the dominance of Russian-made cars which, while low powered, were technologically inefficient. The Polish intensity is much less than that estimated for Estonian or Soviet cars (around 11 liters $/ 100 \mathrm{~km}$ ), because of the large number of smaller cars made in Poland.

Estonian data indicate that city buses required around $12-15 \mathrm{MJ} / \mathrm{vehicle-km}$ in 1991 , in the range of buses in Germany, Sweden, and Japan, but far lower than city buses in the U.S. Estonian intercity buses required about $0.3 \mathrm{MJ} /$ pass-km. This figure was below the levels of the other countries, which is probably due to high load factors.

Estonian train travel appears to require about $0.25 \mathrm{MJ} /$ pass-km in 1992 , with only a very small share electrified. This value is low compared to Western European countries, even though a much higher level of travel is provided with electric trains there, whose delivered energy intensities are lower than those for diesel rail. The reason for the low value in Estonia is again probably high load factors. In Poland, with a higher degree of electrification, the apparent intensity was very similar (using the same equivalence of passenger and tonne- $\mathrm{km}$ ). And in the USSR, the energy intensity of passenger travel was slightly higher, around $0.28 \mathrm{MJ} /$ pass- $\mathrm{km}$, in spite of a higher degree of electrification, but with the same crowded trains!

\subsection{Freight Transportation}

Final energy use per capita for domestic freight transport in 1990 in Estonia was similar to that in the European OECD countries, higher than that in Poland, but below that of the Soviet Union. Energy use fell sharply in between 1990 and 1992 (Figure I-7). The main reasons for high energy use for freight are both a high level of domestic shipping and a significant share of shipping by truck.

\subsubsection{Activity and Structure}

Similar to that of Soviet Union, the Estonian economy relied heavily on shipment of heavy materials. But the U.S. and Soviet Union dwarf Estonia in size, which accounts for their high levels of tonne-km per capita (Figure I-8). Still, the level in 
Estonia is close to levels in Western Europe, in spite of its much lower GDP/capita. " Thus by any measure Estonia's economy is very freight-intensive. Much of this freight was shipped to the Soviet Union, whose own demise accounts for much of the drop in rail activity in 1992.

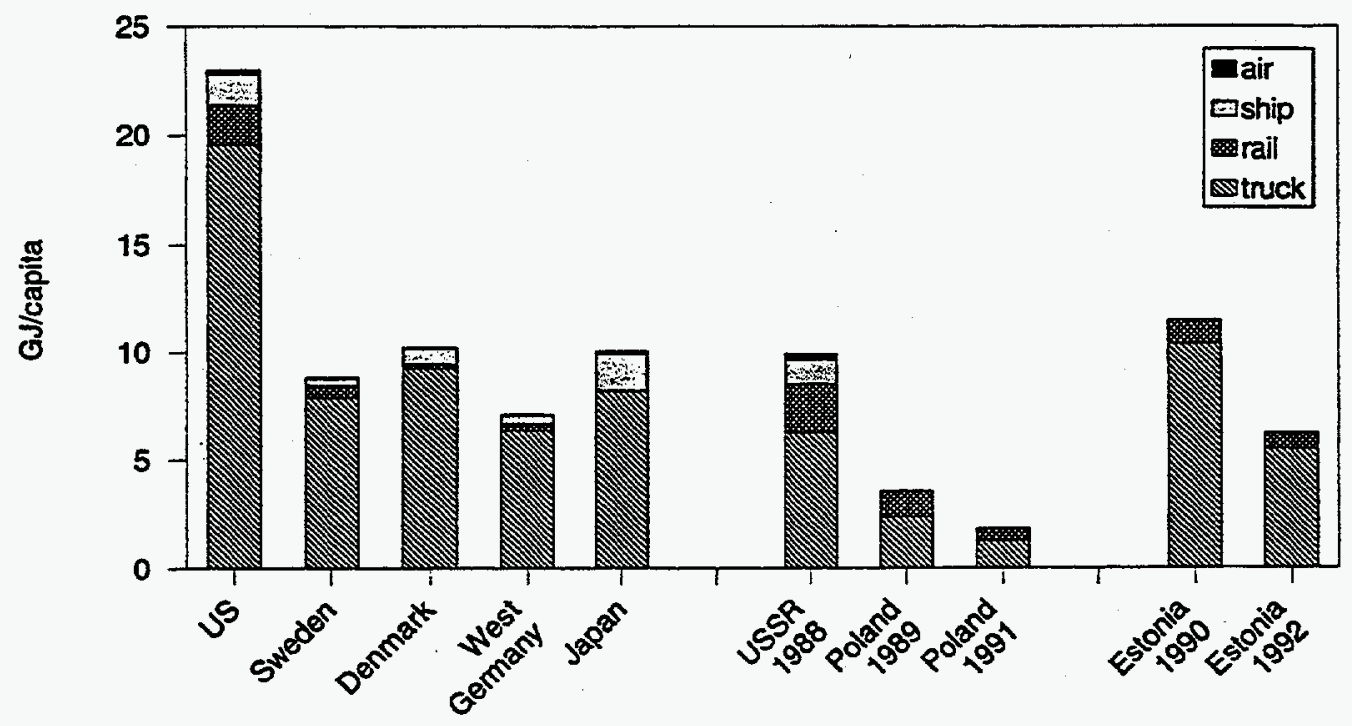

Figure 1-7. Domestic freight transport. 1989 per capita energy use.

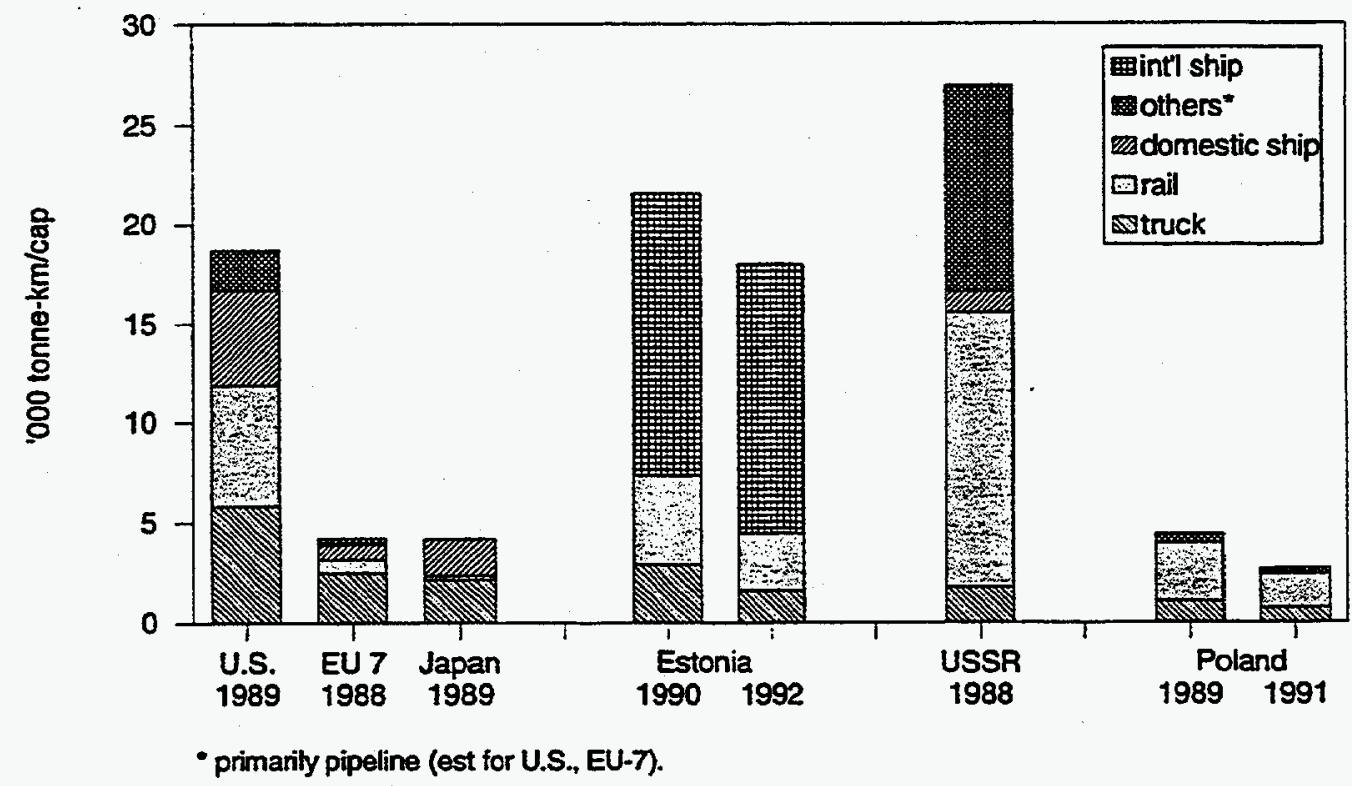

Figure 1-8. Domestic freight per capita. By mode.

1 Foreign shipping is excluded from these comparisons, but we do not believe this alters our conclusion, since all of Western Europe relies heavily on foreign shipping. Inclusion of this shipping would make up some of the difference between the U.S. or Soviet Union and Western Europe. Including foreign shipping for Estonia would more than double the overall level of freight (as shown) and increase energy use by some $30-50 \%$. 
Although the role of rail declined in Estonia after 1991, it still dominates freight transport. The U.S. and Soviet Union, with enormous movement of coal, grain, and other raw materials, also rely heavily on rail travel. By contrast, trucks have become the dominant mode in Western Europe, growing steadily in share over the last two decades. The share of truck freight in Estonia began to rise after 1990, as the economic decline struck rail freight far more seriously and there was much growth in private truck activity.

Energy Intensities

Estonian data for freight energy intensities give few clues that permit precise comparisons. However, the Ministry of Transportation provided information that suggested that intercity trucking (i.e., large trucks with over 8 tonnes capacity) required approximately $10 \mathrm{MJ} /$ vehicle-km or $3.5 \mathrm{MJ} /$ tonne- $\mathrm{km}$ (reflecting average loads of only 3 tonnes), a figure somewhat higher than in Poland but not inconsistent with experience in other countries. Since a significant number of these trucks still use gasoline, the high energy intensity is understandable.

For rail, our estimate of the energy use for freight transport implies an intensity of 0.25-0.3 MJ/tonne-km, which is lower than the Western European and U.S. averages of around $0.35 \mathrm{MJ} /$ tonne-km. However, the Estonian figures are very uncertain because of the difficulties of dividing energy use between passengers and freight.

\subsection{The Residential Sector}

Comparing residential energy use in Estonia with that in other countries is difficult because of the lack of precise data on energy use in that sector. As shown in Figure I-9, our estimate of Estonian residential final energy use per capita in 1990 (around $27 \mathrm{GJ}$ ) is slightly below the average for the former West Germany, France, Italy, and the United Kingdom ("EU-4" in the figure) in 1973 (accounting for climate differences). This apparent similarity hides major differences in structural factors and

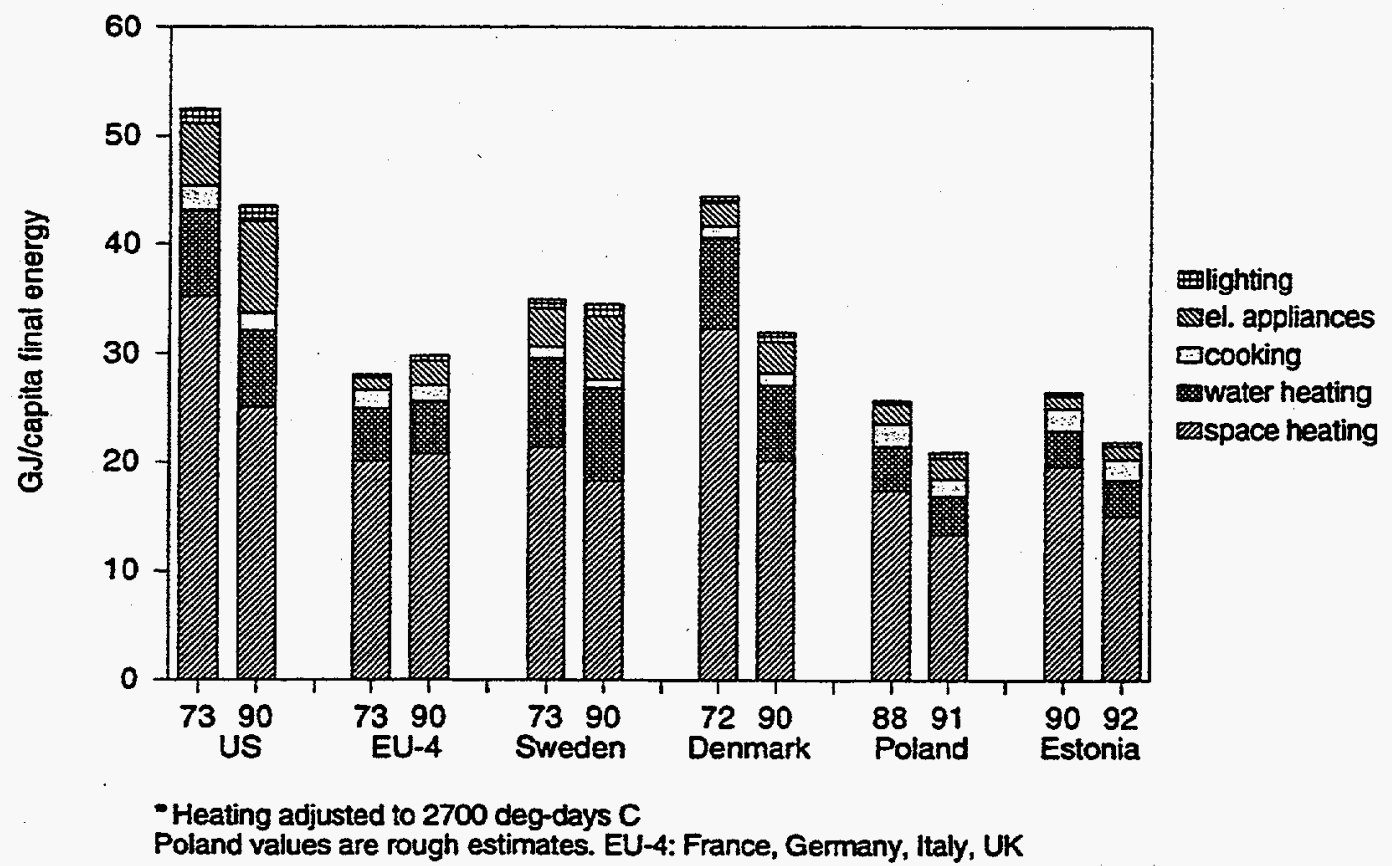

Figure 1-9. Residential energy use per capita*. By end use. 
end-use energy intensities. Since Estonia has a colder climate, it is not surprising that use was higher than in Poland in 1988.

\subsubsection{Structural Factors}

In 1970, per capita living area in Estonian homes averaged 13 square meters, roughly half of the average Western European level at that time, but somewhat larger than in the remaining Soviet republics. By 1990, area per capita in Estonia was 22 square meters, but the levels of area in Western Europe also grew, so the gap between Estonia and Western Europe remained (Figure I-10). These differences in per capita area exist because the average home in Estonia is considerably smaller than its counterpart in Western Europe (58 square meters in 1992 vs. 85-100 square meters (19881990). Household size (people per dwelling) in Estonia is comparable to Western Europe (2.6, versus 2.5 in Scandinavia and 2.6-2.8 elsewhere in Western Europe). This contrasts with values for Poland (3.2) and 3.5 in the Soviet Union as a whole. By Soviet standards, Estonians had the most residential space of citizens of any republic and a large number of summer cottages as well. ${ }^{12}$ This is confirmed by the 1993 Estonian housing survey.

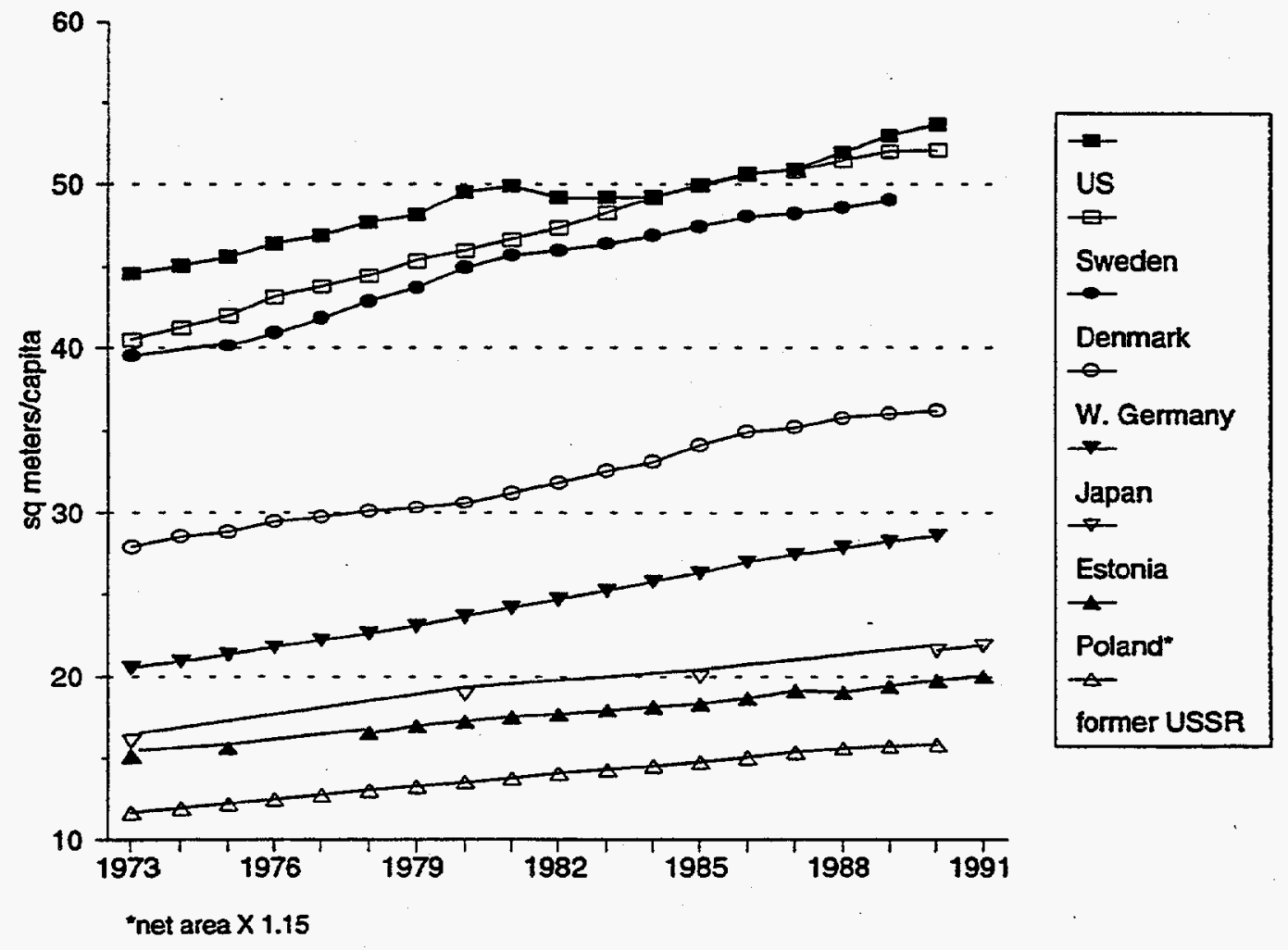

Figure 1-10. Per capita living area in homes.

12 Soviet statistics meticulously avoid revealing the real structure of families, households, and the dwelling stock. The 1989 Soviet census counts "families" as those with two or more members. A rough estimate of the numbers of single persons, however, many of whom live in dorms, barracks, or other collective housing, suggests that the "household size" in the former Soviet Union was small but the number of people in a dwelling was closer to 3.5 . The Soviet census put the number of people in a family in Estonia at 3.1. But unlike most of the citizens in the Soviet Union, Estonians suffered relatively little crowding, i.e., there was a flat for every family, leading to the lowest number of people per home in the former Soviet Union. 
In 1992, when a new housing census was undertaken, about $60 \%$ of Estonian households had either central heating from a system in the building (or nearby) or from district heating. The corresponding figures for 1990 for Western Europe are $75-80 \%$ for West Germany, France, and the U.K., and over 95\% for Sweden and Denmark. An estimated $65-75 \%$ of homes in the entire Soviet Union had central heat in 1988.

In terms of heating equipment, there is a similarity between patterns in Estonia and those in Scandinavia in the 1960s. In both cases, district heating or heat provided by large oil-fired boilers in individual buildings was the dominant heating form. The share of wood and peat as fuels was similar to that found in Sweden and Finland. Overall, the use of district heat stands out as the most important energy carrier in Estonian homes, while natural gas and heating oil, which dominate most of Western Europe, are absent. District heating and central heating from oil boilers were aiso the most important sources of central hot water, which reached nearly $80 \%$ of homes by 1993 . Small instant gas or LPG water heaters are also common, as they are in much of Western Europe. Unlike Western Europe, however, natural gas and LPG dominate cooking, with electricity found in only about $25 \%$ of homes; only in the U.K. and Italy (and Japan and the U.S.) is gas use this widespread.

Estonian homes have fewer and smaller appliances than homes in Western Europe; their numbers are close to the level found in Poland. Nevertheless, this measure of an indoor living standard is ahead of that for the former USSR as a whole. The combined ownership of refrigerators and freezers, slightly above 100 per 100 households, is still behind the 140-150 in Western Europe or the in U.S., but above that in the former Soviet Union. Automatic washing machines are less widespread in Estonia than in the West, although nearly all homes have either an automatic or a manual machine. Clothes dryers or dishwashers are almost unknown, while these are found in one-third to one-half of Western European homes.

Estonian homes are more electrified, about on a par with homes in Poland, than those in the former Soviet Union because of the spread of cooking, water heating, and even some electric heating. But the penetration of both electric cooking and water heating in Western Europe is far higher, accounting for the wide gap in household electricity use between Estonian and Western European households.

\subsubsection{Energy Intensities}

We estimate that Estonians used an average of $50 \mathrm{GJ}$ of final energy per dwelling for space heating in 1992 , which amounts to $0.8 \mathrm{GJ}$ per square meter of living area. The comparable value in Sweden, which also relies heavily on district heating and has a slightly colder climate, was only $0.45 \mathrm{GJ}$ per square meter. While this comparison strongly suggests that space heating in Estonia is inefficient relative to that in Sweden, there are problems with using final energy in such a comparison, since there is more reliance on electricity in Sweden than in Estonia.

If we adjust final energy to reflect the losses in combustion of fuels (assumed to be $33 \%$ for oil and gas, $55 \%$ for solids), we obtain a rough measure of the useful heat entering living spaces. The likely range of useful heat per square meter per degreeday in Estonia in the early 1990s, 170-218 kJ, is well above the comparable values in Western Europe and the U.S. in the late $1980 \mathrm{~s}(110-150 \mathrm{~kJ})$, but close to where many 
of the Western countries stood in the early 1970 s (Figure I-11). ${ }^{13}$ The Estonian figures would be $10 \%$ higher if we used the number of degree-days in their sevenmonth heating season. Whatever the uncertainties however, Estonian heating intensity lies below that of Poland or the former Soviet Union as a whole in the late 1980s. And the drop in 1992 is real.

Preliminary figures from a model in Mustamaee showed consumption of district heat for heat and domestic hot water of around $300 \mathrm{kWh} / \mathrm{sq}$ meter, approximately $1.1 \mathrm{GJ} / \mathrm{sq}$ meter. By contrast, the average for all apartments in Sweden in 1982 was $206 \mathrm{kWh} / \mathrm{sq}$ meter ${ }^{14}$ Only $182 \mathrm{kWh} / \mathrm{sq}$ meter were consumed in 1989, a year as warm as 1992 relative to long-term trends. Since the overall heating requirements in Sweden, as measured by temperatures and the season length, are greater than those in Estonia, this comparison suggests the buildings in Mustamaee consume far more heat than those in Sweden.

On balance, it seems that the higher energy intensity of space heating in Estonia is mainly due to the much lower thermal integrity of building envelopes, relative to Western Europe. One expert put the typical $\mathrm{k}$-value for a wall in a large apartment building in Estonia at over 1 watt/degree/square meter, far higher than the 0.4-0.5 typical for apartments in the Nordic countries. However, the inefficiencies of the district heating distribution system, even within buildings, clearly contribute to the high heating figures. Conversations with Estonian experts suggest that whatever the inefficiencies in home heating, apartments in Estonia were still built with better thermal properties than those in Russia or Poland.

It is difficult to make reliable comparisons of energy intensities of other end uses in Estonia; our figures were estimated from experience in other European countries. Water heating energy use per capita may be higher than in Poland since there is more central provision of hot water in Estonia. Conversations with Electrolux, the largest western importer of appliances in Estonia, suggest that the stock of mostly Russian-made refrigerators use more electricity than do Western counterparts of similar size; comparison with other countries is uncertain, but we know that the Russian models were notoriously inefficient.

\subsection{The Service Sector and Other Sectors}

It is difficult to determine energy use in Estonia's service sector, Worse, we found no estimates of total floor area, although our estimate for the former Soviet Union lay at

13 Estonian sources did not have weighted-average national degree-day values as are used in the West. Weighting average monthly temperatures from Tallinn (75\%) and Tartu (25\%) gave us an approximate time series for degree days from 1990 to 1992 . We counted all months except June, July and August, to make the results consistent with those from other countries. Estonians point out, however, that the real heating season (for central and district heating) excludes May and September, yielding about $10 \%$ fewer degree days than our calculation shows. Using our monthly data, Estonia has approximately 3837 heating degree-days (using a base of $18 \ll d e \gg C$ ) outside of the three summer months. In this system, Sweden and Norway have slightly over 4000 degreedays, Denmark 3300, West Germany 3000, the U.K. 2800, the U.S. 2700 and France about 2400. Poland has approximately 3600 degree-days; the former Soviet Union as a whole and Finland, 4500 degree-days.

14 "Energistatistik foer Flerbostadshus 1990". Örebro: Central Bureau of Statistics, E 16 SM 9202. These surveys, based on a representative sample of 8000 apartment buildings in Sweden, include metered consumption for heating and hot water. 


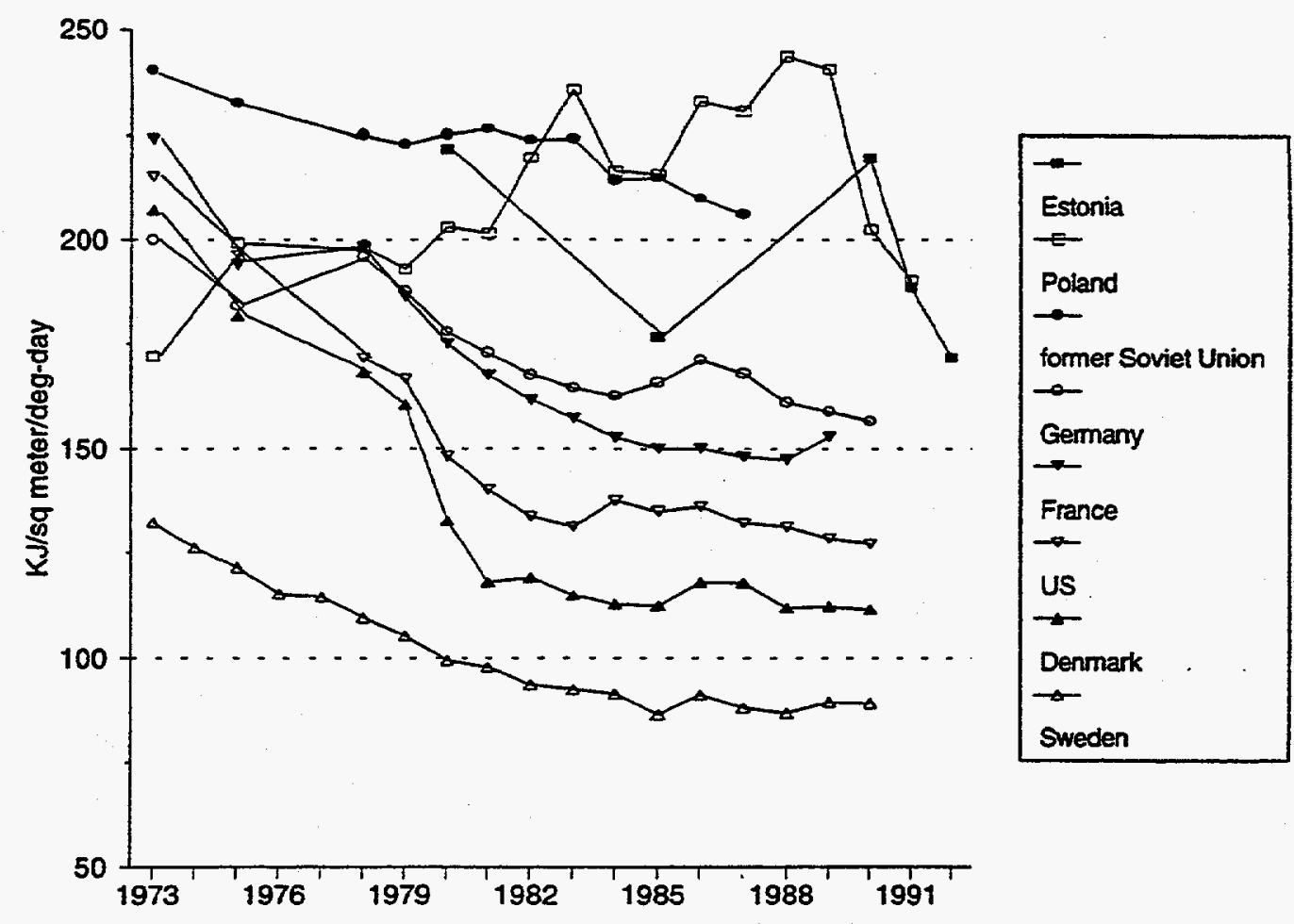

Figure 1-11. Space heating intensities. Useful energy.

below 5 sq meters/capita, around a third of the value we estimated for Western Europe and below $20 \%$ of the value for the United States. Our rough estimate of service sector energy use in 1990 in Estonia yielded a per capita use of 13.4 GJ per capita, falling to $9.6 \mathrm{GJ}$ per capita in 1992. This is less than in Poland and in the OECD countries we have studied..$^{15}$

For electricity, a more precise comparison is possible (values for some Western countries are inflated by use of electricity for heating and air conditioning). Estonian electricity use per capita in the service sector (including transport-related buildings and street lighting) was around $550 \mathrm{kWh}$ in 1990, close to the value in Poland (excluding street lighting in Poland). In Denmark, with little electric heating, consumption was around $800 \mathrm{kWh} /$ capita in 1973 , nearly $50 \%$ higher than the 1990 Estonian level. By 1990 the Danish value was $1400 \mathrm{kWh}$ capita. (The Estonian value had increased to $625 \mathrm{kWh} /$ capita by 1992.) If built space in Estonia was even 8 sq meters/capita, this would be less than half the Danish value. Since Danish buildings have much more electricity-using equipment than Estonian ones, the comparison suggests that the level of end-use efficiency and the quality of electricity management are lower in Estonia. In Sweden, where electric heating is common, servicesector electricity use was more than $1200 \mathrm{kWh} /$ capita in 1973 and $3000 \mathrm{kWh} /$ capita in 1990. About one-quarter of this value in 1990 was for heating. Hence, by standards of nearby countries, the Estonian service sector is small and not well electrified. But the growth in the past two years suggests changes are underway.

is Unlike Poland, Estonia did not have a large private farming sector whose energy consumption was partially buried in the "services" sector. 


\subsection{Energy Prices}

Apart from petroleum products, energy prices in Estonia were subsidized by the state. The degree of subsidy was especially large for households. In contrast to Western practices, which are based more closely on cost of service, in Estonia household prices were much lower than industrial prices. The legacy of low energy prices was certainly a factor in shaping Estonian energy use patterns, and partially explains the differences between Estonia and the West.

Judging how much lower Estonian energy prices were compared to Western Europe is difficult due to the problems of currency conversion discussed earlier. Table 2.1 presented the average Estonian price for various energy carriers in U.S. dollars based on the official exchange rate for 1992. Using PPP values inferred from the World Bank analyses, estimates of GDP figures would raise the Estonian prices by a factor of three but leave most well below Western levels.

While useful, comparing the levels of energy prices tells only part of the story, since the role of energy costs in overall production or household costs also differs. To argue that low energy prices were the major determining factor in shaping technology choices and equipment-use practices in Estonia is to misunderstand the workings and outcomes of the central planning system, as well as the choices that were available given the barriers between the Communist Bloc and the Western world. On the other hand, the combination of higher energy prices, the demise of central planning, and the openness to the West will certainly contribute to the choice of more energy-efficient technologies and practices.

\subsubsection{Comparisons with Poland}

How has the experience of economic transition in Estonia compared with that of Poland? Since 1988, the year of our Polish comparison, Poland's residential heating intensity has declined greatly, but energy intensities in manufacturing have increased due to low utilization of capacity. In transport, the patterns in Poland have moved closer to those that prevail in the West. Not surprisingly, Estonian industry suffered the same collapse in 1992 (and 1993) as did Poland's a few years earlier, with output appearing to fall more than energy use. Household energy intensities did not yet fall, because of the far greater importance of unmetered heat in Estonia, but changes are occurring now as heating prices increase and steps are taken to limit use. As in Poland, the ownership and use of automobiles continued to increase in Estonia despite economic hard times, while the importance of trucks increased in an otherwise declining freight market. Thus the structure of energy use in Estonia appears to be following some similar patterns experienced in Poland a few.years earlier.

There are also important contrasts with Poland worth reviewing. Poland is rich in coal, has some natural gas, and sits on a major natural gas pipeline. While these sources all have problems, no one sees Poland as energy-poor. Estonia, by contrast, has only shale and some forms of biomass (including peat), all of which have their own environmental liabilities and high costs of use. And while Poland's initial energy price shocks were internally driven, as domestic prices skyrocketed, Estonia's were precipitated by huge increases in the prices for oil and gas obtained for Russia. While Polish households cut back on coal use to save money, Estonian authorities cut back on heat supply to households in the face of real cutbacks from Russia, as well as payment problems.

The contrasts extend to end use. While there are many similarities between the household sectors (standard of heating and electrical appliances), there are differ- 
ences in other sectors. Freight in Poland was highly dependent upon a railroad network whose future is uncertain; Poland also has more long-distance domestic freight (by virtue of its size) and transit traffic as well. But the biggest contrasts are in the industrial sector. Estonia is simply wasteful, but does not have the problem of shedding a huge mining and metals sector that Poland faces. If Polish authorities finally bite the difficult bullet on the problem of closing a substantial part of this unproductive industry, there will be great reductions in energy use and pollution as well. But in Estonia, the two existing paper mills have already closed, as has at least one cement plant. In a sense, Estonia has closed a larger share of its energy-intensive materials production than Poland has. Unfortunately, the remaining energy waste in industry in Estonia is scattered in many smaller factories, and may be harder to address with broad closures or radical modernization.

There is one final difference related to Estonia's small size that may make the transition process easier in Estonia. Public and private authorities are concentrated in a few square kilometers of central Tallinn. There is far less political hesitation on the part of Estonian authorities to proceed with a rapid rationalization of both the energy sector and the major energy-use sectors, in part because there are fewer large bureaucracies blocking action. Shale is concentrated in one region (Narva), heating has already been stung by fuel cost increases and is rapidly turning to alternatives, there is no large coal mining industry with interests to guard, and, with independence, the country gained sudden freedom from the former energy planning agencies in Moscow. Thus in an ironic way, Estonia gets a fresher start for confronting its energy future because it has so much less than Poland to give up.

\subsection{Summary}

Total final energy use per capita in Estonia in 1990 was around the same as in West Germany in 1988, which has a somewhat milder climate (Figure I-12). Manufacturing energy use played a similar role in final energy use in Estonia to that in the

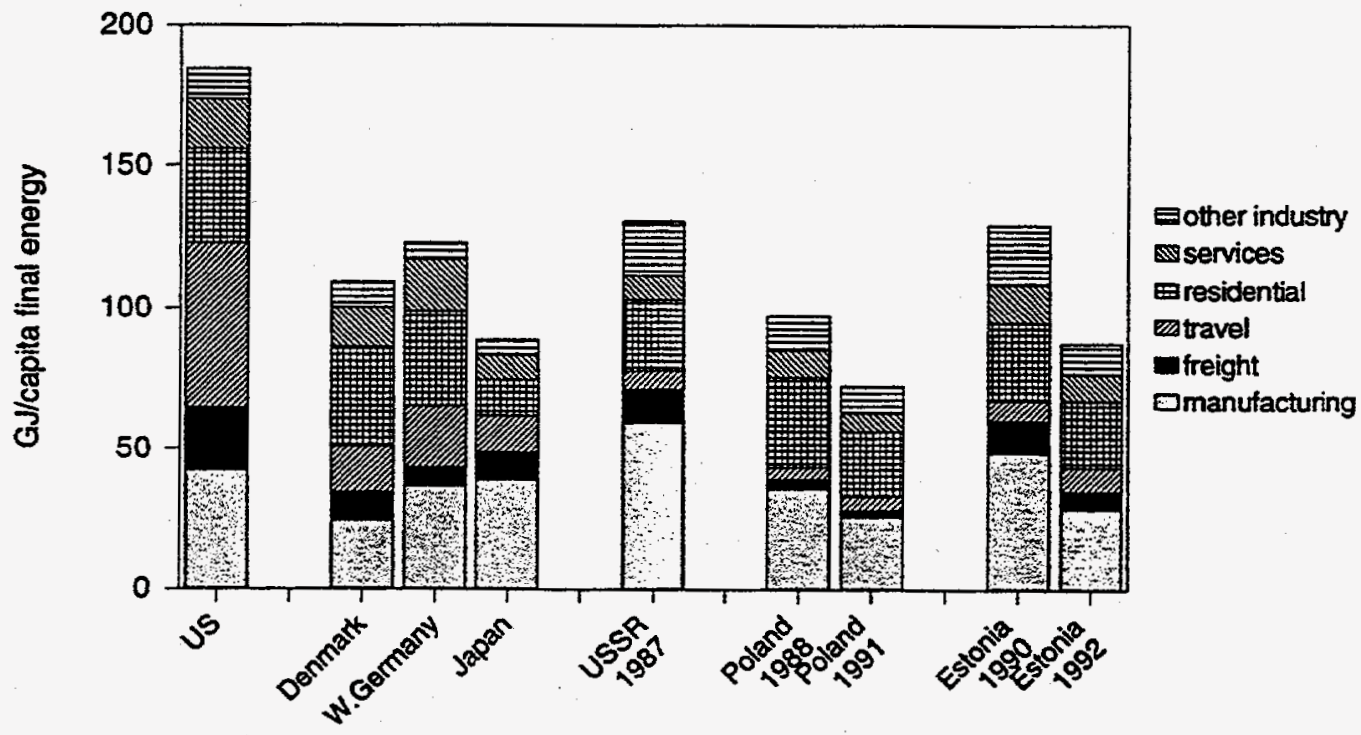

Note: Poland \& USSR disaggregations are approximate. Estonian freight and travel are not disaggregated.

Figure l-12. Final energy use per capita. By sector, 1988. 
OECD countries, except Japan, which exports much of its output. ${ }^{16}$ The role of the residential sector is comparable to that in West Germany or Denmark. ${ }^{17}$ The importance of passenger travel is much less than in the West, but energy use for freight is far greater than for Poland and comparable with that in Western Europe.

In the manufacturing sector, the level of per capita activity (value added) in Estonia, although hard to compare precisely, is clearly much lower than in the West (which indicates how much less productive Estonian manufacturing is). The structure of the sector is slightly less weighted towards energy-intensive industries; however, even before the changes of recent years. Thus, inefficient use bloats manufacturing energy use in Estonia (and the former Soviet Union) relative to the other countries (including Poland).

In passenger travel, both per capita activity and the modal structure of travel lead to much lower energy use per capita in Estonia than in Western Europe. Relative to Poland, however, greater use of busses boosts energy. Energy intensities are about the same (automobiles) or lower than those in the West (rail and bus). In freight transport, per capita activity is comparable to Western Europe, and the importance of trucks in the structure contributes to similar energy use per capita. The difference between energy intensities is hard to judge due to data limitations.

The residential sector has become nearly as important in Estonian energy use as manufacturing since that sector's collapse in 1992. Living area per capita is much less than in the West, meaning less space to be heated and lit. Structural factors (space and water heating equipment and appliance ownership) also lead to lower energy use per capita. But the energy intensity of space heating, by far the most significant end use, is higher than in the West. The intensities of other end uses (average use per capita or per device) appear to be closer to Western European averages, though the Estonian equipment is smaller (e.g. refrigerators). Overall, the small size of Estonian homes, which reduces energy use, is more important than the effect of slightly bigher intensities for heating and appliances and a colder climate in reducing residential energy use in Estonia relative to that in Poland or Western Europe.

The services sector plays a relatively small role in Estonia, as in Poland and the former Soviet Union. Although its energy consumption is uncertain, it clearly uses much less energy per capita than in Western Europe-mainly because Estonia, like Poland, has much lower floor area per capita for services. The levels of electrical equipment in Estonian buildings are much lower than in the West. Thus the likely inefficiencies in heating, which raise service sector energy use relative to Western countries, appears more than balanced by the small extent of the built environment and low level of electrification.

16 We not able to exclude all of the energy transformation sector from Estonian manufacturing energy use, but we were able to exclude "mining" from this comparison for 1990 and 1992. "Other" includes state agriculture and construction and, unfortunately, for the Eastern European economies, some consumption for energy transformation as well.

17 The values for residential energy use in the figure were not adjusted to a common climate, as was the case for Figure I-9. However, values were adjusted to each country's long-term degree-day average, important because 1990 and 1990 were among the warmest years since 1970.1988 was close to normal for Western Europe and the U.S. 
This international comparison of energy use in Estonia leads to remarkable conclusions. Energy use per capita in Estonia was comparable to Western European levels in 1990, despite Estonia's much lower GDP per capita. Comparatively high energy intensities in manufacturing and residential space heating, and the levels of freight are the key reasons for this result. These factors far more than outweigh the impact of the structure of passenger transportation and the low energy intensity of bus and rail travel, which contribute to lower transportation energy use per capita in Estonia than in Western Europe. 



\section{POTENTIAL FOR ENERGY SAVINGS}

\subsection{Introduction}

With a large portion of productive capital and the labor force suddenly without markets or employment, economic reform can be brutal in Eastern Europe. Huge disruptions will occur once it is clear that the state is no longer guarantor or operator. As we witnessed in Poland, reform leads to a slashing of industrial output, in spite of authorities' efforts to keep factories open and running and a decrease in the energy efficiency of production. To compound the problems, energy prices increase rapidly as well. At the same time, consumers of some fuels face staggering price increases while their real incomes shrink. Under these conditions, talking about investments to improve energy use is difficult, even if such improvements would profit both producers and consumers.

Nevertheless, it is important to think about the future of the Estonian economy and its energy use. The inefficiencies we document are only symptomatic of bloated economic structures that are fading or are being forced out. Privatization and modernization of old enterprises, growth of new ones, and above all, a greater consumers' share in the costs of energy and housing have the potential to transform the economy.

In spite of its brutality, this process represents a unique opportunity for improving energy use in Estonia, since much old and outmoded capital, particularly in industry, will be thrown out. At the same time, reorganizing the housing and building sectors means consumers and building tenants will for the first time be able to take responsibility for their own comfort. What we can witness here is the potential replacement of most of the productive capacity in Estonia, the rehabilitation of virtually all of the housing and building stock, and a rapid turnover in the motor vehicle stock, rather than merely viewing an improvement in energy utilization through the slow process of attrition of equipment and buildings.

\subsection{What is "Potential for Energy Savings"?}

"Energy savings" come about through increased energy efficiency or decreased energy intensity (less energy for a unit of output or activity). The energy saved is measured relative to how much energy would have been used had no measures been carried out. "Total savings" is the change in energy intensity times the activity or output that occurs after measures have been taken. 'Additional energy savings occur if the output of energy-intensive industries or activities, like heating or driving, declines. These kinds of "structural changes" will be important factors in future energy consumption and efficiency in Estonia and other former CPEs.

So what is the potential for energy savings in Estonia? In the terms put forward by Cooper and Schipper (1991), one can simply replace, in theory, Estonian dwellings, buildings, and appliances with equivalent Western versions. Comparing energy intensities of existing capital does indeed suggest that Estonian intensities could

In some cases, improving energy efficiency will reduce the cost of the activity enough to stimulate increased activity. Conversely, not improving energy efficiency would raise costs so much as to slow sales of the output or retard activity. For example, people heat their homes slightly more when the cost of heat falls, and they heat less when the cost is higher. 
be reduced by $5 \%$; comparing new Western-style technologies (which are available now in Estonia) suggests more like a $50 \%$ potential for each replacement. The first figure is a good guide to the savings we might expect from rehabilitation of existing equipment or structures; the second, the figure we expect to obtain as new equipment is installed. These estimates represent "instantaneous" savings because they are just that. Improvement is a long and slow process even under the conditions prevailing in Estonia.

The time frame is an important determinant of energy savings potential. In the very short term, i.e., during the present economic slowdown and for the next few years, savings of heat in buildings and industry from housekeeping measures can be substantial. Potential savings in transportation (from better maintenance and use) are small, typically 5-10\%, while improvements to electrical equipment will produce even smaller savings. In the medium term, during the period through 2010 , most motor vehicles and electrical equipment will be replaced, affording a significant savings potential. Policies might accelerate these processes so that greater savings are realized sooner. In the longer term, after 15 years have passed, new factories and industrial processes could come to dominate industrial activity, while the transportation and housing infrastructure could be modified significantly as well.

Several caveats are in order, however. First, the potential for energy savings is not simply the sum or product of individual potentials. Entire processes and factories will change as the socialist approach to both technology and management is replaced by one with a greater market orientation. In this respect, we believe that engineering estimates of energy-saving potential in industry underestimate what can be achieved.

By the same token, changes in the work environment, product quality, and above all, the uses of electricity will by themselves probably increase energy and electricity requirements somewhat more than what we might expect. The same phenomena will occur in the sectors dominated by consumers and building occupants. Better economic times will bring about more home floor area, more comfort, and more and larger electric appliances and office equipment. On balance, however, we think that the reborn Estonian economy will use far less energy in the year 2010 than it does today in almost every production process, and that Estonians will use less energy per unit of comfort or convenience. Total energy use, of course, will also depend on the size of the economy and its structure, two equally important issues we leave for later work. ${ }^{2}$

The replacement of old equipment with new affects energy use in Estonia in two important ways. First, equipment buyers and users now have access to world markets, which almost ensures that any new equipment will lead to energy savings and therefore lower costs of utilization. This effect itself will stimulate some economic growth in Estonia, but not nearly enough to offset the impact of the lower energy intensities, because energy is still only a small component of the total costs of many

2 We acknowledge that the rate of economic growth has an important impact on changes in energy intensities. Faster growth speeds turnover of equipment (and vice versa), which means that industrial output should rise faster than energy use in manufacturing and agriculture. Faster economic growth also funds more rapid rehabilitation of the building stock. But faster growth also allows consumers and businesses to purchase more comfort and mobility. 
activities. ${ }^{3}$ Second, the same effect will stimulate those producing equipment in Estonia (an important producer of electrical machines) to improve what is produced in order to become competitive. But there is a danger lurking. It is tempting for Estonian entrepreneurs to scour the world for second-hand equipment: old metal presses, first-generation Western jet aircraft, old motors, even complete assembly lines. Second-hand equipment will be more energy-intensive than new equipment. To the extent that it is cheap, old equipment can promote economic reform. But low energy prices may falsely signal industrial planners that they can install second-rate equipment without bearing the consequences of the resulting high energy use. Clearly energy-pricing policies will have an important impact on the choices made for purchasing equipment.

Finally, we have emphasized the energy savings offered by technical change. Better management of existing technology, particularly boilers, also shows promise. Better practices are not limited to energy management alone, but need to be applied to all aspects of resource use and the administration of private and public property.

Given the economic uncertainties of the present, what economic criteria can be used to rank energy-saving investments? First, there is clearly a premium placed on certainty: there is always a risk that an enterprise will close, and even a risk that investments in buildings and building heating equipment will not pay back the investment. In this case, it appears that the wisest moves involve "low-cost/no-cost" improvements. "Low cost" really includes any investments that pay back in a year or two, even at a high real rate of interest. For choices among new systems, where incremental investments would mean lower future energy requirements, we favor making those incremental investments.

\subsection{Previous Overall Estimates of Energy Efficiency Potential}

Information about energy consumption and potential energy efficiency gains in Estonia is quite sparse. The statistical information available from Soviet-style sources breaks down energy consumption by end-use sector, but this a sectoral breakdown, not a true functional breakdown (energy use in agriculture, for example, includes transport and housing functions associated with agriculture and its workers). These data by themselves are not very helpful for understanding how energy is consumed and where it can be saved. No detailed studies of energy efficiency potential have yet been conducted, although five recent studies offer overall estimates of efficiency potential:

(a) The World Bank, in its Estonia country study (1993a), conducted a cross-country analysis of the relationship between energy and GDP of 21 countries with climates similar to that of Estonia. The bank's study suggests that "Estonia used two to four times more energy in 1990 than might be expected on the basis of its per capita GDP level compared to other European countries." Although we do not believe that aggregate energy/GDP ratios tell us much, the enormous value for Estonia certainly suggests some efficiency potential. The aggregate finding is confirmed by our sectoral analyses and international comparisons.

3. There are important exceptions. Heating of buildings often costs more than rent. Energy costs for some production processes or transportation represent a significant part of operating costs if there are no current maintenance or capital charges. Since the cost of energy has risen relative to the cost of labor, the higher energy costs affect the cost of doing business significantly. 
(b) The "Energy Master Plan for Estonia"4 concludes that "the quite rough estimation of overall conservation potential, based on comparison of Finnish and Estonian data, is [that] up to $50 \%$ of heat and up to $30 \%$ of electricity [can be saved]." In the short term (5 years or less payback), the Plan estimates that perhaps 4$15 \%$ of energy consumption could be saved with low-cost and elementary actions and an additional $10-15 \%$ with more expensive actions. The Plan did not try to disaggregate data as much as we did nor even make use of all the data existing in Estonia. Nevertheless, our findings support the estimates of the Plan.

(c) The State Energy Department, in cooperation with the Ministry of Buildings (which no longer exists), issued a "Program for Energy Conservation in Estonia" in July 1992. Part of this document related to heating and emphasized simple boiler tunings on a large scale coupled with fuel substitutions to local fuels as means of reducing imported fuels. It concluded that savings of $4-10 \%$ could be obtained from simple and inexpensive methods and 10-15\% more from extensive tunings using imported measurement equipment. All of our experience suggests this goal is conservative and easily achievable.

(d) A report sponsored by the EC Thermie Program claimed that, with Danish materials, a $20 \%$ energy savings could be achieved in the three buildings investigated, with simple payback of less than 4-5 years. ${ }^{5}$ Savings in excess of $20-25 \%$ were deemed too expensive. In an old block building, savings of up to $40 \%$ might be economically achieved, principally because roof insulation is relatively cheap. Comparison of the intensities of heating in Estonia with those in Denmark and Sweden confirms these estimates.

(e) Using average Western practices in regulation, management, and control, Schipper and Cooper (1991) compared Soviet and Western energy intensities. They found that energy intensities in the former Soviet Union could be reduced by $25 \%$ for space heating via district heating, $35 \%$ for space heating via on-site fuel, $20 \%$ for water heating, $25 \%$ for new refrigerators and other electric appliances, and $20 \%$ for new cars and aircraft (and another $20 \%$ simply through better fuel, driving practices, and roads). So much of the energy-consumption technology in Estonia is based on Soviet equipment that these findings can be applied to Estonia as well. The only difference is that buildings in Estonia appear to have been constructed to somewhat better thermal standards than those in Russia.

\subsection{Brief Sectoral Overviews}

\subsubsection{Manufacturing (and Other Industry)}

Manufacturing (and other industry) poses a dilemma: every investigation reveals many opportunities to reduce energy needs with almost no capital investment, but which industries will survive to make the effort worthwhile? Given that capital, both monetary and human, is scarce in Estonia, the challenge is to prioritize investments. A particular danger is that time and money could be expended on factories

\footnotetext{
Ministry of Industry and Energetics, 1993.

5 Ministry of Buildings, 1993.
} 
that will be forced to close, or that energy-oriented efforts might duplicate those that will be carried out in the process of modernizing or replacing old factories and equipment.

Estimating the potential in industry is aided by a significant number of audits already conducted in factories across Estonia by foreign consultants in the past few years. A summary of these findings is presented in this section. The descriptions are primarily based upon three sets of audits conducted by the EC Thermie Program, IVO International, and USAID. These audit programs are described in the appendix to this chapter. In general, the international comparison supports these findings. The only issue is whether any investments in old factories are worthwhile.

A survey of six industrial enterprises in Estonia by the Swedish National Board for Industrial and Technical Development (1992) showed that savings of 10-30\% could be obtained in industry through improvements in operations and maintenance, space heating, cooling processes, and air compression. Other audits have grouped potential savings into three categories according to economic payback: (i) no-cost/ low-cost or short-term measures with typical paybacks of less than one year, (ii) medium-cost or medium-term measures, which might pay back in 2-4 years, and (iii) high-cost or long-term measures with paybacks of longer than 5 years.

(i) No-cost/low-cost or short-term measures. Proper boiler tuning and monitoring were clearly the most popular measures, with the audits showing $1-6 \%$ potential savings, with more typical savings in the range of $2-4 \%$. Some audits showed $2-$ $3 \%$ savings strictly through tuning oxygen levels in combustion. Better energy management was another popular measure and savings of $10 \%$ were commonly cited through better monitoring, accounting, and control. Changes in manufacturing processes were another measure where 5-15\% savings were cited, through changes in equipment-operating practices and procedures. Other low-cost measures involve proper preventive maintenance of equipment, better loading of process ovens and furnaces to reduce total cycle costs, plugging steam and pressurized air leakages, reducing hot water wastage and losses, and substitution of electric heating for central heat in certain types of workspaces.

(ii) Medium-cost, medium-term measures. One of the main types of medium-cost measures is secondary heat recovery from flue gases and process furnaces, with payback times on the order of two to three years cited. Improved insulation of pipes, furnaces, and ovens is another medium-cost measure. And finally, increased return of heating steam condensate could result in significant savings. In some of the cases studied, only $40-70 \%$ of the condensate was being returned, and an improvement of $30 \%$ was feasible.

(iii) High-cost, long-term measures. Lighting measures were considered high-cost measures, undoubtedly because of low electricity prices. Savings from lighting improvements were given in one case as $10 \%$, although greater savings are undoubtedly possible. Other high-cost measures include converting heating systems from steam to water, steam-on-demand, rather than continuous steam, systems for some technological processes, and burner-automation systems for boilers. 


\subsubsection{Residential Sector}

The potential for improvement must be divided along three dimensions: the first is between new and existing homes, the second between public and private homes, and the third between single-family houses and larger multi-family apartment buildings. The technologies, economics, and time scales of energy efficiency vary greatly depending upon these dimensions.

Most residential buildings will have a long lifetime. Consequently, rehabilitation is generally necessary for many. In apartment buildings (regardless of ownership), insulation, air tightness, ventilation, windows, and practically the entire building are worth improving. Large apartment buildings have complex heating systems. Changes in heat losses through outside surfaces affect the basic heat load of the heating system and air infiltration as well. Changes to the outside surfaces should not be made without making adjustments to the boiler and providing heat controls to individual apartments. Otherwise a mismatch between supply and demand, and subsequent increases in heating consumption, could occur. ${ }^{6}$ Without revamping the heating system, the demand for heat will be too low relative to system capability; the over-dimensioned system will simply provide too much heat. Similarly, applying insulation without weatherstripping and careful caulking of cracks, as well as improving the windows, ignores the obvious problems of air leakage. Developing a package of improvements for existing windows alone could probably offer $20-30 \%$ reductions in heat losses through windows. Modern Swedish or Finnish windows probably have only $30 \%$ of the heat transmission of existing windows in Estonia.

We estimate that applying these measures to apartment buildings and adding heating controls would reduce heating needs by about $40 \%$. Applying only the simplest measures to individual apartments affords a smaller reduction, probably on the order of $15-20 \%$. The initial experience with the building retrofit demonstration project in the Mustamaee district of Tallinn (see the appendix to this chapter for more details) seems to confirm that basic retrofit measures can produce at least $15 \%$ or more in savings. Danish studies ${ }^{7}$ clearly indicate that measures applied to the outer shell (insulation, improved windows, and so on) or within the walls (new hot water pipes, ventilation) should be undertaken when the building is slated for rehabilitation. Opening walls is very expensive and should only be done when many related goals can be accomplished simultaneously.

Single-family dwellings (i.e., detached houses) afford somewhat more flexibility, since the buildings are less complex than multi-family structures. Adding insulation to the loft is relatively easy, and adding second (or third) layers to existing windows during the heating season is common in many countries. Improving the boiler and heating system is also important, but since the occupant is also the boiler operator, good feedback does exist whereby the occupant adjusts the boiler according to need. Also, most occupants pay for their heat by how much they actually consume, in stark contrast to occupants of apartments. This creates a direct incentive for occupants to control indoor temperatures and monitor equipment performance.

In $90 \%$ of residences, domestic hot water is provided by the same district or boiler systems that supply central heat. Measures to improve these boilers will re-

- This problem was addressed in the evaluation of the Swedish retrofit program by Anderlind et al., 1980.

7 Energiministeriet, 1990. "Energi 2000". 
duce losses in producing hot water. Increased insulation of holding tanks will also improve energy savings. Small boilers using solid fuels have notoriously high losses in combustion, heat transfer, and storage as well. Other hot water systems that heat water only as required have few losses other than combustion losses where gas or LPG is used.

Estonians cook primarily with older style gas or electric stoves. Many gas stoves (particularly those on LPG) need to be lit, while others have pilot lights. New gas stoves, however, have electronic ignitions that save the losses from the pilot lights. Electric cookers have heavy iron plates as cooking elements. New halogen elements give the same fast reaction as gas but with far fewer losses in starting up. And new ovens are so well insulated as to reduce losses in baking by up to $50 \%$ over old stoves. We expect that these savings will occur as Estonians replace their old stoves with new ones.

The same replacement process will lead to improvements in electric appliances. While inefficient but small Soviet-made appliances dominated the market in the past, Western models are already entering through Electrolux and other importers. Energy requirements for modern refrigerators, freezers, clothes washers, dryers, dishwashers, and televisions are 40-60\% below what they were (for comparable size and features) in the early 1970 s. This reduction was brought about by a combination of higher electricity prices, standards in the U.S., and government-led programs in Japan, Germany, Sweden, and Denmark. To be sure, some of these savings have been offset by increases in size and features. Efficiency improvements will reduce electricity needs for major appliances as much as size and features increase demand. With appropriate action stimulating the sale of efficient appliances however, electricity needs for appliances could actually shrink in the next five years, even as households begin to acquire dishwashers and clothes dryers.

One element of the energy efficiency potential in Estonia deserves separate mention: metering and controls. Metering means charging each dwelling unit for the heat and other energy sources it actually consumes. Control means proving electronic or manual controls so the same dwelling unit can control its share of consumption when provision is collective, i.e., from district heat or a building-wide boiler. There should be no doubt that collectively metered buildings (i.e., when the consumption for the building, but not for individual dwellings is metered and regulated) require more heat per square meter than buildings with individually metered dwellings. This is borne out by a comparison of Swedish multi-family dwellings with no individual meters for heat with single-family dwellings using the same fuels. It is also demonstrated by comparisons of dwellings using the same fuel providing heat either through individual dwelling systems (Etageheizung in Germany, also common in France and Italy) or through a single boiler in the basement. Modern meters that measure consumption as the difference between the incoming and outgoing radiator-water temperature are preferable to small evaporation meters commonly used in Western Europe, but either way occupants tend to be responsive when they see their own consumption. Furthermore, a series of experiments carried out in Finland and Norway confirm that frequent billing periods, rather than once a year as is common in Western Europe, lead to reduced consumption because the feedback time between consumption and cost is closer. ${ }^{8}$ However, metering individual dwellings is not simple for Estonia.

Willhite and Ling (1989) describe this experiment. 
Controls are equally as important. If the occupants of each unit are to be responsible for their own consumption, they must have control over what they actually use. In the Nordic countries, a variety of systems, including thermostatic valves on each radiator, outdoor temperature sensors controlling the flow of heat to the building (or combustion in the boiler), or shunts that permit closing of any room or radiator, all permit occupants to throttle back heat. Installing this equipment is expensive unless the building or heating system is being revamped. However, the initial experience with two retrofit projects in the Viru region of Estonia in 1993 indicates that installation of radiator thermostatic valves and heat meters on an individual apartment level may prove practical and bring about significant savings. The results of these projects after the 1993-94 heating season should provide a sounder basis for consideration of these types of building improvements (see the appendix to this chapter for more details).

Two other problems hinder retrofits in Estonia: the large number of buildings that are linked into district heating in series with the outdoor piping, and the predominant number of buildings where more than one dwelling, or even all dwellings, are connected to the same set of heat pipes. These systems pose special challenges.

\subsubsection{Services}

Most of the problems that plague the residential sector haunt the service sector as well. Heat losses and boiler problems abound. In addition, service sector buildings need ventilation; some even need cooling. Service sector buildings rely more on electricity for motors, electronics, and lighting than do homes.

In Sweden and Denmark, improved heating equipment, added controls, and added insulation to walls (or replacement windows) helped reduce heating energy use in the service sector by approximately 20-30\% between 1973 and 1993. Floor space in both countries increased, even after accounting for shifts to electric heating, because of the rapid rise in electronic equipment, fans, and lighting. We cannot say how much the efficiency improved in spite of these observed increases. However, a study in the U.S. found that in spite of the rapid increase in the number of electricity uses, including heating, electricity use per square meter of floor area in the service sector in the U.S. held steady between 1979 and $1986 . .^{\circ}$ The experience with electricity suggests a significant potential for savings in Estonia by improving the efficiency of equipment. But that savings will be offset considerably by further electrification of most space.

\subsubsection{Travel}

The rapid evolution of travel toward more individual (i.e., automobile) modes in Estonia should come as no surprise to anyone. That new vehicles offer a wide range of fuel intensities is also well known. ${ }^{10}$ Most of this spread can be traced to differences in car size and performance. However, it appears clear that for a given size and performance, Soviet-made cars require significantly more fuel than those made in Japan, Europe, or the U.S.

Present trends suggest Estonians are buying used cars whose average power is greater than typical Russian-made small cars. The "potential" for reducing fuel intensity depends very much on what kinds of cars Estonians buy. While some good

9 Schipper, How arth and Geller, 1990.

10 Schipper, Steiner, Figueroa and Dolan, 1993. 
arguments suggest the overall efficiency of cars will also improve in the next ten years, Estonia can do nothing to affect this trend. "Therefore, the potential for fuel savings in automobiles is directly tied to how Estonian authorities chose to tax both cars and fuel. These choices will affect the new (and used) car stock profoundly, as we have shown for Westem countries. ${ }^{12}$

Because most Estonians do not yet own cars, it is fair to say that policies that keep urban and intercity busses clean, efficient, filled, and running could contribute to massive oil saving by restraining growth in automobile use. This is not simple: the Krakow municipal system reports losing riders to cars as car ownership increases there. ${ }^{13}$

The use of mass transit could be reinforced if the policies now restricting car entry to the Old Town in Tallinn were broadened to include entry fees into Tallinn (and other large cities) per se. It is not that we advocate "punishing" car users, only that our experience in the West suggests that those taking cars into large cities during most daylight, working hours are imposing much larger costs on those cities (as well as fellow citizens, whether drivers or not) than are reflected in either fuel taxes or nominal parking charges. Policy instruments might include a real toll ring around Tallinn (as in some Norwegian cities), electronic pricing for the use of particularly crowded corridors or highways, and, conversely, peak and off-peak pricing for busses and trams. These schemes have a small impact on existing cities already dominated by cars, but the same policies could have a salutary effect on Tallinn's traffic (and associated energy use).

Technological improvements contribute to saving energy in the bus system. Newer, Western busses are more powerful and more efficient than the old Hungarian-made Ikarus that were so common in Eastern Europe. And new busses spew out fewer particulates and gaseous pollutants than older diesel or gasoline busses from Eastern Europe. The system is clearly in need of rehabilitation anyway; as this occurs, the efficiency of busses should increase through replacement. Finally, there are small gains to be made through better driving, improved fuel quality, and utilization of routes. ${ }^{14}$ Working against these factors is the risk that economically necessitated service cuts in the short term would force more people to switch to cars for regular travel. Evidence from most of the West suggests it would be difficult luring them back.

\subsubsection{Freight}

The potential for saving energy in domestic freight rests both on the issue of modal choice as well as that of technology. Because Estonia is a small country, it is hard to envision an expanded role for rail freight. This is compounded by the likely shift in the content of freight away from bulk materials toward more finished consumer products. In Western countries this shift has advanced the share of trucks in freight haulage because the average shipment is smaller than that of bulk raw materials sent by rail. Furthermore, the expansion of private consumption of manufactured goods, if it follows the trend in Poland, will mean an expansion of the decentralized retail

\footnotetext{
Schipper and Meyers et al., 1992.

12 Schipper, Steiner, Duerr, An and Strøm, 1992.

13 Meyers, Schipper and Salay, 1993.

14 Busses in the other Nordic countries have swithed to ethanol or even a very clean (but expensive) diesel for environmental reasons. Estonia might explore limited ethanol production for busses.
} 
sector, which depends on small trucks. Both these changes have increased energy use for freight in Westem countries. ${ }^{15}$

Fortunately for Estonia, the truck fleet is bound for replacement. The narrow range of mostly Russian-made trucks will likely be replaced by a wider variety of Western models. Owners will undoubtedly maintain them better and be more careful about fuel, which is now a cost, not a free good. We expect to see more efficient, diesel-powered, light vehicles (pickups, vans) delivering goods often hauled by heavier Russian trucks in the former Soviet Union. Similarly, private operators face a greater incentive to fully utilize both vehicles and trips, which should reduce empty hauls (and backhauls). And the trend toward containerization could help merge sea, rail, and truck freight so that the rail system could maintain an important role for primary distribution to points where trucking becomes most appropriate.

As with cars, however, price signals play an important role in the future of trucks. Fees based on laden weight and actual use should be levied to match the wear and tear on roads. Authorities will have to form a policy for transit freight moving through Estonia by truck. If the Via Balticum, a superhighway from Finland to Central Europe is built, Estonia (like other countries) will have to charge transit vehicles in proportion to the damage they would inflict on roads and the environment. Exhaust emissions of all vehicles in Estonia should be controlled through regulation of both exhaust and the quality of fuel.

\subsection{Summary Outlook}

From this review, we find that the potential for reducing energy intensities in Estonia is similar to what we sketched for the former Soviet Union as a whole. Some of the key energy intensity figures are shown in Figure ES-1 as percentages of their 1992 values. The theoretical impact of these changes on 1992 consumption for the purposes given is shown in Figure ES-2.

Without endorsing any reform strategy, we postulate three economic scenarios to distinguish three paths of energy efficiency improvement. "Slow Reform" is just that, a series of a few, indecisive steps toward freeing prices, privatization, and marketization of the economy and the energy sector, somewhat akin to the course followed in Russia and Ukraine. The second, "Rapid Reform," experiences these steps at a more deliberate pace, sometimes know as shock therapy, akin to the course followed in Poland. The third scenario, "Extra Effort," presumes that economic reform moves swiftly, but public and private authorities include many initiatives for improving both the technology of energy use and internalizing environmental problems into energy prices.

Whatever the path followed in Estonia, energy efficiency will improve. The process of "Slow Reform" itself might reduce intensities by $15-25 \%$ by the year 2010, all else being equal. "Rapid Reform" could increase the reduction to $35 \%$; "Extra Effort" could push those reductions closer to $50 \%$, the gains being principally in the housing and building sectors. As dramatic as this seems, this achievement would only bring typical energy intensities in Estonia by 2010 to the level of Western Europe in 1990! Note that these calculations do not account for structural changes, which are likely to further reduce energy use in manufacturing but to increase it in the other sectors. ${ }^{16}$

is Schipper and Meyers et al., 1992.

16 See Schipper and Meyers et al., 1992 for a more detailed description of these scenarios. Calculations for the former Soviet Union are presented in Schipper and Martinot, 1992. 
Can these savings be achieved? The savings suggested by "Slow Reform" are almost inevitable. Those proposed in the two other scenarios are problematic. We discuss these problems in the concluding chapter.

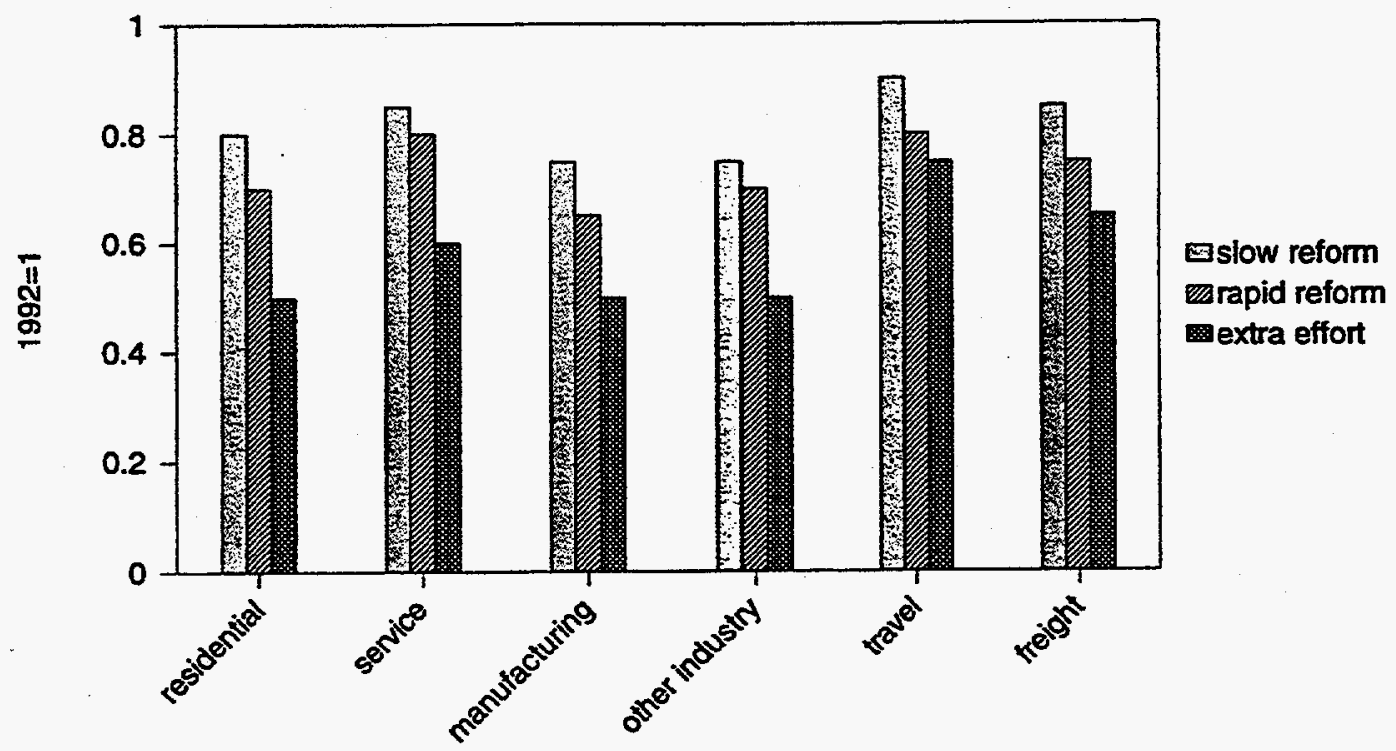

Figure ES-1. Energy saving potential in Estonia. 2010 intensities.

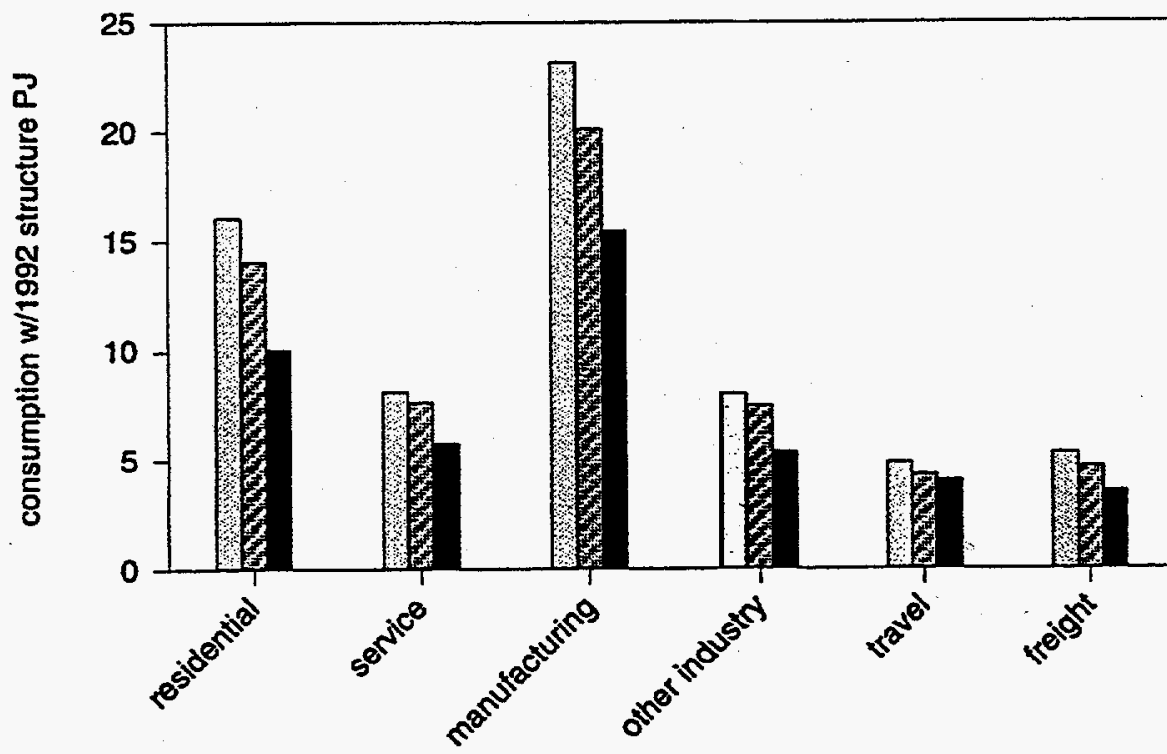

Bsiow reform arapid reform Eextra effort

Figure ES-2. Energy saving potential in Estonia. Changes by 2010. 


\section{APPENDIX: EXPERIENCE FROM SPECIFIC PROJECTS AND PROGRAMS}

A large number of projects related to energy efficiency improvements are being conducted by a diverse group of organizations, both domestic and foreign. The experience and results from the most significant of these projects as of the end of 1993 are reviewed below to give an idea of the scope of this work and the experience available from it. We have purposely not included a number of projects involving conversion of oil boilers to wood and peat fuels. While these projects could be considered as energy efficiency projects because they reduce oil imports, they are really a separate subject requiring a separate paper.

In general, many energy audits have been conducted in Estonia since early 1992, while few physical improvements have been made. The motivation for these audits has ranged from governmental and multi-lateral assistance programs to commercial profit motivations. The lack of physical improvements attests to the difficulty of raising investment capital and of establishing mechanisms for profiting from reduced energy consumption by those making the investments. Two notable sets of audits were done by the EC Thermie Program through the EC Energy Center Tallinn, and by IVO International of Finland in cooperation with Tallinn Technical University. In 1992, the EC Thermie Program conducted eight audits chosen to be representative of industry and services (six factories, a hospital, and a school). Beginning in 1992, IVO International began a series of audits in 20 factories in Estonia. The first ten audits, eight factories and two boiler houses, were completed in the summer of 1993.

In mid-1993 the State Energy Department listed more than 80 foreign energy projects either completed, on-going, or planned for Estonia. Most of these were audits and studies. Thus, the results so far have been analysis, recommendations, and many pages of paper (present study included). Where physical improvements may have been involved, little if any follow-up has been produced to evaluate and disseminate the results. As of December 1993, we had seen only one published record of any foreign energy efficiency program or project conducted in Estonia that had resulted in actual energy savings (the Mustamaee housing retrofit demonstration described below).

In addition to the foreign projects, the State Energy Department has been administering an EC loan for domestic energy projects (72 million EEK in 1993) and a domestic state energy-conservation program (14 million EEK in 1993), which together comprised over 150 projects during 1993 . The majority of these projects involved boiler conversion to wood and peat fuels, while most of the remainder were related to energy efficiency improvements in energy-supply and end-use infrastructure.

The most significant of the foreign programs and projects that have gone beyond the paper study phase are described below. A few of those listed will likely result in real energy savings during the winter of 1993-94, and these projects should provide valuable practical experience by mid-1994.

\section{Building Retrofits in the Mustamaee District of Tallinn}

One demonstration project of residential energy efficiency measures has taken place in the Mustamaee district of Tallinn. The project is a combination of before-andafter comparison and side-by-side measurements involving a retrofitted building 
and a reference building. Technical measures include roof insulation, weatherstripping, a new substation, main pipe-control valves, additional window panes on the top floor, and heat meters. Potential energy savings from this project were initially estimated at $15-25 \%$.

Two typical nine-story, 72-apartment neighboring buildings were selected, one as the renovated building, and the other as the reference building. Initial energy inspections and measurements were made, followed by renovations in the fall of 1992. During the winter of 1992-93, energy consumption and indoor temperatures were monitored and recorded. The indoor climate was also studied using a questionnaire given to tenants.

Total heating energy consumption was initially estimated (with the aid of the energy-calculation program Nya Enorm) as approximately $300 \mathrm{kWh} / \mathrm{m}^{2}$ annually, of which $200 \mathrm{kWh} / \mathrm{m}^{2}$ was for heat and $100 \mathrm{kWh} / \mathrm{m}^{2}$ was for hot water. Later, actual consumption in the retrofitted building was measured as $215 \mathrm{kWh} / \mathrm{m}^{2}$ annually.

An energy savings of around $15 \%$ was obtained during measurements in the 1992-93 heating season, as compared with the reference building after appropriate adjustments. The researchers note that because of lower than normal heat supply during this period, the $15 \%$ savings is lower than it would be under normal heating conditions. Other results reported were that the building's energy signature showed that the retrofitted building's energy consumption was much more adjusted to the current outdoor temperature than that of the reference building. Tenants also obtained a more reliable supply of hot water and experienced an improvement in air quality. The project is quite detailed in its analysis, and the detailed conclusions and further experience from this project will be extremely valuable in understanding the potentials and opportunities for energy savings in buildings in the future.

\section{Building Retrofits in the Oeismaee District of Tallinn}

One other project involving a retrofit experiment is taking place in a 16-story apartment house in the Oeismaee district of Tallinn. The design, equipment, and installation was completed in March 1993 through donations by participating companies, two Swedish and one Estonian. Comparison measurements with a non-retrofitted house were begun in April 1993 and will continue in the winter of 1993-94. Equipment installed included heat exchangers, control equipment, radiator system pumps, balancing valves, energy meters, and valves.

\section{Heating Equipment in Buildings in the Viru Region of Estonia}

In early 1992 officials in the Viru district of Estonia contacted a Danish engineering firm for assistance in energy efficiency in that region. The Danish company successfully obtained financing for this project from the Danish government for both auditing and equipment installation. Two towns are involved: Toila, population 1200, and Haljala, population 3300. In Toila, the project was begun in April 1993 and was completed and handed over to the municipality on June 15, 1993. In Haljala, the project was begun in March 1993 and completed and handed over to the municipality on September 15, 1993.

Most of residences in these towns are served by a central district heating plant, although some of the single-family houses have their own boilers or electrical heating. The boiler plant in Toila produces about $30 \mathrm{MW}$. The distribution pipes are above ground, which, combined with poor insulation, results in approximately $20 \%$ loses of total energy production. Each of the buildings connected to the network has 
its own boiler room with pipe heat exchangers for hot water, and all radiator systems are direct with mixing loop. The boiler rooms have no energy or water meters; all billing is based upon square meters.

The three main phases of the projects were (1) to analyze the existing heating facilities; (2) to install energy meters, evaporation meters, and radiator thermostat values in apartments and municipal buildings to provide control and measurement of actual energy savings and to learn about installation and requirements of energy efficient equipment; and (3) to establish Estonian-Danish joint ventures for commercial development of energy efficiency equipment.

In Haljala, approximately 2000 radiator valves and evaporation heat meters were installed on individual radiators in apartments and a school. In addition, each building had heat meters, valves, and pressure regulators installed in the main boiler room in the basement. The total cost of this installation was 3.7 million EEK for the construction of this project, which lasted from March 1993 to September 1993. Of this total cost, $65 \%$ was used for equipment, $20 \%$ for engineering and wages, $10 \%$ for freight, tools and training, and 5\% for administration and miscellaneous costs. The labor in Toila was slightly more than one man-hour to install one radiator valve.

Results from these installations should be available after the winter of 1993-94. A test installation in one previously evaluated house leads the project to anticipate energy savings of approximately $30 \%$ in individual apartments under existing heating plant operation. However, should the operation of the heating plants be changed to produce lower temperatures to save on fuel costs, this figure could be lower; no one will throttle back their heat consumption with thermostat valves if temperatures are already too low.

\section{USAID Emergency Energy Program Audits and Technical Assistance}

Some of the earliest audits conducted in Estonia were performed by the U.S. Agency for International Development (USAID) under its Emergency Energy Program for Eastern and Central Europe, begun in November 1991. The purpose of the program was to combine both technical and management measures for energy savings in industry. Four audits were conducted by a U.S. consulting firm to analyze energy consumption and recommend technical and management changes to improve efficiency. These four were a chemical plant, a fiberboard plant, a boiler house, and a ship repair yard. The audits were followed by provision of approximately $\$ 30,000$ worth of equipment to each plant consisting of a computer, boiler-tuning and monitoring equipment, combustion analyzers, infrared pyrometers, and other equipment. Training was provided for the use of this equipment.

The USAID projects were designed to train local people, to include participation of local firms, and to build indigenous capacity. This took the form of involving two local engineering consulting firms, training plant personnel, and additional equipment and training for individuals from Tallinn Technical University. The University was reportedly involved in conducting one-day audits of different enterprises in Estonia and providing its equipment for rent.

The plant audits all recommended similar measures: computers with spreadsheets to better manage and keep track of energy in the plant, combustion analyzers to better tune boilers, and the installation of submeters for fuel inputs. According to the audit report calculations and assumptions, simple payback times for these measures are typically less than one year. Expected energy savings through "better energy management" is given as $5-10 \%$ (although only a $1 \%$ savings figure is used for 
calculating payback times). Other measures include better boiler tuning (1-5\% savings), better heat recovery (2-7\% savings), installing metering to better inform management (1-2\% savings), and substitution of electric heating for steam heating. In total, a reduction of 5-20\% of energy consumption was deemed feasible at a minimal cost.

In late 1992, the results from these programs were discussed in a seminar. The main changes reported by the Fosforiit plant involved a cleaner, better lit workplace and some equipment repairs and maintenance. It was reported that new laws and management incentives were required before any more specific energy-saving activities could be conducted. No specific energy savings were reported, but this is not surprising. The implementation of management changes and boiler-tuning recommendations is problematic in Estonia for well-known reasons. Where enterprises are still state-owned, there is less incentive to actively reduce costs and energy consumption. In general, energy efficiency gains from boiler monitoring and tuning requires constant (daily and weekly) vigilance to maintain peak operation. Energy consumption can easily revert to previous conditions in a matter of days or weeks without this vigilance. And management attention and motivation is required to maintain this

vigilance. In state-owned or even privatized enterprises that are struggling simply to stay solvent, this attention and motivation can be lacking or preempted by more pressing concerns.

The most successful of the four plants seems to have been Baltic Ship Repairs, and this could be attributed to an "entrepreneurial spirit" noted among its management. Baltic Ship Repairs reported that replacement of central heating with electric heaters supplied by the project resulted in significant savings, and more efficient fuel combustion resulted in a $6-7 \%$ increase in combustion efficiency and a $2 \%$ decrease in loses. One part of the Baltic Ship Repairs improvements also demonstrates the care that must taken in considering local conditions. Fuel oil flow meters supplied to the plant by USAID were never installed because the plant feared problems using these meters with Russian-origin 2mazut (heavy fuel oil), which contains high levels of particulates and thus could more easily clog meters.

\section{World Bank District Heating Improvements}

The World Bank is currently supporting district heating system-rehabilitation feasibility studies in Tallinn, Tartu, and Parnu. These studies are expected to be completed sometime in 1994 and will form the basis for prioritizing and targeting future World Bank investment funds for district heating rehabilitation in these cities and other energy projects. The loan agreement is expected to be completed by mid-1994 and will be administered through the Ministry of Finance of Estonia. The present feasibility studies are being financed by the Danish government (Parnu), the Finnish government (Tallinn), and the Swedish government (Tartu). It appears that of these three, the study in Tartu is closest to completion. The results of these studies should undoubtedly be valuable in understanding energy efficiency potential in district heating not only in other Estonian cities but cities in other former Soviet republics as well. 


\section{IMPROVING ENERGY EFFICIENCY IN ESTONIA: PROBLEMS AND POLICIES}

At the heart of the inefficient energy uses we observed in Estonia lie three fundamental causes:

- The formerly planned economy had no competition or market forces and few enterprises or private citizens had control of or responsibility for cost minimization.

- Energy prices were unrealistically low and the returns from using energy more efficiently were minimal even if cost reduction was desired.

- Both the economy and political system were closed, and access to information, equipment, and capital for energy-use efficiency was very limited.

In theory, these root causes of inefficiency have been banished. Or have they? Changing the rules on paper is one thing, but it will take time for Estonians as private or public officials or individuals to learn to make economically efficient decisions about resource consumption and capital investments. ${ }^{1}$ But even if the actors in Estonia made a rapid transition to a new economic paradigm, most observers acknowledge that the remaining rigidities will act as barriers to improving energy use in Estonia.

In this concluding chapter, we address these barriers. Our goal is not saving energy per se, but improving the working of the Estonian economy as it uses energy. This means that we seek to identify imperfections in energy-use markets, imperfections that require public policy initiatives to improve resource allocations. We also aim to identify fuzzy areas hard to classify as market failures but where barriers exist. In the end the goal is to accelerate the transition to a better, not a perfect, market for energy uses in Estonia. In the cases where the sometimes painful process of economic reform will likely improve energy-use efficiency anyway, we ask whether policies can both smooth and accelerate the transition.

Finally, energy (and energy efficiency) are but two problems plaguing Estonia and other economies in transition. It is tempting to try to ignore these other problems and focus only on energy and energy efficiency. But experience tells us that many of the "barriers" to improving energy efficiency are the same as those that hinder improved functioning of the economy in other sectors, particularly those related to property rights, the cost of capital, the pricing of energy, and the training of the workforce. The last problem is perhaps the most critical: while citizens in all of the former Soviet republics are among the most highly educated people in the world, few have skills in conventional Western economic and financial analysis, engineering economics, and management.

In the rationing of scarce labor or capital, proposals that the energy problem jump ahead in the queue of other problems should be viewed with skepticism unless it can be shown that the problems being addressed are unique to energy and therefore deserving of what we call an "enercentric" focus. To put it simply, energy-

This point arose in almost all our conversations with Estonian experts. 
efficiency policies must not substitute for sound resource pricing, clear demarcation of public and private responsibility, or a careful evaluation of the real rate of return on scarce capital.

\subsection{Barriers to Improved Efficiency}

The Estonian Plan for Energy Conservation in 1992 quite plainly pointed out generic barriers to energy efficiency in Estonia:

- lack of ownership

- unrealistic energy pricing

- lack of financing

- lack of incentives or motivation (especially price-related)

- lack of domestically produced equipment and materials

- lack of information

- insufficient research

- inadequate training

- insufficient legislation or obsolete standards

Some of these barriers are prevalent in Western societies as well. Consequently, policies have been designed to overcome them, or at least lay them aside. For example, most European and North American nations place minimum thermal-performance requirements on new buildings; some also have minimum requirements on equipment and appliances. These standards are necessary because consumers cannot readily make complicated calculations appraising them of the cost effectiveness of technical options and often have little choice anyway. Tenants struggle with landlords in every country over the proper allocation of energy-efficiency investments, energy costs, and energy bills. And some leading Western countries have yet to conduct real energy-use surveys in every sector to actual measure how energy is used.' In Estonia, the first four items on the above list are particularly important. Lack of private ownership of energy-consuming infrastructure and the consequent lack of responsibility for its maintenance and improvement are clearly barriers to efficiency improvements. Unrealistic pricing blunts the benefits of improved efficiency even where incentives and responsibility exist. Although prices have risen dramatically and privatization is underway, ownership and pricing problems did not disappear with Estonia's break from the Soviet Union, but will linger for quite some time.

A common lament is that there is "no money" for investment in energy efficiency. To some extent, this is not true; investment capital does exist. But it is expensive and generally available only for short-term investment. Lack of affordable, longterm financing stems from several factors. High inflation and real interest rates make investments costly and paybacks very uncertain for projects of longer duration than a few months. Long-term loans are difficult to obtain because of future uncertainties about the economy. Lack of private ownership makes securing collateral difficult for

2 Britain and West Germany are two notable examples. While energy-consumption data are collected from energy suppliers or certain periodic government surveys, neither country has sponsored regular national household, service sector, manufacturing, or transportation energy-use and activity surveys. By contrast, authorities in the U.S., France, and Japan have carried out such surveys periodically. Sweden, Norway, and Finland have carried out energy-use surveys in buildings. 
loans other than retail trade, where the goods purchased form the collateral. All of these issues relate to risk in one way or another. It is actually the risks and uncertainties that play such a key role in financing.

Another barrier, lack of incentives and motivation, can be seen in industry. But is it possible to change the mentality of enterprises? The well-known lack of costreduction incentives from the former Soviet times still exists in state-owned enterprises. For privatized companies, there is an incentive to reduce costs, but the mentality of managers and engineers is still a barrier to efficiency: either energy is viewed as too small a part of total costs to worry about, or they are attracted to the latest high-tech machinery from the West and do not want to focus on the mundane details of low-tech solutions to saving energy. The engineers may say, "Give us a new compressor, or new machine, but don't talk to us about closing doors to save energy."

Associated with all of these issues is the question of how to think in terms of economic payback. On a consumer and enterprise level, people need to understand how investments in more efficient equipment can pay for themselves through reduced future energy costs. On a national level, some of the money spent on expensive, imported fuels can be better spent reducing the need for these fuels in the first place, and authorities need to be able to understand the paybacks involved. But economic payback by itself will not solve the energy-efficiency problem until many of the other barriers are addressed as well.

Inadequate training, lack of research, and little information are problems with their roots in the former regime. On the one hand, the Soviet Union had some of the most highly trained scientists and engineers and a wealth of scientific information. On the other hand, the training and research were closely molded by the state and information was literally locked up. Researchers had to ask for permission to use copy machines or view many foreign references, and computers were a luxury. Input data and results from one institute or even a single experiment were often unavailable to other researchers. Public authorities in Estonia will have to assess existing data and synthesize new data in order to calibrate a fresh "base line" of energy use in Estonia and to assess the state of the energy-consuming infrastructure (such as the recent Housing Census did). This is expensive and time-consuming, but the very process provides research experience and training that public and private institutions will need. The inventory of equipment and infrastructure-tallying the number of vehicles and their use, the thermal condition of buildings, the productivity of industrial machines- will be undertaken as part of reform, and all this can be slanted to provide insights on the energy system and how it can be better utilized.

Finally, there is the problem of legislation and standards. Independent Estonia was left without a post-Communist legal framework for most activities and has had little experience organizing ownership, whether private or public, of utilities and other energy companies, apartment buildings or commercial buildings. Laws governing property and rent, laws governing transfer of property, laws governing finance and banking, including home mortgages, regulations on vehicle registration and inspection, and so forth all need to be put into place. Each of these problems has an impact on energy use and affects the process of changing energy use. The most critical are those governing ownership and rental of buildings, safety, fire, and thermal standards on buildings, and safety and emissions standards on motor vehicles. It is beyond the scope of the present project to be engaged in the actual process of creating or recreating the legal and technical institutional framework under which Estonia lives, but we hope to address some of these challenges in the near future. 


\subsection{Some Key Issues in Housing and Heat Supply}

Complementing this general list of barriers are several key issues related to the housing sector and public heat supply. While complicated, their resolution will greatly influence future energy-efficiency investments and potentials.

(a) How much longer can electricity and heat remain subsidized? As we discussed in Chapter 2, by the end of 1993 electricity subsidies were indirect, in the form of lower rates through debt accumulation, capital deterioration, environmental degradation, and cheap mining extraction. The state or municipalities were directly subsidizing heat to consumers for amounts exceeding $25 \%$ of the consumer's monthly income. At the heart of this issue is the simple fact that Estonia's per capita income does not allow consumers by themselves to pay for and maintain an energy system that must draw fuels and capital from world markets. Energy subsidies would appear to be tied to future income growth and to a reduction in heating costs through use of cheaper domestic wood and peat fuels.

(b) Who controls the central heat supply? September 1993 was a very cold month in Estonia relative to other years. A public debate ensued as to whether to begin the heating season early, since the heating season officially begins October 1. Poorer people wanted to save money and did not object to a month of discomfort, while more affluent citizens were advocating an earlier turn-on. In addition, as more enterprises become privatized, the self-generated heat that they supply to the public system will no longer be subject to central control and something of an "independent heat producers" market may emerge.

(c) Can individuals or buildings monitor and control their own heat consumption? Metering and monitoring are possible, yet control of heat supply to individual flats is often difficult or impossible. Without a way to monitor and control heat consumption through meters and valves, consumers are left with no motivation or means to reduce consumption. More consumers are attempting to become independent from the central heating system by installing electric heaters and even removing radiators. This trend could be dangerous, with fewer people paying for a fixed central-heat infrastructure (although an unresolved legal issue is whether consumers can avoid paying for central heat even if they do not want it; a further complication is that those in the middle of a building receive "free" heat from those around them).

(d) Who will own the buildings and when? Housing privatization will clearly be an important step toward more efficient household energy use for two reasons. First, individuals and associations will become owners and thus have a direct stake and interest in cost-reducing building maintenance and efficiency improvements. Second, once property becomes private, it can be used as collateral for capital investment loans. Privatization of single-family houses was essentially completed by 1993, but privatization of apartments and many enterprises was still being mainly talked about. Opinions are mixed as to how fast privatization of the housing sector will proceed. The slowness of the process could be partly attributed to unresolved property restitution. Because Estonia decided to allow pre-World-War II property restitution upon its independence in 1991, about 200,000 claims existed by mid-1993 and disputed property (including most of downtown Tallinn) cannot be privatized until these claims are settled. 
(e) What will be the role of owner associations? Once privatization proceeds, owner associations may play a role in energy efficiency. Heat metering and control may become more feasible. A building could decide to jointly purchase and install a heat meter and then jointly pay for heat consumed. Owner associations, in addressing questions of maintenance and building investments, will be able to address energy consumption. Some could even opt to shut off central heating to the entire building and replace it with individual electric heating systems. Furthermore, how will decisions be made about consumption and payments? Will richer people in a building be forced to pay for the heat of poorer people who cannot pay?

(f) Who pays for distribution system loses? Currently consumers are billed for heat according to heat produced at the plant plus some correction for distribution system loses, not as it enters their buildings. In one town, the standard distribution system loss used for billing is $18 \%$, while in reality losses are more like $30 \%$. A preliminary experiment carried out with a heat meter for an apartment building revealed that the building actually paid about $20 \%$ more for heat based on a fixed fee per square meter than it would if paying for actual heat entering the building. In reality, its a zero-sum game: if the utility pays for losses, it simply raises heating prices to compensate. But the responsibility for distributing system losses is key to motivation and incentives to invest in reducing them.

(g) Will electric heating increase in popularity? Electric heating has been mentioned several times already in conjunction with increased autonomy and control of heat consumption. And while electricity prices remain low, electric heating is cheaper than purchasing heat from central heating networks for new and renovated buildings. Conversion of heating from central heat to electricity in existing buildings, if allowed, will make the problem worse. Electric heating on a large scale will strain electric distribution networks and commit Estonia to costly future electric power capacity investments sooner than would otherwise be needed. When it becomes time to replace the aging oil-shale-fired electric power plants, the costs will be larger if electric heating increases in popularity. And the present environmental consequences of electric heating are also serious as the electricity is produced from oil-shale with its severe regional and trans-national pollution problems.

\subsection{Priorities for the Future}

In our discussions with experts and authorities, several clear priorities or concrete projects became apparent. The first priority, almost universally acknowledged, is the need to focus on district heating supply systems. The second is to improve the enduse building efficiency. This means first boilers, pipes, shunts, pumps, valves, and so on. The economic returns and cost effectiveness of investment in these systems seems to outdistance those in end-use housing improvements such as insulation, windows, and even substations. As one expert put it, "It simply makes no sense to save energy in apartments when all that heat is being lost in the distribution network and at the boiler." We suspect, however, that end-use improvements in buildings should go together with heat-supply improvements at least initially, until actual experience gives clearer conclusions. And fast action is critical, no matter what the specifics: Estonians face cold winters and mounting oil payments while authorities 
and economists (and academics) debate priorities, heating system ownership, and tariff structures. Public authorities must reinforce the present efforts to improve heating boilers and distribution, both for demonstration purposes and to ensure Estonians basic comfort while they await the full resolution of this debate.

A second clear priority is low-cost/no-cost measures in industry. These typically involve little if any capital investment, but rather such things as regular boiler tuning, smarter energy management, conducting deferred maintenance, and operational process changes. Of course the "cost" of such "no-cost" measures can be measured in management time and attention, which may be in as short supply as investment capital itself. Authorities can sponsor audits and other demonstrations, and measure results carefully.

Within buildings, substation improvement could be a significant priority. More than half of Estonia's homes are connected to district heating supplies. Aside from the district heating system external to a building, the components of the system within it are also important. There are often no heat exchangers and water from the street pipes is fed directly through houses. Loops are out of balance. Parallel loops within the buildings exist. Heat metering and individual radiator thermostat valves within apartments, where possible, are also a high priority; they are inexpensive and could reduce heat consumption significantly if heat billing is tied to actual measured consumption.

While the short-term priorities are supply-oriented, the longer-term needs are sectoral: housing and construction policies, industrial policy, transport policy, and market prices for energy must be revamped. Both long-term and short-term needs should be addressed simultaneously.

Other important priorities for energy efficiency that address some of the barriers discussed earlier are the following:

(a) Define the boundary between the public and private spheres. With industry slowly being privatized (and many factories closing), the future composition of this sector is unclear. Privatization of housing is moving slowly as well, and there are many options. For example, much multi-family housing in Scandinavia is "socialized" through private cooperatives or local government ownership. In some cases, heating efficiency in this type of housing improved more than did housing that was strictly private. Estonia needs to explore alternatives to the national ownership of the housing stock and form regulations that will help define responsibility for improving energy efficiency of residential buildings.

(b) Conduct economic analysis to identify which kinds of investments will be profitable at what point in the future under different scenarios of economic development. What level of heat prices will make certain investments profitable? What prices for peat and wood? At what interest and savings rates? Different options must be compared under different circumstances. These economic analyses are not being performed by many, and not many Estonians have not yet developed the ability to do them. This leads to the next point.

(c) Train and educate Estonians, in cooperation with Western experts, not in technical areas, but rather in areas like energy and resource economics, life-cycle economics, and simply fundamental Western economic concepts. In the words of Juergen Salay et al. (1993), "To overcome technical, legal and economic 
barriers,...local government officials, building [and factory] managers, and engineers also need training in economic management....It is crucial that such training focus on the energy-using sectors and on those persons who are in an economic and institutional position to implement energy-efficiency measures, not only on experts in energy production and distribution."3

(d) Revise thermal performance requirements for new homes and buildings and develop analytical tools to model these requirements. Enforce mechanisms to see that the requirements are followed and train architects and engineers in methods to satisfy the requirements. The old Soviet building codes ("SNIP") were still being used as of the end of 1993, although designers were allowed to design buildings according to any standards they wished as long as they are better than the SNIP codes. A lack of enforcement mechanisms and practices and the spread of owner-built homes has caused chaos in housing standards and practices. We learned that a new building code was being developed by the Ministry of Economy; this effort should receive priority. Of course, there is a large potential to improve homes. ${ }^{4}$

(e) Develop a housing and building financing scheme similar to that in Sweden, whereby incremental investments in thermal insulation or other efficiency measures that go beyond the minimum required by performance codes are granted favorable interest rates.

(f) Develop schemes to raise minimum efficiency requirements for common household electrical appliances and perhaps some equipment for buildings. ${ }^{6}$ Or alternatively, develop incentive schemes to create a market for more efficient electrical appliances imported and sold in Estonia.

(g) Accumulate more retrofit experience through demonstrations and experiments. The lack of heat meters and retrofit experience has impeded so far the gathering of information on actual costs and potential savings from retrofits. Experiments and demonstrations can measure the real changes in energy use that arise when well-defined efficiency strategies are carried out.

(h) Conduct careful, publicly funded and published research to measure energy uses in all sectors. Currently much of the existing work is kept secret at the insistence of private interests or even the bilateral or multilateral authorities sponsoring the work.

3 Salay, Fenhann, Jaanimeagi, and Kristoferson 1993, p. 212.

- Rasmussen, A. 1993. "Analysis and Market Survey: Export Potential for European Building Technologies in the Baltic States. Residential Buildings." Berlin: IABPO Friedeman und Johnson. Typical U-values are $0.85(R-7)$ for walls, 2.4-2.7 (R-2) for windows, and 0.4-0.7 (R-8 to R-12) for roofs; much of the existing equipment for heat and hot water is old and inefficient. Apparently the new building standards being developed specify 0.33 for walls in single-family houses, 0.45 for walls in panel buildings, roofs of 0.25 or lower, and triple-glazed windows.

3 Schipper, Meyers, and Kelly 1985.

6 See Schipper and Meyers 1991. 
Many of our recommendations involve research, both of a scientific and survey or market type. Certainly some information is vital to private firms wishing to market their goods and services in Estonia. It is crucial, however, that public information remains to the greatest extent in the public domain, so that different individuals can judge success or failure on their own. This is particularly important for retrofitting experiments, for policy experiments, and for policy proposals. In this sense, the confidentiality of the much discussed "Energy Master Plan for Estonia," paid for by two foreign electric utilities, sets a poor example for a nation emerging from more than 50 years of suppression of information vital to public policy debates. ${ }^{7}$ And this problem may get worse as more and more private entities conduct energy surveys, audits, and projects with results remaining confidential.

\subsection{The Role of Foreign Assistance}

The foregoing remarks bring up an important issue. Does foreign "assistance" really assist? Many completed foreign projects in Estonia have been criticized for their lack of concrete results and for their lack of follow-up and dissemination of results. By the time a project is finished, consultants have moved on to other work. Often reports are written only in English and the Estonians who would benefit from the information the most do not read English. The results of such projects are often many pages of paper but no saved energy. Apparently, beginning in 1993, foreign aid was only accepted in Estonia when it is associated with capital investment. For example, the World Bank was to provide a loan in 1994 for district heating system projects in Parnu, Tartu, and Tallinn, following up on foreign feasibility studies of these systems which began in 1993.

Information is a vital part of the foreign assistance pattern. Part of the problem is that foreign sponsors and companies need to learn about Estonia. Many multi-lateral and bilateral authorities will only use international consultants, not local ones. While this may be understandable to a certain extent, the effect is insulting to local experts and, worse, passes up an excellent opportunity to train local experts in the kinds of analysis needed in Estonia. In some cases we observed, foreign governments supported consultants from their respective countries who in turn opened local offices in Estonia that employed Estonian experts. This is a good step forward.

Foreign assistance may also compound the confidentiality problem mentioned earlier. If foreign assistance supports private consultants who keep their work confidential, no officially recognized forum exists in which information is published, debated, revised, and finally used. There is nothing wrong with consultants or public entities charging for services provided, data tabulation, and the like (indeed, we paid public and private authorities in Estonia for some data retrieval), but this normal activity must not be permitted to substitute for publicly funded energy economic research that lays on the table the basic information about Estonia-or other countries. ${ }^{8}$

In future work, we hope to specify the kinds of energy-use information we deem valuable for promoting a healthy and democratic public debate over energy in Estonia and for promoting good sense private decisions as well.

7 Ministry of Industry and Energetics of Estonia, 1993.

8 Many of the key documents prepared for Poland's 1992 Energy Policy, for example, or prepared under contract with foreign governments, were simply considered "confidential" by their consultant authors and unavailable for inspection. We also found that the "dollars for data" syndrome, common in many other former Soviet republics, was not a problem in Estonia. 


\subsection{Closing Observations and Summary}

There is no question that energy use in Estonia is inefficient. The very process of reform will improve efficiency markedly. Sound public policies could raise both the scope and the speed of those improvements.

Beyond this, how hard should authorities push? The wider issue, which we cannot easily resolve here, is whether energy-saving investments deserve special consideration above other possible investments by Estonian or foreign investors. If emphasizing energy-saving investments is a strategy proposed to confront the underpricing of energy, then we cannot recommend it, unless it is clear that energy prices will soon rise. If favoring energy-efficiency investments is a strategy to reduce the emissions from energy production and use, we propose instead a series of emissions fees or taxes on the pollution of concern, something of great interest to a government looking for sources of revenue.

If, on the other hand, favoring energy-efficiency investments is proposed as a way of paying more attention, and more quickly, to an important part of economic development that was overlooked during the Communist period, then we support it. But it is critical not to waste government money or attention to subsidies or other special consideration to energy-efficiency investments that really should be made anyway. For example, there is no excuse for leaving heat piping in factories uninsulated. Should national or international resources be devoted to paying entrepreneurs to do what they should do anyway? Western authorities have struggled for decades to improve energy use in apartment buildings, commercial buildings, and even private homes, working against many kinds of market failures. Here there is a clear role for intervention. But without intervention, economic reform will provide higher energy prices, competition among firms to cut costs, and modernized production anyway.

The most important ingredients of economic reform-privatization of property and economic activity, competition, and sound resource pricing -are also the most important ingredients for improving energy utilization in Estonia. Additionally, however, we have identified several key public policy steps that will strengthen these improvements:

- A massive public and private effort to improve the functioning of the present district heating production and distribution system, as well as careful monitoring of the results.

- Selective audits, experiments, and demonstrations of efficiency strategies in buildings, farms, and factories to point to the most cost-effective ways of saving energy.

- Strengthening of building codes, introduction of minimum efficiency standards for key household equipment, and innovative financing for improving the thermal properties of existing and new buildings.

- Development of a long-range transportation plan that balances the rise of private automobile traffic with the well-known externalities associated with traffic which now plague most Western countries. 
With the following summary, we may now answer the questions put forth in the Introduction.

- Judging by international comparisons, energy requirements for Estonian industry are two to three times those of Western industries for similar products. Estonian homes and buildings require twice the heat of those in the countries across the Baltic. Estonian motor vehicles, most of which were made in Eastern Europe, lay close to those in the West in terms of energy use per passenger- or tonne-kilometer, but require 25-50\% more energy per kilometer. Homes appliances in use in Estonia are also less efficient than those produced in the West.

- The onset of rapid economic reform led to the collapse of industrial activity, with energy use for industry and for freight dropping as well, although less rapidly. Energy use for households fell slightly, and that for services also dropped, but neither sector collapsed as did industry. Energy use for travel fell only slightly, as private automobile ownership soared. We observed the same pattern in Poland, which suggests that this is characteristics of the process of rapid economic reform and should be expected in other former Soviet republics.

- In the industrial sector, the structure of output changed rapidly as heavy industry contracted far more than other industries, which reduced energy use. But in transportation, both trucks and cars gained shares of traffic against collective modes, which raised energy use, all else being equal. In all sectors, efficiency worsened because capacity was underutilized, and, in the confusion following economic collapse, little capital could be mustered for new technology to improve efficiency.

- Estonia has seen some successes in both fuel switching (from oil or gas to local fuels, principally biomass and peat) and some improvements in energy use in buildings subject to retrofits.

- Brutal as they may be, market forces have already led to a drastic restructuring of industrial production in Estonia, which has reduced energy use. The current wave of privatization is forcing enterprises to be careful of costs, leading slowly to overall improvements in efficiency. Market forces are absent in large part from the residential and service heating markets because of the lack of meters in apartments, buildings, or offices. Low prices weaken market forces for electricity, gasoline, and diesel. It is clear that market forces will be very slow in coming to the household and service sectors, which are clearly in need of government intervention to provide affordable comfort and other building services with improved energy efficiency.

- Outsiders, whether bi- or multi-national assistance organizations, multi-national corporations and vendors, international lendors, NGOs, and others, can play an important role in improving energy-use efficiency in Estonia if they (i) remember that Estonians themselves must play the key roles, (ii) ensure that energyusing products brought into Estonia are efficient, as should processes assumed or established in Estonia, and (iii) strive to keep the flow of information, as it is developed, in the public domain. 
In early 1994, increased consumer confidence and spending have appeared as signs that the Estonian economy is emerging from the first, most difficult stage of economic and political reform. Let us hope that these first signs are reflected in the energy markets as well. 


\section{BIBLIOGRAPHY}

Anderlind, G., A. Elmroth, B. Lindorn and T. Lundgren. 1980. Energispareffekter $i$ bostadshus där ätgärder genomförts med statligt energisparstöd (The Evaluation of the Swedish Retrofit Program]. Stockholm, Sweden.

Building Research Institute of Estonia. 1992. Research on Building Construction (in Russian). Tallinn, Estonia.

Central Bureau of Statistics, Sweden. 1990. Energistatistik för Flerbostadshus 1990. [Energy Statistics for Multifamily Dwellings]. Örebro, Sweden: Central Bureau of Statistics, E 16 SM 9202.

Cooper, R.C. and L.J. Schipper. 1992. The efficiency of energy use in the USSR-An international perspective. Energy-The International Journal 17:1-24.

Cooper, R.C. and L.J. Schipper. 1991. The Soviet energy conservation dilemma.Energy Policy 19:344 363.

Energiministeriet. 1990. Energi 2000: Handlingsplan for en baeredygtig udvikling. [A Plan of Action for Sustainable Development]. Copenhagen, Denmark: Energiministeriet.

Fenhann, J. (ed.) 1992. Energy and Environment in Estonia, Latvia, and Lithuania. Roskilde, Denmark: Risø National Laboratory.

Fenhann, J. (ed.) 1992. Energy Conservation Potentials in Lithuania and Latvia. Roskilde, Denmark: Risø National Laboratory.

Hansen, J., 1993. World Bank. Priv. comm., October.

Howarth, R. and L.J. Schipper. 1991. Manufacturing energy use in eight OECD countries: Trends through 1988. The Energy Joumal 12:15-40. Also as Lawrence Berkeley Laboratory Report No. LBL-31228.

Howarth, R., LJ. Schipper, P. Duerr and S. Strøm. 1991. Manufacturing energy use in eight OECD countries: Trends through 1988; Decomposing the impacts of changes in output, industry structure, and energy intensity. Energy Economics 13:135-142.

International Energy Agency. 1993. Review of Energy Policies and Prospects: Estonia, Latvia, and Lithuania. Paris, France: IEA.

Leisalu, A. 1992. Raising energy utilization efficiency in Estonia. In: Proc 1992 Int Energy Efficiency and DSM Conference. October 20-22, Toronto, Canada.

Marer, P, J. Arvay, J. O'Conner, M. Schrenk and D. Swanson. 1992. Historically Planned Economies: A Guide to the Data. Washington, DC: World Bank.

Meyers, S., J. Salay and L.J. Schipper. 1994. Energy use in a transitional economy: The case of Poland. (submitted for publication in Energy Policy).

Meyers, S., L.J. Schipper and B. Lebot. 1993. Domestic Refrigeration Appliances in Poland: Potential for Improving Energy Efficiency. Lawrence Berkeley Laboratory Report No. LBL-34101.

Meyers, S., L.J. Schipper and J. Salay. 1993. Energy Use in Poland, 1970-1991: Sectoral Analysis and Intemational Comparison. Lawrence Berkeley Laboratory Report No. LBL-33994.

Meyers, S., L.J. Schipper and J. Salay. 1994. Energy use in Poland: An international comparison. Energy-The International Journal (in press).

Ministry of Buildings. 1993. Energy Savings in Housing in Estonia. Report No. 1, Energy Audits and Catalogue of Energy Saving Measures (Preliminary). Prepared by the Danish Building Research Institute, Hørsholm, Denmark and COWIconsult, Lyngby, Denmark.

Ministry of Industry and Energetics of Estonia, Vattenfall AB, Imatran Voima OY, and State Enterprise Eesti Energia. 1993. Energy Master Plan for Estonia-Summary and Conclusions. Tallinn, Estonia.

Moetus, M. 1993. Energy Situation in Estonia after Currency Reform and New Energy Saving Program for the Near Future. Institute of Energy Research: Tallinn, Estonia.

Ots, M. 1993. Energeetika ja Majandus, [Economic Evaluation of Energy Conservation Measures in Estonia]. Göteborg, Sweden: Chalmers University of Technology (ISSN 0283-8761).

Rasmussen, A. 1993. Analysis and Market Survey: Export Potential for European Building Technologies in the Baltic States. Residential Buildings. Berlin, Germany: LABPO Friedeman und Johnson.

Salay, J., J. Fenhann, K. Jaanimaegi and L. Kristoferson. 1993. Energy and environment in the Baltic States. Annual Review of Energy 18:169-216. Palo Alto, CA: Annual Reviews, Inc.

Schipper, L.J. and C. Cooper. 1991. Energy Use and Conservation in the USSR: Pattems, Prospects, and Problems. Lawrence Berkeley Laboratory Report No. LBL-29830.

Schipper, LJ. and D. Hawk. 1991. More efficient household electricity use: An international perspective. Energy Policy 19:244-263. 
Schipper, LJ., R. Howarth, B. Andersson and L. Price, 1992. Energy Use in Denmark: An International Perspective. Lawrence Berkeley Laboratory Report No. LBL-32362.

Schipper, LJ., R. Howarth and H. Geller. 1990. United States energy use from 1973 to 1987: The impacts of improved efficiency. Annual Review of Energy 15:455-504.

Schipper, L.J., R. Howarth and D. Wilson. 1990. A Long-Term Perspective on Nonwegian Energy Use. Lawrence Berkeley Laboratory Report No. LBL-27295.

Schipper, L.J., A. Ketoff and A. Kahane. 1985. Explaining Residential Energy Use by International Bottom-Up Comparisons. Annual Review of Energy 10:341-405.

Schipper, L.J. and E. Martinot. 1992. Decline and Rebirth: Energy Demand in the Former Soviet Union-Towards Efficiency in 2010. Lawrence Berkeley Laboratory Report No. LBL-33162.

Schipper, L.J. and E. Martinot. 1993. Energy Efficiency in Former Soviet Republics: Opportunities for the West. Lawrence Berkeley Laboratory Report No. LBL-33824.

Schipper, L.J. and S. Meyers. 1991. Improving appliance efficiency in Indonesia. Energy Policy 19:578-588.

Schipper, LJ, S. Meyers and R. Howarth. 1992. Energy intensities in OECD countries, 1970-1989. Int J Global Energy Issues 5:76. Also as Lawrence Berkeley Laboratory Report No. LBL-33108.

Schipper, L.J. and S. Meyers, with R. Howarth and R. Steiner. 1992. Energy Efficiency and Human Activity: Past Trends, Future Prospects. Cambridge University Press, Cambridge, UK.

Schipper, LJ., S. Meyers and H. Kelly. 1985. Coming in from the Cold: Energy-Efficient Homes in Scandinavia Seven Locks Press, Washington, DC. Report to the German Marshall Fund.

Schipper, L.J., R. Steiner, P. Duerr, F. An and S. Strøm. 1992. Energy use in passenger transport in OECD countries: Changes between 1970 and 1987. Transportation 19:25-42. Also as Lawrence Berkeley Laboratory Report No. LBL-29831.

Schipper, L.J., R. Steiner, M.J. Figueroa and K. Dolan. 1993. Fuel prices and economy: Factors affecting land travel. Transpor Policy 1:6-20.

State Energy Department. 1992. The Program for Energy Conservation in Estonia. Tallinn, Estonia. State Statistical Office of Estonia. 1992. Estonia: A Statistical Profile. Tallinn, Estonia.

State Statistical Office of Estonia. 1992. Quarterly Statistical Bulletin, No. 4. Tallinn, Estonia.

State Statistical Office of Estonia. 1993. Energy Balance of Estonia. Tallinn, Estonia.

Stockholm Konsult/Energy \& Environment and Stockholm Energi. 1993. Demonstration of Energy Saving Potential in Estonian Apartment Buildings. Draft report, October 20, 1993. Stockholm, Sweden.

Swedish National Board for Industrial and Technical Development (NUTEK). 1992. Energy Survey of Six Energy-Intensive Industries and an Office Building in Estonia. Stockholm, Sweden: NUTEK.

Tähtinen, M. and H. Nurste. 1992. Energy Use and Emission Scenarios to the Year 2000 for Estonia. Espoo, Finland: Technical Research Center of Finland.

Wilhite, H., R. Ling, A. Uutela, U. Antilla and A. Arvola. 1993. A Nordic Test of the Energy Saving Potential of New Residential Billing Techniques. Nordiske Seminar- og Arbejdsrapporter 1993:627, Copenhagen, Denmark: Nordic Council of Ministers.

USAID. 1992. Industrial Energy Efficiency Improvements in Estonia: Policy Options and Institutional Roles. (Draft). Prepared by RCG/Hagler Bailly, Arlington, VA, and Enpro Engineers Bureau, Tallinn, Estonia.

USAID. 1992. Energy Efficiency Audit Report, Eesti Fosforiit Chemical Plant, Maarmo, Estonia. Prepared by RCG/Hagler Bailly, Enpro Engineers and Tallinn Technical University, Tallinn, Estonia.

USAID. 1992. Energy Efficiency Audit Report, Pussi Fiberboard Plant, Pussi, Estonia. Prepared by RCG/Hagler Bailly, Enpro Engineers and Tallinn Technical University, Tallinn, Estonia.

USAID. 1992. Energy Efficiency Audit Report, Baltic Ship Repairs, Tallinn, Estonia. Prepared by RCG/Hagler Bailly, Enpro Engineers and Tallinn Technical University, Tallinn, Estonia.

Virudan Ingenjioerselskab IS. 1993. Energy Conservation Plan No. I for the Viru Area in Estonia: Hand Over Report for the Town of Toila. Holte, Denmark.

Virudan Ingenjioerselskab US. 1993. Energy Conservation Plan No. I for the Viru Area in Estonia: Hand Over Report for the Town of Haljala. Holte, Denmark.

World Bank. 1993a. Estonia: The Transition to a Market Economy. World Bank, Washington DC.

World Bank. 1993b. Estonia Proposed Energy Project. World Bank Preparation Mission, June 1625, 1993, Aide Memoire.

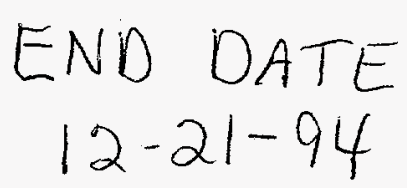

